\title{
Chemistry and the Worm: Caenorhabditis elegans as a Platform for Integrating Chemical and Biological Research
}

\section{Citation}

Hulme, S. Elizabeth, and George M. Whitesides. 2011. "Chemistry and the Worm: Caenorhabditis Elegans as a Platform for Integrating Chemical and Biological Research." Angewandte Chemie International Edition 50, no. 21: 4774-4807.

\section{Published Version}

doi:10.1002/anie.201005461

\section{Permanent link}

http://nrs.harvard.edu/urn-3:HUL.InstRepos:12967817

\section{Terms of Use}

This article was downloaded from Harvard University's DASH repository, and is made available under the terms and conditions applicable to Open Access Policy Articles, as set forth at http:// nrs.harvard.edu/urn-3:HUL.InstRepos:dash.current.terms-of-use\#OAP

\section{Share Your Story}

The Harvard community has made this article openly available.

Please share how this access benefits you. Submit a story.

\section{Accessibility}




\title{
Chemistry and the Worm: Caenorhabditis elegans as a Platform for Integrating Chemical and Biological Research
}

\author{
S. Elizabeth Hulme and George M. Whitesides*
}

[*] Dr. S. E. Hulme, Prof. G. M. Whitesides

Department of Chemistry and Chemical Biology

Harvard University

12 Oxford Street

Cambridge, MA 02138 (USA)

Fax: (+1)617-495-9857

Email: gwhitesides@gmwgroup.harvard.edu

Homepage: http://gmwgroup.harvard.edu

Abbreviations: TGF- $\beta$, transforming growth factor $\beta$; IGF-1, insulin-like growth factor 1; ROS, reactive oxygen species; SOD, superoxide dismutase; DOG, 2-deoxy-D-glucose; MS, mass spectrometry; GLC, gas-liquid chromatography; LC, liquid chromatography; CE, capillary electrophoresis; SDS-PAGE, sodium dodecyl sulfate polyacrylamide gel electrophoresis; NMR, nuclear magnetic resonance 
This review discusses the potential usefulness of the worm Caenorhabditis elegans as a model organism for chemists interested in studying living systems. C. elegans, a 1-mm long roundworm, is a popular model organism in almost all areas of modern biology. The worm has several features that make it attractive for biology: it is small (<1000 cells), transparent, and genetically tractable. Among multicellular organisms, C. elegans is arguably one of the simplest and easiest to work with. Despite its simplicity, the worm exhibits complex phenotypes associated with multicellularity: the worm has differentiated cells and organs, it ages and has a well-defined lifespan, and it is capable of learning and remembering. This review argues that the balance between simplicity and complexity in the worm will make it a useful tool in determining the relationship between molecular-scale phenomena and organism-level phenomena, such as aging, behavior, cognition, and disease. Following an introduction to worm biology, and a comparison of worm biology with human biology, the review provides examples of current research with C. elegans that is either chemically relevant or potentially interesting to those with a molecular focus. It also describes tools-biological, chemical, and physical—that are available to researchers studying the worm.

\section{From the Contents}

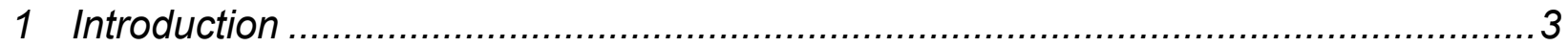

1.1 Choosing Models: What is the Best Organism for Chemists? .................. 4

1.2 Sydney Brenner and the Selection of C. elegans as a Model Organism....7

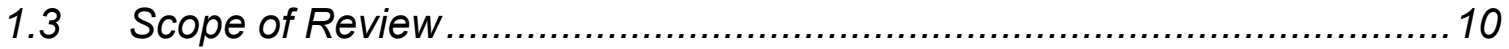

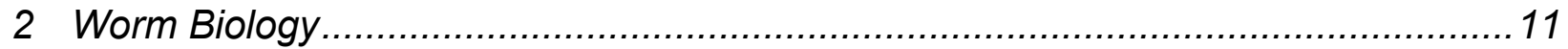

2.1 Development and Lifespan .................................................... 11

2.2 The Genome and Proteome ................................................... 12

2.3 Pathways of Signal Transduction ............................................... 14

2.4 Basic Anatomy and Physiology .................................................... 15

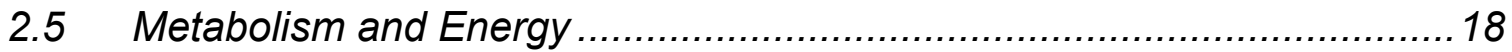

3 How Can Chemists Use the Worm? ..................................................... 23 


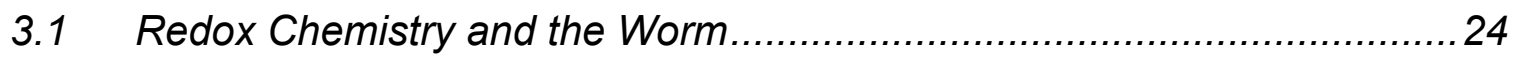

3.2 Molecular Mechanisms of Aging in C. elegans.....................................26

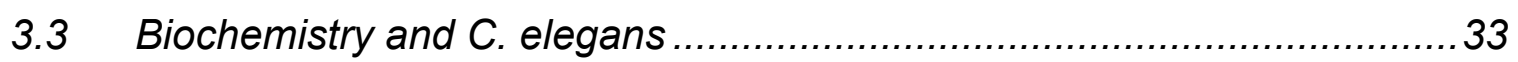

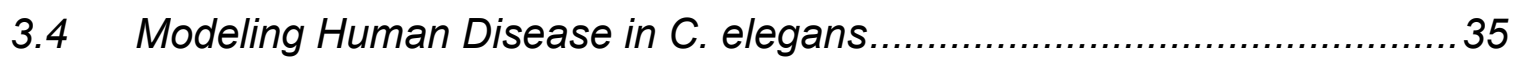

3.5 C. elegans as a Model for Parasitic Worms........................................... 43

4 What Tools for Studying the Worm Are Available to Chemists? .............................5 50

4.1 Microfabricated Tools for Manipulating and Confining Worms .................50

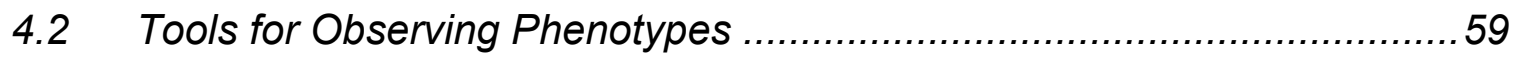

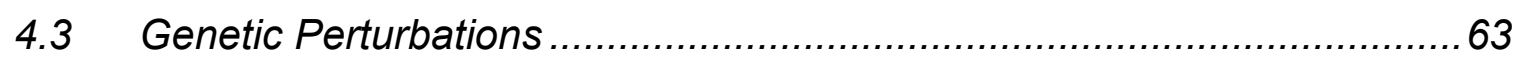

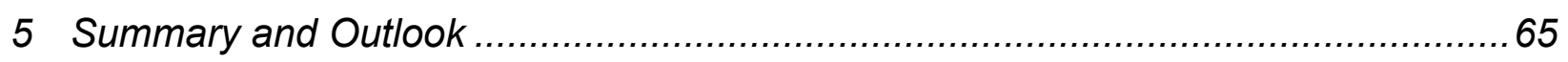

5.1 Model Organisms for Chemists: Alternatives to the Worm? ....................65

5.2 Relevance of the Worm to Human Health .........................................66

5.3 How Can Chemistry Be Exploited for Worm Research? .........................67

5.4 For What Should Chemists Use the Worm? ........................................69

\section{Introduction}

Chemistry underlies biology: molecular interactions provide the foundation and structure of all life. Chemists, however, are not biologists. What, then, should be the subject, and goal, of a chemist who is studying living systems? One response to this question is that chemists should work to understand the nature of biomolecules and the interactions among them. For example, molecular phenomena such as molecular recognition, the hydrophobic effect, multivalency, enzymatic catalysis, and signal transduction are far from fully understood and remain active and important topics of research. At its most reductionist level, this type of research focuses on processes involving individual molecules, small numbers of molecules, individual reactions, and small networks of reactions. 
Pursuing an understanding of biology at the level of molecules is clearly an important goal, and one for which chemistry is uniquely suited. But what of higher-level questions? What is life? How do networks of molecules, molecular interactions, and reactions-properly compartmentalized — develop and maintain the astonishing set of characteristics we attribute to "life"? Molecules are not alive, but organized networks of the reactions that interconvert them are; how does this transformation occur? These questions cannot be answered using only molecules - there are limits to reductionism—one must look to cells and organisms. Further, there are questions that may only be answered using multicellular organisms. What is aging? What is disease? What is cognition? What is behavior? How do fundamental molecular interactions aggregate into these complex phenomena? How are organisms organized from cells, and how do the component cells interact and communicate? How does a fertilized egg-a single cell—differentiate into an organism? This second set of questions highlights an opportunity for chemists to explore how the biochemical processes that go on within, and between, individual cells relate to the complex phenotypes of multicellular organisms, including humans.

\subsection{Choosing Models: What is the Best Organism for Chemists?}

Evolution has resulted in a great variety of living creatures, ranging from the simplest bacterium to the most complex, large, multicellular organisms. "Complexity" can mean many things; ${ }^{[1,2]}$ by "complex organism," we mean one with a large number of parts, and a large

number of interactions between those parts. ${ }^{[3,4]}$ We also use complexity to refer to organizational complexity: all organisms have cells, but in more complex organisms, those cells may be organized into tissues, and, beyond tissues, into distinct organs. ${ }^{[3,4]}$ The variety and diversity of life is so enormous that — to focus efforts, and avoid intellectual pointillism—it is 
necessary to concentrate investigation on a small number of organisms, chosen for experimental convenience, and try to understand those organisms in detail. The organisms chosen for this type of study are called "model" organisms. Table 1 compares a selection of model organisms from both a scientific standpoint, and from the practical consideration of their tractability for study by chemists.

The simplest model organisms are unicellular: single-celled bacteria, algae, yeasts, and protozoa. Unicellular organisms are, of course, alive, and are the best organisms with which to address many of the issues surrounding the question "what is life?" E. coli is certainly the most studied; Mycoplasma genitalium, with the smallest genome of any known organism that can reproduce independently in pure culture, ${ }^{[5]}$ is perhaps the best suited for understanding the core question of how molecular networks become alive. Unicellular organisms are very convenient to study in some regards, but also have disadvantages. Although the simplicity of these organisms (in regards to the degree of intercellular interaction, amount of differentiation, and size and complexity of the genome) can be beneficial in experiments, their usefulness in addressing higher-order biological questions is limited. Yeast and bacterial cells may exhibit changes over time that are suggestive of cellular aging ${ }^{[6,7]}$ (for example, mother cells of the budding yeast Saccharomyces cerevisiae can produce only a limited number of daughter cells ${ }^{[6]}$ ), but aging in these cells lacks the great diversity of phenotypes involved in mammalian aging.

The higher-order phenomena that are most relevant to humans — phenomena like aging, disease, cognition - appear in complex form in multicellular life only. What is the best organism for chemists to use in studying complex, multicellular organisms, and more generally multicellularity, and its consequences, in life? The ideal organism would be complex enough to 
address higher-order questions, but simple enough to be experimentally tractable and easy to work with. Multicellular organisms include i) organisms that exhibit little or no cellular differentiation and do not have a well-defined lifespan (such as filamentous yeasts and bacteria), ii) organisms that exhibit more cellular differentiation than the first group, but do not have cellular types or body structures that are analogous to those in humans, and do not have a welldefined lifespan (such as multicellular fungi, multicellular algae, social amoebae, and plants), and iii) organisms that do have differentiated tissues and distinct organs, and have a defined lifespan. It is in the third group — which includes worms, flies, zebrafish, mice, primates, and humans - that organisms exhibit the level of biological complexity in which we, as humans, are most interested. The organisms in this group that have the most relevance to human biologyother mammals, such as mice and primates — are also the most difficult to work with, because of complexity and expense. One of the simplest organisms in this group is the nematode Caenorhabditis elegans: a 1-mm long roundworm that has an average lifespan between two and three weeks at $20^{\circ} \mathrm{C}$, and is easy and inexpensive to cultivate.

Experimentally, the culture of C. elegans is far simpler than the maintenance of higher organisms, such as mice, and is also far simpler than the culture of mammalian cells. Experiments with C. elegans are free of the ethical concerns - and accompanying regulationsassociated with working with higher organisms, particularly vertebrates. The maintenance of C. elegans requires no specialized training or equipment. ${ }^{[8]}$ Worms can grow at room temperature, and in unmodified air; it is thus possible to maintain cultures on the laboratory bench. Requirements of sterility are less stringent with C. elegans than with cultures of mammalian cells because contaminated stocks of $C$. elegans are easily identified and cleaned. ${ }^{[8]}$ 
In addition, when multiple strains of $C$. elegans are maintained simultaneously, the occurrence of unrecognized cross-contamination — a significant concern in the use of mammalian cell lines ${ }^{[9]}$ is unlikely. Thus worms provide chemists with a tractable platform for quickly testing chemical hypotheses in a simple multicellular organism.

In this review, we will argue that $C$. elegans is an organism of just the right level of complexity to enable chemists to pursue a molecular understanding of multicellular life (and thus of metabolism, regulation of networks, many features of biological information storage, transmission, and expression, development, reproduction, aging, disease, and death). This complexity is balanced with an ease-of-use, which should enable C. elegans to be easily adopted by chemical research groups - an important consideration for chemists who wish to keep a molecular focus, and who do not wish to embrace the technical rigors of mammalian cell culture, or the expense, complexity, and regulatory difficulties of working with mammals. The ease with which the worm can be adopted should encourage chemists to study not only the worm, but organisms in general. For chemists and other scientists who are interested in molecular organismic biology, but do not have experience working with model organisms, the worm is a useful starting point.

\subsection{Sydney Brenner and the Selection of C. elegans as a Model Organism}

In the early 1960s, Sydney Brenner, then at the MRC Laboratory of Molecular Biology at Cambridge, selected, developed, and popularized the use of C. elegans (or, simply, "the worm") for biological research, particularly as a model for development and organogenesis; for this work he received the Nobel Prize in Physiology or Medicine in 2002. ${ }^{[10]}$ Since its popularization by Brenner, the worm has become a widely-used model organism in biology. 
Following the discoveries of the structure of DNA, and the processes of translation and transcription in the middle part of the $20^{\text {th }}$ century, there was a feeling in the group that included Brenner and his colleagues that molecular biologists had solved, or were well on their way to elucidating the details of, the problems of classical molecular biology—principally, the nature of the replication and expression of DNA. The field had accomplished this work largely using bacteria and bacteriophage, which were useful model organisms because of their simplicity and the fact it was possible to manipulate them in large numbers easily. ${ }^{[1]}$ Whether right or wrong in his assessment of his field, Brenner was interested in shifting the focus of molecular biology from the chemical details of biomolecular machinery to higher-level biological processes, particularly development, and also neuronal function. ${ }^{[11]}$ For such processes, bacteria and phages were no longer appropriate models; this consideration inspired Brenner to seek out a higher organism — one that could be manipulated like a microorganism, and could be studied using the tools of molecular biology.

Brenner wanted an organism that had a short generation time, to simplify the study of development, and a relatively small number of cells, to enable the tracking of cellular lineages. ${ }^{[11]} \mathrm{He}$ also wanted an organism that was straightforward to cultivate, and was easily observed with a microscope ${ }^{[11,12]}$ For the study of development, Brenner initially considered unicellular organisms that exhibit some form of cellular differentiation—including the bacterium Caulobacter, and the protist Naegleria (Table 1) — but concluded that these organisms were biological curiosities, and thus too exotic to be useful as model organisms. ${ }^{[12]} \mathrm{He}$ also considered rotifers — which are multicellular, and have differentiated tissues and organs 
(Table 1) — but was frustrated by their slow reproduction and complex life cycles. ${ }^{[12]}$

Eventually, Brenner settled on C. elegans as the simplest organism that met his criteria.

C. elegans has a short generation time (a fertilized eggs develops into a sexually mature adult in approximately 3 days at $20^{\circ} \mathrm{C}$ ) and a short lifespan (the average lifespan is between two and three weeks at $20^{\circ} \mathrm{C}$ ) and can be cultivated in the laboratory on a diet of bacteria (typically E. coli), either on agar plates or in liquid. Figure 1a shows a photomicrograph of worms crawling on the surface of an agar plate. The worm is small in size (the adult is $1 \mathrm{~mm}$ in length, and $50 \mu \mathrm{m}$ in width), and has a small number of cells (adult hermaphrodites have 959 somatic cells; adult males have 1031). Figure 1b displays an image of an adult hermaphrodite. The transparency of the body of the worm enables every nucleus in the worm to be imaged using light microscopy.

The worm has two sexes: self-fertilizing hermaphrodites, and males, which arise rarely $(0.1 \%$ of the time $)$ from self-fertilization. This division of the sexes was an attractive feature to Brenner from the standpoint of genetic analysis, as males could be crossed with hermaphrodites to produce new combinations of mutant genes. In the past 50 years, further developments in research have made C. elegans even more attractive as a model organism; these developments include i) the reconstruction of the complete lineage of every cell in the worm from fertilization to maturity by John Sulston and colleagues, ${ }^{[13,14]}$ ii) the reconstruction of the entire nervous system of C. elegans by John White and colleagues, ${ }^{[15]}$ iii) the discovery of the usefulness of RNA interference in manipulating the expression of genes in C. elegans by Andrew Fire and Craig Mello, ${ }^{[16]}$ and iv) the publication of the complete genetic sequence of the worm by the C. elegans Sequencing Consortium. ${ }^{[17,18]}$ 
Brenner's goal — to find a simple model organism with which to correlate genetic manipulations and developmental effects - is a specific instance of the goal we propose for chemists - to find an organism with which to correlate generic chemical states $(\mathrm{pH}$, level of oxidation, net charge) or processes (protein-ligand interactions, redox reactions) to phenomena at the level of the organism. Brenner sought to find the simplest possible organism that allowed the correlation to be made. The success of the worm as a model organism for studying the genetics of complex phenomena in biology confirms Brenner's insight in selecting C. elegans.

Although a large amount of work has examined the organismic consequences of genetic modifications, there has been relatively little work done to explore the organismic consequences of chemical modifications. Many of the features that make the worm so valuable to molecular biologists and geneticists will also make the worm useful to chemists. The handoff of worms from biologists to chemists is a natural step in the reductionist cascade in science.

\subsection{Scope of Review}

In this review, we first present a brief overview of the biology of C. elegans and discuss the relevance of the worm as a model organism for organismic (and some aspects of human) biology. We then present examples from the literature illustrating how C. elegans can be used to link chemical details to phenomena at the organismic level. Although the principal focus of the review is the fundamental biochemistry of the worm, we also sketch its relevance to human disease. A number of important human diseases (largely in the developing world) are due to nematodes or parasitic worms of similar complexity, and the study of C. elegans is directly relevant to these diseases. To provide chemists with a starting point for research, we review the biochemical, chemical, and physical tools that are available to facilitate research with the worm. 
We conclude by considering the opportunities that lie ahead for chemists in the field of worm biology. We discuss opportunities both for tool makers - those who develop devices and protocols useful in studying the molecular biochemistry of the worm - and tool users - those who can use these tools to study the biochemistry.

\section{Worm Biology}

Gaining a complete understanding of fundamental biological processes is a goal at the very core of science. The simplicity of the worm makes it an excellent starting point in this pursuit. From an applied perspective, it is also interesting to consider the relationship between worm biology and human biology. How useful is knowledge gained with the worm for understanding human biology, health, and disease? This section provides an overview of worm biology, and, where relevant, compares human and worm biology. Table 2 lists some online resources for learning more about C. elegans biology. A review by Antoshechkin and Sternberg provides a detailed description of online databases and tools that facilitate the study of C. elegans. ${ }^{[19]}$

\subsection{Development and Lifespan}

C. elegans begins life as an embryo, and progresses through four larval stagesL1, L2, L3, and L4 - before becoming a fully-developed, sexually mature adult. At $20{ }^{\circ} \mathrm{C}$, the generation time - the time between fertilization and the onset of reproduction in adulthood-is

approximately 2-3 days, and the average lifespan is between two and three weeks. ${ }^{[20]}$ During the transition from L1 to L2, if C. elegans experiences low concentrations of food or crowding (high population density), it may also form an alternative third larval stage known as dauer-which is 
a German word meaning "enduring". Dauers are motile, but do not feed, and develop a thick cuticle that protects them from treatment with harsh chemicals, such as sodium dodecyl sulfate (SDS). ${ }^{[21]}$ When levels of food increase, or population density decreases, dauer larvae can proceed to the L4 larval stage. ${ }^{[20]}$ As dauers, C. elegans can live for several months. ${ }^{[22]}$

In the laboratory, the typical source of food for C. elegans is a slow-growing strain of E. coli, OP50. ${ }^{[23]}$ While the use of $E$. coli as a food source was likely a convenient choice when Brenner was developing the worm as a model organism, E. coli is probably not the principal food source for C. elegans in nature. In fact, there is evidence that suggests $E$. coli may even be pathogenic to C. elegans. ${ }^{[24,25]}$ Researchers have isolated wild C. elegans from garden soil and compost, and also from snails, woodlice, and other invertebrates. ${ }^{[26]}$ The diet of C. elegans in these environments is not known, but may include microorganisms associated with rotting organic matter. Studies in C. elegans and other Caenorhabditis species suggest that the association between C. elegans and macroscopic invertebrates like snails and woodlice facilitates the dispersal of worms. ${ }^{[2]}$ This association may also be necromenic — that is, worms may feed on the corpse of the host after it dies. ${ }^{[26]}$ It is possible to grow C. elegans using bacteria-free, chemically-defined media; for unknown reasons, however, worms develop more slowly in bacteria-free medium than they do when fed bacteria. ${ }^{[27]}$ We discuss this issue in more detail in Section 3.2.2.

\subsection{The Genome and Proteome}

Despite the simplicity of the worm, there is substantial overlap between worm and human with respect to genes and biochemical pathways. Although the genome of the worm is substantially smaller than that of humans (the C. elegans genome is $\sim 100 \mathrm{Mb}$; the H. sapiens 
genome is $\sim 3,000 \mathrm{Mb}$ ), the worm has nearly as many genes (worms have $\sim 20,000$ genes; humans have $\sim 23,000) .{ }^{[18]}$ Bioinformatic analyses suggest that $60-80 \%$ of the genes of the worm are homologous to human genes. ${ }^{[28]}$ (Homologous genes are genes in different organisms that evolved from a common ancestor; it is possible to identify putative homologs on the basis of sequence similarity in the genetic code.$^{[29]}$ )

To diversify its proteome, C. elegans can perform both post-transcriptional modifications (alternative splicing of messenger RNA) and post-translational modifications (covalent modification of proteins). Alternative splicing of genes occurs to a much greater extent in humans than in worms: at least $60 \%$ of human genes have at least one alternative form; in the worm, only approximately $10 \%$ of genes have alternative forms. ${ }^{[30]}$ Thus the proteome of H. sapiens is probably significantly larger, and more complex, than that of C. elegans. The C. elegans genome encodes proteins that enable a repertoire of post-translational modifications that is similar to that of humans; these modifications include phosphorylation, acylation (including acetylation of histones), ubiquitination, ${ }^{[31]}$ alkylation (including methylation, and prenylation ${ }^{[32]}$ ), and glycosylation (including $N$ - and $O$-linked). ${ }^{[33]}$

\subsubsection{The Organization of Genes in C. elegans}

Unlike other eukaryotes, worms use operons - genetic structures in which a single upstream promoter regulates the serial transcription of a group of genes into a single strand of messenger RNA - to regulate the co-expression of genes. (In other eukaryotes, each gene typically has its own promoter region. ${ }^{[34]}$ Approximately $15 \%$ of protein coding genes in C. elegans are found in operons. ${ }^{[35]}$ Prokaryotes also use operons (e.g., the lac operon of E. coli), but operons in nematodes most likely evolved independently, possibly because the short time 
between mitotic divisions in embryogenesis created a selective pressure towards a smaller genome. ${ }^{[36]}$ The use of operons is a partial explanation for the C. elegans genome being approximately 30 times smaller than the human genome, despite having a similar number of genes. A second explanation is that the C. elegans genome contains less non-coding DNA (i.e., DNA that does not code for proteins). For example, transposable elements-mobile segments of DNA that do not code for proteins - and their inactive (immobile) remnants account for approximately $12 \%$ of the C. elegans genome, but nearly $50 \%$ of the human genome. ${ }^{[37]}$ Overall, coding DNA makes up $25.55 \%$ of the C. elegans genome, but only $1.5 \%$ of the human genome. ${ }^{[36]}$

\subsection{Pathways of Signal Transduction}

Many of the biochemical pathways associated with signal transduction are at least partially conserved between humans and worms. ${ }^{[38]}$ Reference [38] includes a comparison of signal transduction pathways in worms and humans. Some pathways show a high degree of conservation. For example, the genome of C. elegans has homologs for all of the components of the transforming growth factor $\beta$ (TGF- $\beta$ ) pathway. ${ }^{[39]}$ In contrast, some other human pathways are only partially present in C. elegans (the Toll-like receptor pathway and the JAK/STAT signaling pathway, ${ }^{[40]}$ for example), and still others are believed to be absent in C. elegans (e.g., the hedgehog signaling pathway). ${ }^{[38,39]}$ One of the best studied signaling pathways in C. elegans is the insulin/insulin-like growth factor 1 (IGF-1) signaling pathway. ${ }^{[41]}$ This pathway contains a single insulin/IGF-1 receptor, DAF-2, the inactivation of which results in an increased lifespan in C. elegans. ${ }^{[42]}$ The C. elegans genome contains 37 insulin-like proteins; INS-1 is the most closely related to human insulin. Both INS-1 and human insulin are DAF-2 
antagonists. Many of the members of the insulin/IGF-1 signaling pathway are conserved among worms, flies, and mammals. Mutation of the daf-2 equivalent in Drosophila also increases lifespan, thus raising the intriguing possibility that molecular mechanisms for controlling lifespan are conserved across species. ${ }^{[43]}$

A type of signaling in C. elegans that is not well understood is the use of hormones for nuclear signaling. ${ }^{[4]}$ The genome of the worm encodes 284 genes that, based on sequence, are predicted to be nuclear hormone receptors. ${ }^{[45]}$ In contrast, the human genome has 48 predicted nuclear hormone receptors. ${ }^{[46]}$ Approximately 15 of the predicted nuclear hormone receptors in C. elegans are believed to be homologous to nuclear hormone receptors in humans. ${ }^{[47]}$ The identity of the corresponding ligand is unknown for all but one of the predicted receptors in C. elegans; researchers recently identified three cholesterol-derived molecules that serve as ligands for the nuclear receptor DAF-12, which influences development (dauer formation) and

reproduction in C. elegans. ${ }^{[48]}$ For some nuclear receptors, it is possible to predict the identity of the corresponding ligand based on motifs in the sequence of the gene that correspond to known recognition sites in other organisms; for example, based on sequence data, the corresponding ligand for the C. elegans nuclear hormone receptor NHR-14 is most likely an estrogen or estrogen-like compound. ${ }^{[49]}$

\subsection{Basic Anatomy and Physiology}

Despite the simplicity of the anatomy of the worm, many tissues and organs in C. elegans have structures and/or functions that are recognizably similar to our own: muscle tissue in C. elegans looks like human muscle; neurons in C. elegans look like human neurons (although they are not myelinated and do not have Schwann cells; they do, however, have glial cells that 
support neuronal function and structure ${ }^{[50]}$ ); the pharynx, gut, and uterus of the worm have clear analogs in human anatomy.

\subsubsection{Organs and Tissues}

The anatomy of C. elegans includes an alimentary system (mouth, pharynx, intestine, rectum, anus), a reproductive system (gonad, uterus, spermatheca, vulva in the hermaphrodite; gonad, seminal vesicle, vas deferens, cloaca in the male), a nervous system (302 neurons in the hermaphrodite, with a cluster of synapses — the "nerve ring"-located in the head), and an excretory system (a group of four cells believed to control osmolarity and the elimination of waste). ${ }^{[20]}$ Worms have muscle (striated and non-striated), hypodermis, a protective cuticle covering the body (secreted by the hypodermis), as well as connective tissues and basement membrane. ${ }^{[20]}$ The cuticle is a $0.5-\mu \mathrm{m}$ thick coating on the external surface of the worm; it comprises five layers (from innermost to outermost): a layer of collagen fibrils, a fluid-filled layer with "struts" of collagen, a layer of collagens and cuticle-specific proteins, a layer of lipids, and a surface coat of glycoproteins. ${ }^{[20]}$

The body of the worm is essentially a tube — the alimentary tract — inside of another tube - the hypodermis and cuticle. Between the two tubes is a fluid-filled body cavity - the pseudocoelom. ${ }^{[20]}$ C. elegans does not have a circulatory system, and relies on passive diffusion in the pseudocoelomic fluid for the transport of $\mathrm{O}_{2}, \mathrm{CO}_{2}$, and nutrients. It is also possible that the locomotory movement of the body of the worm mixes the contents of its interior fluid. Gas exchange with the environment occurs by diffusion through the cuticle or the surface of the gut. ${ }^{[51]}$ 


\subsubsection{Immune System of the Worm Is Not Adaptive}

Unlike humans and other vertebrates, C. elegans does not have an adaptive immune system; C. elegans does not produce antibodies. Instead, the worm relies on innate recognition and responses to protect itself from pathogens. ${ }^{[52]}$ Although the innate immunity of the worm is not entirely characterized, it is known that some signaling pathways used in innate immunity are conserved in C. elegans and humans, including the p38 mitogen-activated protein kinase pathway, and the apoptotic pathway. ${ }^{[52]}$ In addition, pathways known to play a role in adaptive immunity in mammals appear to be involved in the innate immunity of $C$. elegans: the TGF- $\beta$ pathway controls $\mathrm{T}$ cell differentiation in mammals, and is involved in the induction of the innate immune response in C. elegans. ${ }^{[52]}$

The response of the worm to pathogenic bacteria involves the use of lysozymes, which attack bacterial cell walls, and caenopores, which are peptides that disrupt bacterial cell membranes, to break up bacteria. The immune response of the worm also involves up-regulation of the expression of catalases, superoxide dismutases, metallothioneins, and glutathione S-transferases - molecules that are likely involved in detoxification. ${ }^{[52]}$ In addition, the body cavity of the worm contains six coelomocytes — six large (10-15 $\mu \mathrm{m}$ wide) cells believed to play a role in the immune system of the worm by taking up foreign or toxic molecules via endocytosis. ${ }^{[52]}$

\subsubsection{Neurobiology}

In C. elegans, adult hermaphrodites have 302 neurons. Unlike neurons in vertebrates, neurons in C. elegans are not myelinated. Only a subset of neurons in C. elegans appear to 
generate classical "all-or-nothing" action potentials. ${ }^{[53]}$ Rather than action potentials, most neurons in the worm exhibit graded potentials, the shapes of which depend on the amplitude, duration, and shape of the signal that stimulated neuronal activity. ${ }^{[54]}$ Despite these differences, worms use many of the same neurotransmitters as humans, and the mechanisms for the biosynthesis, release, recognition, and removal of neurotransmitters are highly conserved in worms and humans. ${ }^{[55]}$ Table 3 compares neurotransmitters used in worms and humans. C. elegans neurons are also responsive to many compounds that are neuroactive in humans, including acetylcholinesterase inhibitors, ${ }^{[56]}$ serotonin-specific reuptake inhibitors, ${ }^{[57]}$ and anesthetics. $^{[58]}$

C. elegans exhibits a variety of behaviors - including locomotion (crawling and swimming), feeding (pharyngeal pumping), defecation, egg-laying, and mating (when the population contains males) — that are easy to observe. ${ }^{[59]}$ Laser ablation of neurons has enabled the elucidation of the neuronal circuits involved in each of these behaviors. ${ }^{[59]}$ C. elegans can sense, and respond to, chemical, mechanical, and thermal stimuli in surprisingly sophisticated ways for an organism with only 302 neurons. Worms are capable of multiple forms of learning — defined as a change in behavior based on experience-including habituation and classical conditioning. ${ }^{[60]}$ Worms also have memory. For example, when provided with food at a specific temperature and then transferred to a thermal gradient, worms locate, and crawl along, the isotherm corresponding to the original feeding temperature. ${ }^{[61]}$

\subsection{Metabolism and Energy}

The presence of sequences in the genome of the worm that correspond to functional motifs in human proteins suggests that pathways associated with the breakdown of nutrients, the 
storage of energy, and the synthesis of small molecules are highly conserved between worms and humans. ${ }^{[62]}$ For some, but not all, potentially-conserved genes, experiments have confirmed that the associated protein is expressed and functional. ${ }^{[63]}$ The genome of the worm contains genes coding for all of the proteins necessary for the fundamental pathways of cellular respiration: glycolysis (the conversion of glucose to pyruvate), pyruvate decarboxylation (formation of acetyl-coA from pyruvate), $\beta$-oxidation of fatty acids, the citric acid cycle, the electron transport chain, and ATP synthesis. ${ }^{[63]}$ Like mammals, C. elegans uses flavin adenine dinucleotide (FAD) and nicotinamide adenine dinucleotide $\left(\mathrm{NAD}^{+}\right)$as cofactors in cellular respiration. The proteins involved in these pathways are highly conserved between humans and worms. ${ }^{[2-64]}$

To meet energetic needs under anaerobic conditions, C. elegans - like humans - can rely on anaerobic glycolysis, which produces lactic acid as a waste product. Unlike humans, however, cells in C. elegans can also perform ethanolic fermentation ${ }^{[63]}$ and malate dismutation - a metabolic pathway, also found in parasitic nematodes, that employs a specialized mitochondrial electron transport chain. This chain uses fumarate, rather than oxygen, as the electron acceptor, and produces acetate, succinate, and propionate as waste products, rather than carbon dioxide and water. ${ }^{[65]}$

Worms can generate glycogen from glucose for the storage of energy. Glycogen makes up approximately $3.3 \%$ of the dry mass of adult worms. ${ }^{[66]}$ The principal location of glycogen storage in worms is in the gut. ${ }^{[33]}$ In mammals, enzymes can break down stored glycogen in the liver into glucose, which can circulate in the bloodstream to meet the energetic demands of tissues throughout the body. C. elegans lacks glucose-6-phosphatase, which is required for the final step in the breakdown of glycogen into glucose. ${ }^{[64]}$ It is possible that C. elegans obtains 
glucose from glycogen using trehalose as an intermediate; worms have enzymes that catalyze the synthesis of trehalose from glucose-6-phosphate, as well as enzymes that catalyze the hydrolysis of trehalose into glucose. ${ }^{[64]}$ It is unknown whether it is trehalose, glucose, or both that diffuse from glycogen stores to energy-requiring tissues following the breakdown of glycogen. ${ }^{[62,64]}$

Worms also store energy as lipids. Triacylglycerides and free fatty acids make up approximately $36 \%$ of the dry mass of adult worms. ${ }^{[66]}$ C. elegans can obtain fatty acids from dietary sources (from the bacteria they eat), or from de novo biosynthesis. Like humans, C. elegans synthesizes, and uses, saturated, monounsaturated, polyunsaturated, and branched chain fatty acids. ${ }^{[67,68]}$ In C. elegans, fat stores are located in the hypodermis and in droplets in intestinal cells. ${ }^{[69]}$

C. elegans cannot synthesize sterols de novo. The worm has genes coding for the necessary molecular machinery for the synthesis of the polyisoprenoid molecule farnesyl pyrophosphate, a precursor of dolichols, ubiquinone, and sterols. The steps in this synthetic pathway are conserved in humans and worms. While the worm can proceed to synthesize dolichols and ubiquinone, it cannot produce sterols from farnesyl pyrophosphate. The worm therefore requires a dietary source of fully-synthesized sterols — or their immediate synthetic precursors-from plants or animals. ${ }^{[70]}$ In the laboratory, media for C. elegans typically contains cholesterol. ${ }^{[8]}$ Interestingly, because statins, a class of drugs that lower levels of cholesterol in humans, lower cholesterol by inhibiting the activity of 3-hydroxy-3-methylglutaryl-CoA (HMG-CoA) reductase, which acts upstream of farnesyl pyrophosphate in the biosynthesis of sterols, the worm may be a particularly useful model for investigating effects of statins that are independent from the reduction in levels of cholesterol. ${ }^{[32]}$ 
Worms require a dietary source of heme, and - in contrast to mammals, yeast, and bacteria — appear to lack several enzymes required for the biosynthesis of heme. ${ }^{[71]}$ Analysis of the genome of C. elegans suggests that worms generate a number of heme-containing proteins, including globins, guanylate cyclases, adenylate cyclases, catalases, cytochrome P450s, and cytochromes involved in cellular respiration. ${ }^{[71]}$ Bacteria provide a source of heme when C. elegans is grown using bacteria as a food source. It is also possible to supply worms with heme by adding hemin chloride or heme-containing proteins, such as hemoglobin, myoglobin or cytochrome $\mathrm{c}$, to the media. ${ }^{[62,71]}$ Worms also require dietary sources of specific amino acids. Table 3 compares essential and non-essential amino acids in humans and worms.

\subsubsection{C. elegans Can Survive Hypoxia and Anoxia}

Interestingly, worms are able to survive periods of anoxia (no oxygen) and hypoxia (low oxygen). At oxygen tensions down to $\sim 3.6 \mathrm{kPa}(0.036 \mathrm{~atm})$, the metabolic rate of C. elegansas measured by monitoring carbon dioxide production ${ }^{[72]}$ or oxygen consumption ${ }^{[73]}$ —remains indistinguishable from that of worms in normoxic environments, where the oxygen tension-or partial pressure-is $\mathrm{P}_{\mathrm{O}_{2}} \approx 21 \mathrm{kPa}$. Below the threshold of $3.6 \mathrm{kPa}$, metabolic rate decreases with decreasing oxygen tension. At an oxygen tension of $1 \mathrm{kPa}$, the metabolic rate of C. elegans is half of that of worms in normoxic conditions. ${ }^{[72,73]}$ C. elegans can survive limited exposure to anoxic conditions (defined in one study as $\mathrm{P}_{\mathrm{O}_{2}}<0.001 \mathrm{kPa}^{[74]}$ ). All developmental stages of worms, from embryos to adults, exhibit relatively high rates of survival ( $\sim 85-90 \%)$ following exposure to anoxia for $24 \mathrm{~h}^{[74-76]}$ The survival of worms to anoxia declines with longer exposure: after $72 \mathrm{~h}$ of anoxia, the rate of survival decreases dramatically for adult worms to 
$\sim 5-10 \% .{ }^{[75,76]}$ Larvae (L1-L4 stage worms) show a similar decline in survival after $72 \mathrm{~h}$ of exposure. ${ }^{[76]}$

How do worms survive anoxia? Exposure to anoxia causes worms to enter a state of suspended animation, characterized by an absence of locomotion, feeding, egg-laying (in adults), and development (in embryos and larvae). ${ }^{[75,77]}$ This arrested state may minimize energetic needs and promote survival during anoxia. In addition, anoxic exposure results in the production and excretion of L-lactate, acetate, succinate, and propionate by $C$. elegans. ${ }^{[78]}$ The production of these metabolites suggests $C$. elegans uses anaerobic metabolic pathways-lactic acid fermentation and malate dismutation — to generate cellular energy during anoxia. ${ }^{[65,78]}$

To describe the survival of $C$. elegans in hypoxic environments, it is useful to define three ranges of oxygen tension: mild hypoxia $(0.25-1 \mathrm{kPa})$, severe hypoxia $(0.01-0.1 \mathrm{kPa})$, and anoxia $(<0.001 \mathrm{kPa})$. C. elegans embryos have a high rate of survival $(>90 \%)$ following exposure to mild hypoxia for $24 \mathrm{~h}$, and this survival is dependent on the expression of hif-1, a homolog of the mammalian hypoxia-induced factor. ${ }^{[74,76,79]}$ As described above, C. elegans embryos also have a high rate of survival $(>90 \%)$ following exposure to anoxia for $24 \mathrm{~h} .{ }^{[74,76]}$ Survival in anoxia, however, is independent of hif-1. ${ }^{[76]}$ Perhaps surprisingly, C. elegans embryos have a relatively low rate of survival $(<30 \%)$ following exposure to severe hypoxia for 24 h. ${ }^{[74]}$ It thus appears that the mechanisms that protect worms during anoxia or mild hypoxia are either inactive or ineffective during exposure to severe hypoxia. Unlike embryos exposed to anoxia, embryos exposed to severe hypoxia do not enter a state of suspended animation. ${ }^{[74,76,79]}$ Treatment of worms with carbon monoxide during exposure to severe hypoxia, however, does induce suspended animation, and also increases the rate of survival for a $24 \mathrm{~h}$ exposure 
significantly. ${ }^{[74]}$ These results suggest that, although severe hypoxia alone (without CO treatment) is insufficient to induce suspended animation, the suspended state, if induced, can protect C. elegans from harm during anoxia or hypoxia. ${ }^{[74]}$

\section{How Can Chemists Use the Worm?}

The worm has served predominantly as a model organism for understanding how genes specify biological processes. ${ }^{[80]}$ The conventional approach, therefore, to studying the worm has focused on determining i) the phenotypic effect of a genetic mutation, ii) the interactions among different genes and gene products (RNA and proteins), and, ultimately, iii) the function of a particular gene. ${ }^{[38,80]}$ One explanation for this strong focus on genetics may be historical: Sydney Brenner and his colleagues explicitly developed C. elegans as a model organism to study how genes specify organismic development. ${ }^{[11,12]}$ A second, and related, explanation is that Brenner selected C. elegans specifically because the organism was amenable to genetic study. With the sequencing of the C. elegans genome, ${ }^{[17]}$ the attractiveness of the worm as a model organism for genetics has only increased. From a chemical perspective, however, a genetic mutation is a highly complex molecular perturbation. A single mutation may have direct consequences for the structure and function of the protein for which the gene codes, and may also have diverse downstream consequences due to the altered function of the protein. If the gene codes for a regulatory protein, the downstream chemical consequences could be farreaching and diverse. For chemists, therefore, genes may be a much less useful and interesting framework for experimental design than "proteins", "catalysis", "metabolism", "networks", or many others. The relation between the simple information coded in the genome, and the very 
complex information relevant to understanding life, has grown increasingly obscure as we learn more about both genes and life.

With the overall goal of understanding the relationships between organism-level phenotypes and their underlying chemical states, we envision that chemical research with the worm would rely on one or more the following experimental strategies: i) modifying the chemical state of the worm directly, independently of genetic manipulation, ii) making use of genetic mutations that produce simple and well-defined chemical changes (such work could rely heavily on the work of geneticists in elucidating the function of genes), and iii) using conventional biochemistry and other techniques to monitor the chemical/molecular state of the worm in response to genetic, environmental, chemical, and physical perturbations. The following sections provide examples of research with $C$. elegans that have a significant chemical component.

\subsection{Redox Chemistry and the Worm}

Cai and Sesti investigated the effect of chemical oxidation and reduction on behavior and aging in C. elegans. ${ }^{[81]}$ Treatment of living worms with oxidizing agents such as hydrogen peroxide and chloramine-T (sodium salt of $N$-chloro 4-methylbenzenesulfonamide) diminished the ability of worms to perform chemotaxis. Furthermore, treatment of aging worms with a reducing agent, dithiothreitol, slowed the age-related decline in ability to chemotaxis (in comparison with untreated worms). Because of the importance of $\mathrm{K}^{+}$channels to neuronal function, the authors explored whether the oxidation of KVS-1, a voltage-gated $\mathrm{K}^{+}$channel expressed in the neurons of the worm, was responsible for the change in behavior. Mutant worms - expressing a version of KVS-1 with a cysteine-to-serine mutation at a single position- 
showed less of a decline in chemotaxis following exposure to chemical oxidants than did worms expressing wild-type KVS-1. This result suggests the oxidation of the cysteine residue of KVS-1 is partially responsible for the decline in ability to chemotax, and provides a possible mechanism by which oxidative stress — from, for example, reactive oxygen species (ROS)—can lead to a decline in neuronal function. ${ }^{[82]}$

In the work by Cai and Sesti, ROS appear to act by damaging the function of a protein. ROS, however, can also act as signaling molecules in cells. ${ }^{[83]}$ A study of $C$. elegans clk-1 mutants, which lack an enzyme required for the synthesis of ubiquinone, has provided indirect evidence of ROS-mediated signaling in the worm. ${ }^{[84]}$ The $c l k-1$ mutants exhibit slower rates of development, slower rates of germline development, and longer lifespans than wild-type worms. ${ }^{[84]}$ These mutants may also have lower levels of ROS than wild-type worms. ${ }^{[84]} \mathrm{A}$ double mutant carrying mutations in $c l k-1$ and sod-1, which encodes a cytosolic superoxide dismutase, had a higher rate of germline development than worms carrying the $c l k-1$ mutation only. Based on the assumptions that $c l k-1$ mutants have decreased levels of ROS, and that mutation of sod-1 caused an increase in levels of ROS, the authors concluded that ROS are involved in a signaling pathway that moderates the rate of germline development. ${ }^{[84]}$ Further genetic evidence in the study suggested that the oxidation of low-density lipoproteins by ROS may play a role in the signaling pathway. ${ }^{[84]}$ Thus, this study has provided genetic evidence of a role for ROS in controlling rates of development. Further work is needed to confirm the existence of an ROS-mediated pathway controlling development, and to determine the biochemical interactions that form the basis for such a pathway. 


\subsection{Molecular Mechanisms of Aging in C. elegans}

What is aging? Is it a programmed process in living organisms (like development)? An accumulation of damage ${ }^{[43]}$ There are many theories. ${ }^{[85]}$ Because of its short lifespan (2-3 weeks), C. elegans is particularly well-suited for studying aging. Aging in C. elegans involves a number of changes in phenotype, including a loss of reproductive capacity, an increase in the disorder of muscle fibers, a wrinkling of the cuticle, and a progressive decline in locomotion. Researchers have discovered over 100 genes that, when mutated, produce an increase in the lifespan of worms. ${ }^{[86]}$ From a chemical perspective, the fundamental problem in the research of aging is to discover what chemical changes in the worm lead to an extended lifespan. It is possible that multiple molecular mechanisms may independently contribute to longevity. Below, we describe three known classes of perturbations that increase lifespan in C. elegans: i) mutations in the insulin/IGF-1 signaling pathway, ii) dietary restriction, and iii) mutations in genes coding for mitochondrial proteins. ${ }^{[22]}$

\subsubsection{Insulin Signaling and Aging}

As described above, inactivation of DAF-2, the sole insulin/IGF-1 receptor in C. elegans, increases lifespan. ${ }^{[69]}$ The insulin/IGF-1 signaling pathway is involved in the formation of dauer larvae under conditions of low food or high population density; daf-2 mutants constitutively enter the dauer state during development (daf mutants are so named because of the involvement of these genes in dauer formation). ${ }^{[69]}$ Long-lived mutants in this group typically exhibit higher resilience toward oxidative stress, hypoxia, heavy metals, UV radiation, high temperature, and infection by pathogenic bacteria than do wild-type worms. ${ }^{[42]}$ The daf-2 mutants also display 
metabolic changes such as increased storage of glycogen and fat. ${ }^{[43,69,87]}$ It is unclear, however, which, if any, of these characteristics are necessary and sufficient to confer increased lifespan.

\subsubsection{Dietary Restriction, Diet, and Aging}

Many organisms, including mammals, show an increase in lifespan when raised on a diet that is reduced in calories, but still contains the nutrients necessary to sustain life. It is not well understood what genetic and molecular-level changes are associated with dietary restriction in C. elegans. ${ }^{[42]}$ The lifespan of $C$. elegans depends on the concentration of bacteria in the environment in non-monotonic manner. ${ }^{[88-90]}$ In the regime of low bacterial concentration $\left(\sim 0-10^{8}\right.$ cells $\left./ \mathrm{ml}\right)$, lifespan increases with increasing bacterial concentration, probably because of starvation at low bacterial concentrations. In the regime of intermediate bacterial concentration $\left(\sim 10^{8}-10^{10}\right.$ cells $\left./ \mathrm{ml}\right)$, lifespan decreases with increasing bacterial concentration, possibly because of dietary restriction. At higher bacterial concentrations $\left(>10^{10}\right.$ cells $\left./ \mathrm{ml}\right)$, however, worms die during development, possibly because of depletion of oxygen in the environment by bacteria. ${ }^{[88,}$ ${ }^{89]}$ Because of the apparent detrimental effect of high bacterial concentrations to C. elegans, it remains to be determined what ranges of bacterial concentrations correspond to "abundant food" and to "dietary restriction."

It is possible to use eat-2 mutants - which have reduced pharyngeal function and thus a reduced ability to feed on bacteria — as models for dietary restriction. ${ }^{[91]}$ The eat-2 mutants have extended lifespans, and express higher levels of superoxide dismutase (SOD) and catalase than do wild-type worms. ${ }^{[88,91]}$ The extension in lifespan induced by the eat- 2 mutation depends upon the expression of genes known to play a role in macroautophagy - a cellular process, conserved in mammals, in which organelles and sub-cellular components are degraded in 
lysosomes. ${ }^{[92,93]}$ This process enables cellular components to be broken down and recycled. The eat-2-induced extension in lifespan does not depend on insulin signaling. ${ }^{[91]}$

Bacteria-free, chemically-defined media for C. elegans could, in principle, facilitate a greater understanding of how diet is related to longevity and health in C. elegans. ${ }^{[27]}$ For reasons that are unclear, worms grown in a bacteria-free medium develop more slowly and are longerlived than worms grown on bacteria. In addition, worms grown in bacteria-free medium exhibit increased thermotolerance, moderately increased resistance to oxidative stress (treatment with hydrogen peroxide or paraquat), and increased levels of SOD and catalase. ${ }^{[94]}$ A possible explanation is that worms are not able to ingest liquid, bacteria-free medium as well as they ingest bacteria; in this scenario, feeding bacteria-free medium to worms would result in dietary restriction. $^{[42]}$

Even without chemically-defined media, it has still been possible to examine how diet influences longevity by feeding worms bacteria supplemented with specific nutrients. For example, multiple studies have found that the addition of D-glucose to the bacterial diet of C. elegans decreases lifespan. ${ }^{[95-97]}$ This glucose-mediated reduction in lifespan appears to involve the insulin/IGF-1 signaling pathway described above. ${ }^{[95]}$

Treatment of worms with 2-deoxy-D-glucose (DOG) — a competitive inhibitor of glucose-6-phosphate isomerase, which is used in the second step of glycolysis - prevents the metabolism of glucose. Schulz and coworkers found that treatment with DOG extends lifespan in C. elegans. ${ }^{[97]}$ DOG-treated worms also exhibited a higher rate of oxygen consumption than untreated worms, and an increased reliance on fat as a source of energy (extracts from DOG- 
treated worms had lower levels of triglycerides than extracts from the control group). ${ }^{[97]}$ These observations suggest that worms compensate for DOG-mediated inhibition of glycolysis by increasing mitochondrial respiration, using fatty acids as a source of energy. In support of this idea, DNA microarray experiments demonstrated that treatment with DOG results in increased expression of proteins associated with the transport of lipids, the oxidation of fatty acids, and mitochondrial respiration. ${ }^{[97]}$

These results alone do not explain the observed increase in lifespan in DOG-treated worms. A possible explanation is the so-called "hormetic effect"-a phenomenon in which exposure to a low dose of a stressor that is toxic at higher doses produces a beneficial result, such as increased lifespan. ${ }^{[98]}$ In DOG-treated worms, increased mitochondrial respiration could increase the production of ROS (the stressor), which, in turn, could elicit a protective response, and thus promote longevity. ${ }^{[98]}$ To monitor ROS formation, Schulz et al. treated worms with 2,7-dichlorodihydrofluorescein $\left(\mathrm{H}_{2}-\mathrm{DCF}\right)$, which becomes fluorescent when oxidized to 2,7-dichlorofluorescein (DCF). The DOG-treated animals had higher levels of DCF fluorescence than untreated worms, suggesting that levels of ROS are higher in DOG-treated worms. Pre-treatment of DOG-treated worms with antioxidants, including N-acetylcysteine (a precursor of glutathione), ascorbic acid, and vitamin E, eliminated the life-extending effect of DOG. This observation supports the notion that ROS are responsible for eliciting a protective, life-extending response in C. elegans. The authors also found evidence of a protective response: extracts from worms treated with DOG for six days had significantly higher levels of catalase, which catalyses the decomposition of hydrogen peroxide, than extracts from untreated worms. ${ }^{[97]}$ 
Other simple changes to the diet of C. elegans can have an effect on lifespan. For example, supplementing the bacterial diet of C. elegans with acetic acid increases lifespan. ${ }^{[99]}$ Although the mechanism of this effect is unknown, it is possible that acetic acid (or acetate) interacts with carbohydrate or lipid metabolism to produce this life-extending effect.

\subsubsection{Mitochondrial Mutations and Aging}

Mutations in genes coding for mitochondrial proteins can also increase the lifespan of C. elegans. For example, long-lived clk-1 mutants are defective in the synthesis of ubiquinone, which is part of the electron transport chain in aerobic respiration. Some, but not all, long-lived mitochondrial mutants exhibit a lower consumption of oxygen than do wild-type worms. ${ }^{[42]}$ One theory suggests that chemical damage from ROS is responsible for the process of aging. ${ }^{[100]}$ Reduced mitochondrial activity could result in decreased ROS production. Disruption of the electron transport chain could also stimulate the worm to use anaerobic metabolic pathways, such as malate dismutation, which are believed to produce fewer ROS. ${ }^{[2,86]}$ Treatment of worms with compounds that have antioxidant activity—including vitamin $\mathrm{E}$ and related compounds, ${ }^{[101,102]}$ ubiquinone, ${ }^{[102]}$ polyphenols extracted from blueberries and other plants, ${ }^{[103,}$ 104] _ results in increased lifespan. It is not clear, however, that the extension in lifespan from antioxidants is due to a decrease in ROS—other mechanisms may be responsible. For example, the increase in lifespan produced by polyphenols extracted from natural sources depends on genes involved in innate immunity in C. elegans. ${ }^{[103,104]}$ It is also possible that a decrease in mitochondrial activity is indirectly responsible for extending lifespan. Temporary exposure of developing larvae to RNAi against proteins in the electron transport chain is sufficient to extend 
lifespan; ${ }^{[105]}$ thus decreased mitochondrial activity may serve as a signal that results in permanent metabolic changes in the worm.

\subsubsection{Does a Molecular Response to Stress Promote Longevity?}

Many perturbations that lead to increased lifespan in C. elegans mimic some form of environmental stress: insulin signaling is closely tied to dauer formation, which is the response

of developing worms to low food and crowding; ${ }^{[69]}$ the restriction of calories or glucose imposes limits on the intake of energy; ${ }^{[97]}$ mutations to mitochondrial activity mimic a low-oxygen environment; ${ }^{[42]}$ life-extending natural products—including polyphenols extracted from blueberries and polysaccharides extracted from Reishi mushrooms - activate the immune system and may thus induce a protective response. ${ }^{[99,103,104]}$ How does real or perceived exposure to stress lead to increased lifespan? Many long-lived worms exhibit increased levels of SOD and catalase, suggesting that removal of ROS increases lifespan. Although many long-lived worms are resistant to oxidative stress, some long-lived worms are hypersensitive to treatment with hydrogen peroxide ${ }^{[106]} \mathrm{A}$ broader possibility is that environmental stress up-regulates pathways for dealing with problematic molecular species: toxic byproducts of metabolism, including ROS, xenobiotics, unfolded proteins, and lipofuscin (lipophilic molecular "junk"). ${ }^{[22]}$ DNA microarray experiments have demonstrated that $d a f-2$ mutants up-regulate groups of genes associated with i) the breakdown of problematic compounds (cytochrome P450s, short chain dehydrogenases and reductases, UDP-glucuronosyltransferases, and glutathione S-transferases), and ii) the maintenance of properly-folded proteins and removal of misfolded proteins (chaperonins, and heat shock proteins). ${ }^{[22]}$ 


\subsubsection{Outlook for the Research of Aging with C. elegans}

A puzzling aspect of aging research in C. elegans is that long-lived worms have diverse, and sometimes conflicting, attributes. For example, genetic or chemical perturbations can produce long-lived worms that have an increased,${ }^{[97]}$ decreased,${ }^{[107]}$ or unchanged ${ }^{[88]}$ metabolic rate when compared with control worms. This conflict may reflect a need for standardization of experimental methods, but may also reflect the complexity of the aging process. Another complicating factor is the hormetic effect, in which stress plays a counterintuitive role in lifespan extension. ${ }^{[98]}$

One area where chemistry could contribute to the research of aging is in the development of additional tools for probing the chemical state of the aging worm. Direct knowledge of parameters such as the redox state of the cell, the chemical activity of the mitochondria, and the molecular composition of intracellular "junk" would certainly help to sort out the underlying molecular basis for aging and longevity.

Another way forward in the study of aging in C. elegans is the development of new tools for research. In the research of aging, it can be useful to perform longitudinal experimentsexperiments in which the traits of individual organisms are tracked over the lifespans of the organisms. Such experiments can be informative for determining biomarkers of aging in isogenic, identically-treated worms because it is possible to track age-related changes in phenotype in each individual and correlate those changes with each other, and with lifespan. ${ }^{[108]}$ We developed a microfluidic device for performing longitudinal experiments with C. elegans (Figure 2 describes the device). ${ }^{[109]}$ The device enables lifelong tracking of a population of individual worms in a well-controlled chemical environment, and is compatible with the 
observation of locomotory behavior and with sub-cellular imaging. Using this device, we identified age-related changes in size and locomotion that correlated with lifespan in C. elegans. ${ }^{[109]}$

\subsection{Biochemistry and C. elegans}

In comparison with the great amount of research that has been performed using genetic approaches to studying C. elegans, there are relatively few reports in the literature that use conventional biochemistry to study the worm. ${ }^{[62,80]}$ This subject, clearly, is one to which molecular biochemistry could make important contributions. Although some cite a difficulty in obtaining large quantities of individual tissues from the worm as the reason for the relatively small number of biochemical studies, ${ }^{[80]}$ the development of highly-sensitive techniques for analyzing small-volume samples (including MS, GLC/MS, and CE/MS) helps to diminish this problem. Others cite the physical barriers created by the cuticle and eggshell of the worm as the reason. ${ }^{[62]}$ It is possible to overcome these barriers, however, using genetic, ${ }^{[110]}$ chemical, ${ }^{[111,112]}$ or mechanical ${ }^{[112]}$ approaches. In the following section, we discuss biochemical research with C. elegans.

\subsubsection{The Proteome of C. elegans}

Two-dimensional gel electrophoresis, and two-dimensional LC, along with MS have enabled the examination of how the expression of proteins differs between populations of worms that differ with respect to developmental stage,${ }^{[113]}$ sex, ${ }^{[14]}$ rate of aging, ${ }^{[115]}$ and reproductive capacity. ${ }^{[116]}$ In addition, these proteomic techniques have allowed identification of the proteins that are present in mitochondria isolated from worms. ${ }^{[17]}$ 
Using isotopes of nitrogen, Krijgsveld and coworkers were able to compare the expression of proteins in different populations of worms quantitatively. ${ }^{[16]}$ Growing E. coli in ${ }^{15} \mathrm{~N}$-enriched media, and then feeding those bacteria to worms, enabled the generation of worms with ${ }^{15} \mathrm{~N}$-containing proteins. It was then possible to combine protein extracts from worms from two populations - worms containing ${ }^{14} \mathrm{~N}$ and worms containing ${ }^{15} \mathrm{~N}$ - in a 1:1 ratio, and to quantify the relative amounts of ${ }^{14} \mathrm{~N}$-labeled and ${ }^{15} \mathrm{~N}$-labeled proteins in the sample using twodimensional electrophoresis and mass spectrometry. This method allowed the determination of the relative level of expression of a protein in the ${ }^{15} \mathrm{~N}$-labeled population of worms using the level of expression in the ${ }^{14} \mathrm{~N}$-labeled population as a reference (and vice versa). More recently, this method facilitated the study of how protein expression changes in a long-lived C. elegans mutant. ${ }^{[115]}$ Long-lived daf-2 mutants expressed both lower levels of proteins related to lipid transport and RNA translation, and higher levels of proteins related to amino acid biosynthesis, oxygen metabolism, ROS metabolism, and carbohydrate metabolism, than wild-type worms.

\subsubsection{Monitoring Glycosylation in C. elegans}

Nishiwaki and coworkers used protein immunoblotting to determine that faulty morphogenesis of the gonad in a C. elegans mutant was due to disrupted glycosylation of a protein involved in guidance of the distal tip of the gonad during development. ${ }^{[118]}$ Others have used immunoblotting to determine that mutations interfering with the addition (or removal) of $O$-linked $\mathrm{N}$-acetylglucosamine ( $\mathrm{O}$-GlcNAc) to (or from) proteins resulted in altered metabolism in C. elegans: an increase in levels of glycogen and trehalose, and a decrease in lipids. ${ }^{[33,119]}$ This result may be relevant to human health; a single nucleotide polymorphism $O$-GlcNAcase is linked to type II diabetes in humans. ${ }^{[33]}$ 
Laughlin and coworkers developed a new way of visualizing glycans in living worms by feeding azido-functionalized derivatives of glucosamine, galactosamine, and mannosamine to worms. Over time, the modified sugars are incorporated into glycoproteins. Copper-free "click chemistry" enables the derivatization of the modified sugars with a fluorophore, and thus allows the visualization of glycoproteins with fluorescence microscopy. ${ }^{[120]}$

\subsubsection{Outlook for Biochemical Research}

The relative lack of biochemical research (in comparison with genetic research) in C. elegans may reflect a need for new tools and thus represents an important opportunity for chemists in organismic biology and biochemistry. The ability to probe to the biochemistry of the worm will undoubtedly be valuable in understanding how its status at the molecular level corresponds to its status at the organismic level.

\subsection{Modeling Human Disease in C. elegans}

It may be possible to use C. elegans to understand some aspects of human disease. ${ }^{[28]} \mathrm{A}$ challenge in developing models of human diseases in C. elegans is to determine the degree to which the C. elegans model for a particular disease accurately mimics molecular aspects of the disease in humans. It is likely that studies of diseases that affect processes that are highly conserved between worms and humans (such as neuronal signaling or basic metabolism) have the most to gain from the use of C. elegans. Future work will show what commonalities exist.

Worms allow the study of disease in the context of an intact, multi-organ, multi-cellular organism, and may thus be useful in understanding the interaction among multiple biological systems in the pathology of a disease. Worms exhibit a very wide variety of physiological and 
behavioral phenotypes - ranging from gene expression and biochemical state to behavior and aging. Perturbations to the worm at the molecular level (e.g., mutation of disease-associated genes, the addition of drugs) therefore have the potential to produce striking effects at the organismic level (e.g., changes in lifespan, morphology, behavior). For example, it is possible to use egg-laying, which is easily observed and quantified, as a readout of serotonergic

signaling. ${ }^{[121]}$ Table 4 provides a list of human diseases for which C. elegans models have been proposed and demonstrated. In some cases, homologs of disease-related genes in humans exist in C. elegans. In other cases, it is necessary to insert human genes into C. elegans to create the appropriate model. For each of the diseases in Table 4, the table lists the associated changes in phenotype in the worm.

\subsubsection{Neurodegenerative Diseases}

It is possible to insert genes coding for aggregation-prone polypeptides ${ }^{[122]}$ into the genome of C. elegans, and then observe the effects of the polypeptides on the organism. This strategy has enabled the study of analogs of multiple human neurodegenerative diseases, including Alzheimer's disease (AD $)^{[123-125]}$ and Huntington's disease (HD), ${ }^{[126,127]}$ in C. elegans.

In humans, $\mathrm{AD}$ is characterized by the aggregation of proteins containing amyloid $\beta$ peptide (A $\beta)$ into plaques or fibrils in the brains of patients, and by severe oxidative damage to the tissues of the brain. ${ }^{[128]}$ The most obvious altered phenotype in transgenic worms expressing $A \beta$ is progressive paralysis. ${ }^{[123,129]}$ These transgenic worms enable monitoring of the formation of amyloid plaques (measured histochemically in intact worms) and the presence of carbonyl groups in proteins (as a measure of the oxidation of proteins; determined by reacting the carbonyl groups in extracted protein with 2,4-dinitrophenylhydrazine, separating the proteins via 
SDS-PAGE, and detecting the derivatized carbonyl groups with immunostaining). ${ }^{[123,125]}$

Compared with protein extracts from wild-type worms, extracts from A $\beta$-expressing worms have elevated levels of carbonyl groups. ${ }^{[125]}$ Using a temperature-sensitive strain of A $\beta$-expressing worms (which only expressed $\mathrm{A} \beta$ when elevated to $23{ }^{\circ} \mathrm{C}$ ), Drake and coworkers found that paralysis and increased levels of carbonyl groups occurred before the onset of plaque formation. $^{[123]}$ This result suggests that plaque formation may be a symptom of $\mathrm{AD}$, rather than solely responsible for the pathogenesis of the disease.

It may be possible to gain insight into the mechanism of HD pathogenesis using transgenic worms expressing polyglutamine (polyQ) expansions. In C. elegans, animals expressing longer polyQ expansions (polypeptides with a higher number of Q repeats) contain a higher number of polyQ aggregates, exhibit an earlier onset of polyQ aggregation, crawl more slowly, and undergo a more rapid age-related decline in locomotion than animals expressing shorter polyQ expansions. ${ }^{[127]}$ In addition, the expression of polyQ appears to affect the stability of other proteins in C. elegans. ${ }^{[126]}$ It is possible to generate temperature-sensitive mutations in C. elegans in which a mutant phenotype is observable at one temperature (the restrictive temperature), but not at another temperature (the permissive temperature). For example, a mutation could lead to a temperature-dependent defect in the folding of a protein; in this case, a change in phenotype (due to misfolding) would only occur at restrictive temperatures. In mutant worms carrying temperature-sensitive mutations in a variety of proteins, co-expression of polyQ expansions resulted in the exhibition of the temperature-sensitive phenotype at permissive temperatures. For example, worms carrying a temperature-sensitive mutation in paramyosin develop normally at $15{ }^{\circ} \mathrm{C}$ (the permissive temperature), but arrest growth during development at 
$25^{\circ} \mathrm{C}$ (the restrictive temperature). When worms with this mutant background also carried genes coding for polyQ repeats, nearly half arrested growth during development at $15^{\circ} \mathrm{C}$. This result indicates that the presence of polyQ (and possibly the formation of polyQ aggregates) mimics the effect of the restrictive temperature. The authors of this study suggested that the formation and buildup of polyQ aggregates may overwhelm the cellular machinery for folding proteins, and for correcting or clearing misfolded proteins, and thus polyQ aggregation may amplify the instability caused by temperature-sensitive mutations. ${ }^{[126]}$ This hypothesis, though untested, would provide a universal mechanism for the cellular toxicity associated with aggregation-prone polypeptides and proteins.

\subsubsection{Cancer}

During development, hermaphrodites produce exactly 1090 somatic cells. At different points during the developmental process, 131 of these cells undergo apoptosis, leaving behind a total of 959 cells in the fully developed worm. The number of somatic cells in the adult worm remains fixed at 959; the cells of the adult worm do not undergo further mitotic division. These non-proliferative cells do not give rise to somatic tumors. ${ }^{[130]}$ It may therefore appear that the worm is an unlikely candidate as a model organism for understanding cancer. Three approaches, however, have facilitated the development of models for studying cancer and carcinogenesis in C. elegans.

The first approach focuses on the discovery of genetic changes that result in unchecked proliferation of cells in C. elegans. Mutation of the C. elegans gene gld-1 results in worms with a tumor-like proliferation of cells in the gonad. In these mutants, uncontrolled mitotic division of germ cells replaces the production of oocytes from the germ cells by meiosis; this 
proliferation can rupture the gonad and, eventually, the worm. ${ }^{[131]}$ Kenyon and coworkers found that mutations that extend lifespan in C. elegans - including daf-2 (part of the insulin/IGF-1 signaling pathway), eat-2 (a mutation that imposes dietary restriction), and clk-1 (a mutation that disrupts cellular respiration)_reduce the proliferation of germ cells in gld-1 animals, and, in some cases, prevent early death. ${ }^{[131,132]}$ In worms carrying mutations in gld-1 and daf-2, apoptosis contributes to the a reduction in the total number of germ cells. ${ }^{[131]}$ Unlike apoptotic events during development, apoptotic events that reduce the number of germ cells are dependent on CEP-1, a homolog of the human tumor suppressor protein $\mathrm{p} 53 .{ }^{[131]}$ This result suggests that there may be some — albeit distant_relationship between the formation of tumors in humans and worms.

The second approach focuses on the study of pathways that are relevant to human cancer and are conserved between humans and worms. The $R A S$ genes code for a family of small GTPases that play a key role in an evolutionarily conserved signaling pathway involved in cellular proliferation, differentiation, and survival. ${ }^{[133]}$ Dysregulation of the RAS pathway is known to play a role in tumorigenesis. Approximately $20 \%$ of all human tumors contain activating mutations in one of the RAS proteins. ${ }^{[133]}$ The RAS signaling pathway is highly conserved in humans and worms, although in worms, the pathway is simpler; for example, worms have a single RAS protein (LET-60), while humans have three. ${ }^{[134]}$

Research with $C$. elegans enabled significant breakthroughs in the elucidation of the RAS signaling pathway. ${ }^{[135,136]}$ An enabling element of this work was that alterations to the RAS pathway generate easily observable phenotypic changes in vulval development in the worm: mutations that prevent activation of the $C$. elegans RAS protein produce a vulva-less worm; 
mutations that cause the RAS protein to be constitutively active produce a multi-vulva phenotype. ${ }^{[134]}$ In addition, the descendents of only three cells form the vulva in wild-type C. elegans. ${ }^{[134]}$ The effects of alterations to RAS signaling on the fates of cells in the development of the vulva are therefore straightforward to observe. In addition to serving as a simple model for understanding the mechanism of RAS signaling, C. elegans may also serve a model for the development of drugs that interfere with RAS signaling. Inhibition of the RAS signaling pathway is a potential direction for anti-cancer therapies. ${ }^{[133]}$

The third approach focuses on studying the mechanism of action of carcinogenic compounds. A carcinogen can contribute to the growth of tumors by i) altering the DNA of a cell to initiate tumor formation, or ii) interacting with the cellular machinery in a way that allows problematic, tumorigenic cells to persist and proliferate. ${ }^{[137]}$ One mechanism of tumor proliferation is the inhibition of apoptosis. ${ }^{[138]}$ Although it is unclear to what degree the inhibition of apoptosis in C. elegans relates to carcinogenesis in mammals, there is a significant overlap between the apoptotic pathways in humans and in worms. ${ }^{[139]}$ Because both the number of cells that develop, and the number of cells that undergo apoptosis are invariant in the worm, it is possible to perform an assay for the inhibition of apoptosis simply by counting the number of "extra" cells in the developed worm. Using this approach, Kokel and coworkers examined the capacity of different compounds to inhibit apoptosis in worms carrying a partial loss-of-function mutation in ced-3, a gene coding for an apoptosis-promoting caspase (ced = cell death). ${ }^{[130,140]}$ Upon reaching maturity, ced-3 mutants carry a small number of extra cells (in wild-type worms, 16 cells in the anterior pharynx undergo apoptosis; in ced-3 mutants, $1-2$ of these cells persist). Naphthalene, dichlorobenzene, benzene, biphenyl, and toluene increased the number of 
persisting cells in ced-3 mutants - that is, they further suppressed apoptosis in these animals. Mesitylene (1,3,5-trimethylbenzene), cyclohexane, and camphor did not increase the number of extra cells. ${ }^{[130,140]}$ Scheme 1 compares the chemical structures of these compounds.

A challenge in determining mechanisms of carcinogenesis is that the metabolic breakdown of a compound may produce many different reactive species, one or more of which may be carcinogenic. For example, the lower panel of Scheme 1 shows a partial overview of the compounds that are produced in the metabolism of naphthalene in humans; the reaction scheme shows pathways that lead to reactive species, such as quinones and arene epoxides. ${ }^{[141]}$ Reactive metabolites can produce carcinogenic effects by bonding covalently with biomolecules (such as proteins or DNA), or by generating oxidative stress. ${ }^{[142]}$ Using a set of genetic mutants in combination with the apoptosis assay, Kokel et al. determined that the likely target of the apoptosis-inhibiting compounds was the CED-3 protein. ${ }^{[140]}$ In vitro experiments demonstrated that although naphthalene does not reduce the activity of CED-3 (or its human counterpart, caspase-3), naphthoquinone - a metabolite of naphthalene ${ }^{[141]}$ (see Scheme 1) - does. ${ }^{[140]}$ Quinonic derivatives of benzene and toluene also reduced the activity of human caspase-3 in vitro. ${ }^{[130]}$ Although there are still uncertainties regarding the mechanism by which the compounds in Scheme 1 inhibit apoptosis_additional metabolites and biological targets may be involved $^{[141,142]}$ — this work demonstrates the potential usefulness of C. elegans as a simple model organism for deconstructing how different classes of compounds interact with the apoptotic machinery. ${ }^{[130,140]}$ 


\subsubsection{Drug Discovery Using C. elegans}

The ease with which very large populations of worms can be produced and manipulated makes C. elegans potentially useful in high-throughput screens for drug development and discovery. ${ }^{[28]}$ An important consideration in drugs screens is the bioavailability of compounds to C. elegans - for compounds to reach potential drug targets, it is necessary that they first physically enter the body of the worm. The cuticle and intestinal lining of the worm present a significant physical barrier to many chemical species. ${ }^{[143]}$ One possible strategy to address the selective permeability of the cuticle is the development of mutant strains of C. elegans that have compromised cuticles, but are otherwise healthy; ${ }^{[110]}$ this strategy, however, has not been adopted.

To characterize the bioavailability of a large group of molecules to the worm, Burns and coworkers measured the degree of accumulation of over 1000 drug-like compounds and their metabolites within the body of C. elegans. ${ }^{[143]}$ Scheme 2 shows the five most common structural motifs in molecules that did accumulate in C. elegans, as well as the five most common motifs in molecules that did not accumulate. Nearly half of the bioaccumulating compounds contained one of the structural motifs shown in the left column of Scheme 2, and nearly half of the nonaccumulating compounds contained one of the motifs shown in the right column of

Scheme 2. ${ }^{[143]}$ Burns and co-workers developed a computer-based model for predicting whether or not compounds will accumulate in C. elegans on the basis of molecular structure. This model is freely available. ${ }^{[143]}$ This work will help to prioritize which molecules are tested in wormbased screens, and thus increase the likelihood of finding hits using C. elegans. 


\subsection{C. elegans as a Model for Parasitic Worms}

One niche in human health where C. elegans may be particularly useful is in the study of parasitic worms. Parasitic worms, or helminths, include nematodes (roundworms) and platyhelminths (flatworms- flukes and tapeworms). ${ }^{[144]}$ Although C. elegans is not parasitic, it is related to parasitic worms evolutionarily, ${ }^{[145]}$ and may therefore be a useful model organism for understanding the biology of helminths, and for developing anthelminthics — drugs to treat parasitic worm infections-and vaccines. ${ }^{[146,147]}$

The relevance of C. elegans to parasitic species is an important consideration. Draft genomes for several species of human-infecting helminths (including the nematode Trichinella spiralis, the filarial nematode Brugia malayi, the tapeworm Taenia solium, and the blood flukes Schistosoma mansoni and Schistosoma japonicum ${ }^{[145]}$ ) have enabled genetic comparison. Although there are genetic differences—notably in genes relating to parasitism ${ }^{[148]}$ —it appears that, overall, C. elegans is as similar to parasitic worms as parasitic worms are to each other. ${ }^{[146,}$ ${ }^{147,149]}$ For the development of broad-spectrum anthelminthics, C. elegans may, therefore, be just as relevant as any worm. ${ }^{[146]}$ The relatively close evolutionary relationship between C. elegans and parasitic worms, along with the striking similarities between C. elegans and other worms (especially other nematodes) with respect to body plan and developmental progression, suggest that genes in different species that overlap in sequence are likely to overlap in function as well. ${ }^{[147]}$ Functional overlap is important: for example, in anthelminthic development, it will be advantageous if candidate drugs have the same physiological effects in C. elegans and in parasitic worms. 


\subsubsection{Helminthic Infection: a Neglected Disease}

More than 2 billion people worldwide are infected with parasitic worms; these infections are a significant cause of morbidity and mortality in humans, particularly in the developing world. The three most common helminthic infections worldwide are from Ascaris lumbricoides, whipworm (Trichuris trichiura), and hookworm (Necator americanus and Ancylostoma duodenale.$^{[150]}$ These worms are of greatest prevalence in developing regions of Africa, Asia, and Latin America. ${ }^{[14]}$ Table 5 lists the most problematic species of parasitic worms for humans with respect to the number of people infected.

Moderate to severe helminthic infections produce a dramatic decline in quality of life for the infected person. The severity of infection corresponds to the number of worms with which a host is infected. ${ }^{[144]}$ Infections can cause malnutrition (including anemia, vitamin deficiencies, and protein loss), permanent damage to tissues, stunted growth, reduced fitness, and impaired cognition and memory. ${ }^{[144]}$ In pregnant women, helminthic infections increase the likelihood of maternal death during pregnancy or childbirth, and also cause premature births and low birth-weights for newborns. ${ }^{[144]}$ Some species of worms disable the host severely: lymphatic filariasis, caused by infection with filarial nematodes, produces extreme swelling of the legs and genitals; onchocerciasis, caused by infection with the nematode Onchocerca volvulus, can cause blindness. ${ }^{[144]}$ In addition, helminthic infections appear to increase the transmission, and enhance the progression, of other diseases, including HIV/AIDS and malaria. ${ }^{[144]}$

Despite the fact that helminthic infections are one of the most common clinical conditions in humans, there are relatively few available anthelminthics. ${ }^{[151]}$ Benzimidazole-derived compounds (mebendazole and albendazole), pyrantel pamoate, and 
ivermectin are broad-spectrum anthelminthics. Diethylcarbamazine is used for some filarial nematodes, and praziquantel and oxamniquine are used for schistosomes. ${ }^{[152]}$ Scheme 3 shows the chemical structures of these compounds. Anthelminthic drug resistance - a significant and widespread problem in animal husbandry ${ }^{[152]}$ _is appearing in worms that infect humans. ${ }^{[144]}$ The practice in resource-poor areas of controlling helminthic infections by administering a single drug periodically to all members of a population or sub-population (e.g., school-children) ${ }^{[144,151]}$ may be contributing to the growing problem of anthelminthic resistance. ${ }^{[144,152,153]}$ There is, therefore, a clear and urgent need to increase the number of available treatments for helminthic infections.

\subsubsection{C. elegans: a Model Parasite?}

Research of helminths faces two significant challenges. First, research of helminths receives much less funding than other globally-important health issues. Figure 3 summarizes how global investment in research and development for neglected diseases was divided in fiscal year 2008. Funding for helminthic research represented $2.3 \%$ of global investment. ${ }^{[154]}$ (Combined, research of HIV/AIDS, malaria, and tuberculosis received $>70 \%$ of the total investment. $^{[154]}$ ) Second, because parasitic worms cannot be cultured without a host organism, it is difficult and expensive to work with parasitic worms. Because C. elegans is easy and inexpensive to work with, it may help to surmount both of these challenges.

The principal benefit that $C$. elegans offers as a "model parasite" is experimental tractability. The biological, chemical, and physical tools and techniques that have been established for C. elegans are not easily transferrable to the research of parasitic worms. ${ }^{[155]}$ The lifecycles of parasitic worms are often complicated and involve one or more host organisms. ${ }^{[148]}$ 
Parasitic worms typically live outside of a host for only part of their developmental cycle (hookworms, for example, live outside a human host only as embryos and early-stage larvae ${ }^{[151]}$ ) and are thus not accessible at all developmental stages. Because of the difficulty in making simple phenotypic observations for worms within a host, phenotype-based assays are limited to those developmental stages where the worm can live outside the host. ${ }^{[156]}$ In addition, because there are not methods for culturing parasitic worms without a host, it is not possible to generate and maintain isogenic stocks of mutants for parasitic worms. In contrast, with C. elegans, observing worms at different stages of development, and maintaining isogenic stocks of mutants, are straightforward tasks. The great amount of accumulated knowledge for C. elegans also contributes to its usefulness in helminth research. The existence of a well-annotated genome for C. elegans has been instrumental in the identification of genes and their functions in the genomes of parasitic worms. ${ }^{[157-159]}$

\subsubsection{C. elegans and the Development of Anthelminthics}

C. elegans has already played a valuable role in elucidating molecular aspects of anthelminthic activity and resistance. Genetic work with $C$. elegans demonstrated that benzimidazole and related compounds act by disrupting the assembly of $\beta$-tubulin into microtubules. $^{[160]}$ Later, Kwa and coworkers isolated $\beta$-tubulin genes from benzimidazole-sensitive and benzimidazole-resistant populations of the sheep-infecting nematode Haemonchus contortus. The principal difference between genes from sensitive and resistant populations was the replacement of phenylalanine with tyrosine at position 200 of the predicted amino acid sequence in genes from resistant worms. ${ }^{[156]}$ After confirming that it was possible to express functional $\beta$-tubulin from $H$. contortus in $C$. elegans, the authors 
demonstrated that mutation from Phe to Tyr at position 200 in the parasite-derived $\beta$ tubulin was sufficient to generate resistance to benzimidazole in C. elegans. ${ }^{[156]}$

Kaminsky and coworkers used C. elegans to determine the mechanism of action of a new class of potential anthelminthics—amino-acetonitrile derivatives (AADs) ${ }^{[161]}$ Screens in parasitic larvae, and in worm-infected non-human mammals (mice and sheep), identified several AADs as candidate drugs. Exposure of C. elegans to the compounds produced a combination of phenotypes - hyper-contraction of the body muscles, spasmodic contractions of the pharynx, defective molting, and necrotic cell death—not seen in response to existing anthelminthics. It was also possible to test the ADDs in strains of C. elegans that are resistant to ivermectin, benzimidazole, and levamisole. These worms were still sensitive to AADs. These results suggested that the mechanism of action of the AADs is distinct from that of existing anthelminthics. A forward genetic screen identified AAD-resistant C. elegans mutants, which carried mutations in a specific sub-family of nicotinic acetylcholine receptors (nAChRs). ${ }^{[161]}$ Importantly, the authors were able to verify the relevance of this mechanism for parasitic worms by selecting for AAD-resistant larvae of $H$. contortus. PCR confirmed that AAD-resistant H. contortus carried mutations in an $\mathrm{nAChR}$ that was homologous to one of the receptors identified in C. elegans. ${ }^{[161]}$

How else might $C$. elegans assist in the research of parasitic worms? C. elegans may facilitate the identification of new molecular targets for anthelminthic development by simplifying the determination of the function of potential targets. To be effective, anthelminthic drugs must produce a physiological change in the worm that results in either the death of the worm (directly or indirectly) or the expulsion of the worm from the host. ${ }^{[144]}$ Existing 
anthelminthics elicit a variety of physiological effects, including interference with microtubule formation (benzimidazole), paralysis of the pharynx (ivermectin), and inhibition of the synthesis of nucleic acids (oxamniquine). ${ }^{[152]}$ By examining the function in C. elegans of proteins that are conserved among worms, it may be possible to identify promising targets for drug development. ${ }^{[158,162,163]}$

\subsubsection{Parasite-Host Interactions}

Parasitic worms have evolved protective strategies to evade, and even control, the immune response of the host. ${ }^{[164]}$ Within the host, worms release molecules that can either block activities of the immune system directly, or modulate the activity of the immune system by interfering with signaling pathways. ${ }^{[164]}$ For example, parasitic worms release cystatinscysteine protease inhibitors - that disrupt the presentation of antigens and thus prevent the proliferation of $\mathrm{T}$ cells. Cystatins also modulate cytokine signaling in the host. ${ }^{[164]}$ Compounds secreted by parasites also appear to down-regulate macrophage activity, up-regulate the production of NO, which inhibits the growth of lymphocytes. ${ }^{[164]}$ The ability of parasites to modulate the immune system allows parasitic infections to persist for years. (Interestingly, inoculation of humans with hookworm appears to be an effective treatment for Crohn's disease - an inflammatory disease of the gut. It is possible that the therapeutic effect is mediated by the suppression of immune activity by the parasites. ${ }^{[165]}$ )

Although C. elegans is a free-living worm, it may facilitate an improved understanding of parasite-host interactions in helminthic infections. In humans, parasitic infections elicit a type 2 immune response - a characteristic set of molecular responses generated by type 2 helper $\mathrm{T}$ cells (Th2). ${ }^{[166]}$ Tawill and coworkers demonstrated that extracts from B. malayi (a parasitic 
nematode) and $C$. elegans both produced a type 2 immune response in mice. ${ }^{[166]} C$. elegans thus appears to be a relevant model system for unraveling the molecular interactions involved in the induction of the type 2 response. Treatment of mice with fractionated extracts from C. elegans suggested that nematode glycoproteins play an important role in generating the characteristic immune response. ${ }^{[166]}$

C. elegans research may assist in the development of vaccines against parasitic helminths. Among nematodes, proteins and glycoproteins expressed on the surface of the cuticle are highly conserved. ${ }^{[162,167]}$ Such molecules, because they are exposed to the host, are logical targets for vaccine development. The molecules that are expressed on the surface change with developmental stage, and also in response to environmental cues. ${ }^{[167]}$ The study of temporal and spatial patterns of expression of these molecules in C. elegans may help to guide the selection of target antigens for vaccine development. ${ }^{[162]}$ It may also be possible to express and examine parasite-derived antigens in C. elegans. ${ }^{[168]}$

\subsubsection{Outlook for Studying Parasitic Worm Infections with C. elegans}

There are, of course, limitations to the usefulness of $C$. elegans for the study of parasites. There may be families of genes and chemical pathways that are exclusively found in parasitic worms (although through comparative studies, C. elegans, as a model free-living worm, may

help elucidate what biological processes are necessary for parasitism). ${ }^{[146,148]}$ In addition, it will always be necessary to validate that a result obtained in $C$. elegans is relevant in parasitic species. Validation, however, is a simpler experimental task than discovery. 
The ease with which C. elegans can be adopted in the laboratory should encourage and enable chemists to undertake research with relevance to helminth biology. C. elegans may also be an experimental stepping-stone for chemists interested in working with parasitic worms.

Overall, C. elegans offers chemists an excellent entry point into studying one of the world's most important classes of pathogens.

\section{What Tools for Studying the Worm Are Available to Chemists?}

Research that seeks to relate chemical details to biological and organismic phenomena in C. elegans will require tools for measuring organismic phenotypes, tools for measuring molecular phenotypes, and tools for applying chemical, physical, and biological perturbations to worms. This section describes such tools. We place particular emphasis on microfluidic tools, which are becoming popular in C. elegans research. ${ }^{[109,169-198]}$

\subsection{Microfabricated Tools for Manipulating and Confining Worms}

Microfluidic devices have four principal features that make them useful for C. elegans research: i) they are compatible with the application of a broad range of stimuli, and the observation and quantification of a broad range of phenotypes; ii) they create well-defined environments for worms, and can thus reduce variability in experiments due to subtle changes in the chemical and physical environment; iii) they are either scalable (and thus enable the observation of many worms in parallel) or high-throughput (and thus enable the observation of many worms in rapid succession) and should therefore facilitate the collection of statistically meaningful data; and iv) they have features of the appropriate size for worms: adult worms are 
approximately $1 \mathrm{~mm}$ in length and $50 \mu \mathrm{m}$ in width, and channels with these dimensions are straightforward to generate. ${ }^{[199,200]}$

In the laboratory, worms typically live on the surface of agar in agar-filled Petri dishes (Figure 1a). A layer of bacteria on the surface of the agar provides a source of food for the worms. While it is possible to make simple (and useful) observations of worms in this environment, many experiments require more detailed examination. Fortunately, a number of tools facilitate observation of the worm through physical confinement of its body.

A number of new tools for studying the worm are microfluidic devices fabricated in the elastomer poly(dimethyl siloxane) (PDMS) using soft lithography. ${ }^{[199,200]}$ PDMS is a useful material for constructing these devices because it is transparent down to $230 \mathrm{~nm}$-and is thus compatible with conventional light microscopy — and because is it non-toxic and transparent to gases—and is thus compatible with living organisms. ${ }^{[200]}$ C. elegans is capable of living on hydrated surfaces exposed to air, or submerged in liquid. PDMS-based devices and tools for studying the worm can therefore consist of air-filled microchannels resting on an agar substrate, ${ }^{[181,190]}$ or closed microchannels that are filled with fluid.$^{[173,184,192]}$

\subsubsection{Immobilization and Imaging of Worms in Microfluidic Devices}

For many experiments with C. elegans, it is desirable to immobilize live worms without harming them. The principal motivation for immobilization is to ease, or enable, the observation of tissue-level, cellular, and sub-cellular phenotypes in intact worms, including, but not limited to, i) the morphology of tissues (e.g., muscles, organs) within the body of the worm, ii) the level of expression and localization of proteins, as monitored using genetically-encoded fluorescent 
reporters (e.g. GFP), ${ }^{[201]}$ iii) the activity of neurons, as monitored using fluorescent indicators of changes in intracellular concentrations of calcium, ${ }^{[202]}$ and iv) the biochemical composition of the tissue of the body, as measured using fluorescent organic dyes. In addition, immobilization enables the performance of laser-mediated microsurgery, which is used in C. elegans research to ablate specific tissues without inflicting damage elsewhere in the body of the animal. ${ }^{[203,204]}$

It is possible to immobilize large populations $(>1000)$ of worms simultaneously by exposing the animals to paralytic drugs, such as sodium azide (a metabolic inhibitor); ${ }^{[205]}$ however, for certain experiments - the observation of neuronal activity using calcium imaging, ${ }^{[202]}$ for example — it is preferable to use live, non-anesthetized worms. One solution is to use cyanoacrylate glue to immobilize worms on an agarose pad; this approach has enabled FRET-based calcium imaging. [202, 206]

More recently, a new approach—microfluidic devices fabricated in PDMS— has enabled immobilization of the worm. ${ }^{[172-174,182,184,188,192,193,195,197]}$ These devices present a broad range of strategies for immobilization. In general, there exists a tradeoff between simplicity of fabrication and operation, and the degree of immobilization that is achieved.

Chronis and coworkers presented a simple microfluidic tool, which they call a worm trap, for immobilizing worms. ${ }^{[173,195]}$ The trap consists of a single microfabricated chamber that is slightly larger in width than the diameter of the worm, and slightly smaller in depth than the diameter of the worm. The worm is able to generate forward and reverse body waves that resemble the body waves in freely crawling worms, but because the device compresses the body of the worm slightly in one dimension, the worm cannot generate any net displacement. The 
immobilization effected by the trap is sufficient to enable calcium imaging in individual neurons. In addition, because a worm within the trap has (limited) motility, it is possible to correlate neuronal activity with locomotory behavior.

Our laboratory has developed a device containing an array of microfluidic worm clamps - tapered channels, into which single worms can be loaded and physically immobilized. ${ }^{[184]}$ Figure 4a shows the design of the device and a photomicrograph of worms immobilized within the device. To operate the device, it is necessary only to add a suspension of worms to the inlet of the device and to apply suction to the outlet; the geometry of the device automatically distributes a single worm to each clamp. ${ }^{[184]}$ A version of the device with 128 clamps enables the simultaneous immobilization and observation of over 100 animals. The worm clamps have proven useful for the immobilization of worms for laser-mediated ablation of neuronal axons ${ }^{[180]}$ and synapses. ${ }^{[169]}$ In these experiments, the clamps also enabled time-lapse imaging of neuronal growth in immobilized animals. ${ }^{[169,180]}$ Using a similar strategy for sorting worms, Stirman and coworkers developed a microfluidic device that automatically distributes worms into individual channels in which they are partially immobilized (as with the worm trap, above). This device enabled the observation and quantification of the neuromuscular activity of many worms simultaneously. ${ }^{[198]}$

Other non-invasive, microfluidic methods of immobilization include the use of suction, ${ }^{[192]}$ compression, ${ }^{[172,182,188]}$ and combined suction and compression. ${ }^{[193]}$ Figure 4 bb-c illustrates these approaches. These approaches immobilize worms sufficiently for laser-mediated microsurgery and sub-cellular imaging. ${ }^{[182,192,193]}$ Krajniak and coworkers used Pluronic F127—a block copolymer than undergoes a reversible sol-gel transition near room 
temperature - to immobilize worms reversibly in a microfluidic device by flowing a liquid solution of the polymer into worm-containing chambers, and then raising the temperature to solidify the polymer in place around the worm. ${ }^{[197]}$

Although physical immobilization prevents the bodies of the worms from moving, it does not prevent motion of structures inside the body of the worm - the muscles along the wall of the body and the pharyngeal muscles are still able to contract. This feature could be beneficial if, for example, one was interested in observing the motion of the pharyngeal muscles. Exposure to low temperature $\left(4^{\circ} \mathrm{C}\right)$ and treatment with carbon dioxide both induce complete paralysis in C. elegans. It is therefore possible to immobilize worms by introducing a second layer of microfluidic channels_-directly above the channels containing worms - and flowing either liquid coolant ${ }^{[174]}$ or gaseous $\mathrm{CO}_{2}{ }^{[172]}$ through this second layer. An added benefit of immobilization with $\mathrm{CO}_{2}$ is that the removal of oxygen from the system reduces the rate of photobleaching for fluorescent markers within the worm. ${ }^{[172,207]}$

In contrast to the method of gluing worms described above, the microfluidic methods for immobilization described above are all reversible. These devices therefore allow the release of worms from immobilization for further analysis. We observed that worms that were recovered from the 128-clamp device following immobilization exhibited lifespans similar to worms that had not been immobilized. ${ }^{[184]}$ Following immobilization, it is possible to use on-chip pneumatic valves $^{[208]}$ to sort worms based on phenotype — determined during immobilization — into different down-stream reservoirs for further observation on-chip, ${ }^{[192]}$ or off-chip. ${ }^{[174,178]}$ 
As an alternative to observing worms and other objects with conventional microscopy, Yang and coworkers developed an "optofluidic microscope" - a lens-free method of imaging worms using a microfluidic channel mounted directly on top of a CCD or CMOS sensor array. ${ }^{[179,183]}$ The simplest method of imaging an object without a microscope using a CCD or CMOS array is to record a direct projection of the object on the array. With this method, the resolution of the resulting image is limited by the dimensions of the pixels in the sensor array. Yang and coworkers found a method of overcoming this limit in resolution. In the optofluidic microscope that they developed, a thin layer of metal prevents light from reaching the sensor array in all areas except for a row of small holes $(\leq 1 \mu \mathrm{m}$ in diameter $)$ in the metal, diagonallyarranged across the floor of the microfluidic channel. In the direction perpendicular to the length of the channel, the holes are offset by half their diameter. In the direction along the length of the channel, the holes are spaced such that each hole is associated with a unique pixel on the sensor array. With this geometry, after an object flows along the length of channel and across the diagonal row of holes, it is possible to reconstruct an image of the object based on the signal from the sensor array. ${ }^{[179,183]}$ In this arrangement, the size of the holes, and not the size of the pixels, determines the spatial resolution. One limitation of the optofluidic microscope is that it cannot image moving objects - it is necessary to paralyze worms before imaging them. The device can, however, image worms at a relatively high rate — up to 40 worms $\min ^{-1}$. ${ }^{[183]}$

A commercial instrument is available for rapidly screening and sorting worms based on phenotype: the COPAS ${ }^{\mathrm{TM}}$ Biosorter (Union Biometrica, Holliston, MA) enables flow cytometry to be performed on large objects, including worms. ${ }^{[209]}$ The COPAS ${ }^{\text {TM }}$ system can measure optical density and multicolor fluorescence intensity as a function of length along the body of a 
worm, and can thus identify tissue-level changes in phenotype. Although the spatial resolution achieved using the COPAS ${ }^{\mathrm{TM}}$ system is not as high as the resolution that is achievable with standard microscopy, this automated system can collect phenotypic data for populations of tens of thousands of worms. ${ }^{[209]}$

\subsubsection{Confinement of Worms in Microfluidic Devices}

In addition to tools for immobilizing worms, there also exist a variety of microfabricated devices for confining worms in a microfluidic environment without completely immobilizing them. It is possible to divide these devices into two general categories: i) devices that house single worms in individual chambers ${ }^{[109,172,188,192,197]}$ or droplets, ${ }^{[176,177,196,210-212]}$ and ii) devices that house worms in "arena-style" chambers_-single chambers containing multiple worms. ${ }^{[170,171,181,187,189-191,194,195]}$ Figures $\mathbf{2}$ and $\mathbf{5}$ provide examples of these devices. Confinement within a microfabricated or microfluidic device enables the observation of organism-level traits, principally behavior and survival. In C. elegans, behavior encompasses locomotion, feeding, defecation, egg-laying, and, if males and hermaphrodites are present, mating. ${ }^{[59]}$ It is possible to observe all of these behaviors, as well as survival, in worms in a microfluidic device.

Microfabricated devices can restrict the location of a population of worms to within the field of view of a microscope objective. This restriction enables the observation of the whole population simultaneously. It is then possible to track the behavior of the population over time. Continuous recording of the worms can enable the tracking of individuals in arena-style chambers using automated tracking software ${ }^{[213]}$ (although interruptions in recording or collisions between worms can result in the loss of the identities of the worms). The strategy of 
confining worms within a fixed field of view in a microfluidic device facilitated the cultivation

and observation of C. elegans in space. ${ }^{[185,186]}$ Devices that house individual worms in chambers and droplets enable the maintenance of the identities of individual worms over extended periods of time without tracking software. We developed a microfluidic device for the maintenance of single worms within individual chambers for their entire adult lifespans ${ }^{[109]}$ (see Figure 2). The device allowed us to determine relationships between age-related changes in locomotion and body size with ultimate lifespan. ${ }^{[109]}$ Droplet-generating devices enabled researchers to raise single worms from the embryonic stage to adulthood within individual droplets. ${ }^{[177,196]}$

Several research groups have combined chambers for confinement and mechanisms for immobilization in a single device, so that it is possible to monitor behavior and survival within the chambers, and then immobilize worms temporarily for imaging at higher-resolution. ${ }^{[109,172,}$ 188, 192, 197] This approach has enabled the study of the relationship between locomotion and neuronal death. ${ }^{[188]}$

\subsubsection{Creating Well-Defined Environments in Microfluidic Devices}

Using microfabrication, it is possible create uniform and well-defined environments for the worm. For comparison, Figure 1a shows the conventional environment for C. elegans in the laboratory - an agar-filled Petri dish that has been seeded with E. coli. The chemical and physical environment of the Petri dish is not easily controlled. Moisture from the agar can evaporate over time, and the hydration of the agar can affect the behavior of C. elegans. ${ }^{[205]}$ In addition, the concentration of food on the plate is not uniform; typically, agar plates are seeded with bacteria such that there is a lawn of bacteria at the center of the plate that does not extend to the edges of the plate. Moreover, consumption of oxygen by the bacteria may produce non- 
uniform concentration of oxygen at the surface of the agar. ${ }^{[181]}$ Worms crawl all over the surface of the agar (and sometimes burrow into the agar); because of the non-uniformity in the environment of the plate, individual worms may experience changes in environment with time, and different worms may experience slightly different environments. These differences may increase animal-to-animal variability in experiments.

Microfluidic devices enable the generation of well-defined and tunable chemical environments. Microfluidic devices are also compatible with the application of a wide variety of physical stimuli. For example, the concentration of food-a relevant parameter in the research of dietary restriction and mechanisms of aging - is not easily modified on an agar plate, but can be controlled in the liquid culture of worms in a microfluidic device. ${ }^{[109]}$ In addition, in a microfluidic device, it is possible to modify the chemical environment of the worm simply by switching the composition of the liquid that flows through the device. Rhode and coworkers developed a multiplexed, microfluidic interface for connecting the inlet of a microfluidic device to the contents of a multi-well plate. ${ }^{[192]}$ Chronis and coworkers exploited laminar flow in microfluidic devices to develop a scheme for rapidly switching the chemical environment in the vicinity of the nose of an immobilized worm. ${ }^{[173]}$ Microfluidics enabled the generation of i) spatial gradients of odorants associated with bacteria in air-filled microchannels on agar surfaces to facilitate the study of bacterial preferences and memory, ${ }^{[190,194]}$ ii) spatial gradients of oxygen in air-filled microchannels on agar surfaces to facilitate the discovery and investigation of "aerotaxis"- the movement of animals to a specific oxygen concentration - in C. elegans, ${ }^{[170,}$ $171,181,195]$ and iii) temporal gradients of odorants in the air flowing over an array of droplets containing single worms to facilitate the study of chemotaxis. ${ }^{[210]}$ 
It is possible to exploit the permeability of PDMS to oxygen, nitrogen, and carbon dioxide to control the levels of these gases in the environment of the worm. Devices in which liquid-filled channels containing worms and gas-filled channels are separated by a thin layer of PDMS allow researchers to control the composition of gases that are dissolved in the liquid environment of the worm by changing the composition of the gas flowing through the device. This approach has been useful for the immobilization of worms with $\mathrm{CO}_{2},{ }^{[172]}$ and for the study of the neuronal responses of C. elegans to changes in $\mathrm{O}_{2}$ levels. ${ }^{[195]}$

The principal stimuli that have been applied to worms in microfluidic devices are dissolved chemical compounds and gases. Worms exhibit behavioral and biochemical changes in response to diverse physical stimuli, including electric fields, ${ }^{[191,214]}$ temperature, ${ }^{[211,215]}$ and ionizing radiation (UV light, protons, gamma radiation, and iron atoms ${ }^{[216-218]}$ ). It should be possible to incorporate these stimuli into microfluidic devices; for example, Rezai and coworkers recently used a microfluidic device to examine the locomotion of worms in an electric field. ${ }^{[191]}$

\subsection{Tools for Observing Phenotypes}

\subsubsection{Observing the Worm with Microscopy}

There are a number of techniques in microscopy that are useful for observing the worm. Bright-field microscopy enables observation of lifespan, behavior, and gross morphology. It is possible to image moving worms at high magnification using a microscope with a motorized stage and computer program that tracks the center of mass of the worm. Programs are available that track the motion of crawling worms. ${ }^{[213,219]}$ Locomotory behavior is an easily observed 
phenotype in C. elegans, and can be an informative readout of neuronal and muscular function, survival, and chemotactic behavior.

Nomarski (differential interference contrast) microscopy enables detailed imaging of body structures in C. elegans. For example, using Nomarski imaging, it is possible to visualize every cellular nucleus in the worm, ${ }^{[13]}$ to identify cellular corpses from apoptosis, ${ }^{[14]}$ and to observe internal motion, such as the rhythmic motion of the pharyngeal muscles, in detail. ${ }^{[220]}$ Polarized light microscopy can also aid in the visualization of certain body structures - for example, the ordered structure of the myofilament assemblies of the muscles in C. elegans are more easily viewed with polarized light microscopy than with conventional bright-field microscopy. ${ }^{[221]}$ For specific imaging applications, it is possible to use non-linear optical techniques. For example, coherent anti-Stokes Raman scattering (CARS) enables the imaging of lipid stores within the worm without the need for lipophilic dyes. ${ }^{[22]}$ Fluorescence microscopy enables the visualization of neuronal activity (using FRET-based $\mathrm{Ca}^{2+}$ dyes $^{[202]}$ ) and gene expression (using fluorescent-protein-conjugated proteins). The use of transmission electron microscopy (TEM) to image transverse sections of the worm - sectioned using an ultramicrotome - is a classic technique in worm biology. This technique enabled the microscopic reconstruction of the complete nervous system of $C$. elegans in the 1970s. ${ }^{[15,223]}$

\subsubsection{Chemical and Biochemical Readouts}

Section 3.3 includes a description of the use of HPLC, SDS-PAGE, MS, and immunochemistry to identify proteins expressed in C. elegans. Biochemical techniques have also facilitated the identification and characterization of metabolites secreted by the worm. ${ }^{\text {[224] }}$ Worms constitutively secrete dauer pheromone - a mixture of monosaccharide derivatives — into 
their environment. The pheromone serves as a signal of population density; a high concentration of pheromone causes $C$. elegans larvae to enter the dauer larval stage - an alternative developmental stage in which growth is arrested. It is possible to obtain crude dauer pheromone by filtering liquid medium that has been used to culture $C$. elegans. Chromatography enables fractionation the crude pheromone; it was possible to identify fractions containing active components of pheromone simply by treating worms with different fractions and determining which fractions induced dauer formation ${ }^{[225]}$ or inhibited exit from the dauer stage. ${ }^{[224]}$ Proton NMR and LC-MS allowed the identification of the chemical structure of each of the active components of the pheromones mixture. ${ }^{[224,225]}$ Scheme 4 shows three active components of dauer pheromone.

Technological advances in the resolving power of solid-state NMR have enabled the chemical characterization of complex, inhomogeneous samples. Blaise and coworkers used ${ }^{1} \mathrm{H}$ high-resolution magic angle spinning NMR spectroscopy to characterize the metabolic profilethe molecular phenotype - of intact worms. ${ }^{[226,227]}$ The authors used NMR to examine molecular differences among three strains of C. elegans: wild-type worms, sod-1 (superoxide dismutase) mutants, and ctl-1 (catalase) mutants. ${ }^{[226,227]}$ Both sod-1 and $c t l-1$ code for proteins involved in the elimination of ROS. Worms carrying mutations in these genes are not distinguishable from wild-type worms visually. Compared with the NMR spectrum for wild-type worms, spectra for sod-1 and ctl-1 worms had lower signals for resonances associated with lipids, and also higher signals for aldehyde resonances. ${ }^{[226]}$ These results are consistent with the idea that in the absence of anti-oxidant enzymes like SOD-1 and CTL-1, lipids would be unprotected from oxidation from ROS. ${ }^{[226]}$ Although it is a relatively new technique, ${ }^{[226,227]}$ whole-organism NMR has to 
potential to be enormously useful in increasing our understanding of molecular-level phenotypes in C. elegans.

\subsubsection{Biophysical Readouts}

Pruitt and coworkers have developed tools for measuring the mechanical stiffness of the body of the worm, ${ }^{[228]}$ and for measuring the mechanical forces generated by crawling worms. ${ }^{[229]}$ These tools may enable the discovery of previously-unobserved phenotypes in C. elegans.

Metabolic rate is an important physiological metric. There are a number of approaches for the determination of the metabolic rate of C. elegans, including the measurement of i) the production of $\mathrm{CO}_{2}$ by a population of approximately 50 worms using mass spectrometry, ${ }^{[230]}$ ii) the consumption of $\mathrm{O}_{2}$ by single worms using fluorimetry, ${ }^{[231]}$ iii) the production of heat by a population of worms using microcalorimetry, ${ }^{[232]}$ and iv) the concentration of ATP in living worms using transgenic strains expressing luciferin and luciferase. ${ }^{[232,233]}$

It is possible to perform both intracellular and extracellular electrophysiological recordings of the activity of intact neurons and muscles in C. elegans. Intracellular recordings require that the experimenter dissect a living worm and apply electrodes directly to its internal structures - it is a challenging experimental procedure, but enables the collection of quantitative data concerning the movement of ions into, and out of, active cells. ${ }^{[234]}$ Raizen and Avery developed a simple method for performing extracellular recordings of the activity of the pharyngeal neurons in C. elegans. ${ }^{[235]}$ Extracellular recordings are less informative than 
intracellular recordings with regards to the actual potential of the cells, but are much easier to perform. ${ }^{[234,235]}$

\subsection{Genetic Perturbations}

Not all chemists will be interested in learning the techniques of genetic manipulation. For those who are interested, C. elegans is a particularly convenient organism for forward and

reverse genetics. ${ }^{[38]}$ Fortunately for those who are not familiar with genetic techniques, there are many ways to perform research with mutant animals. First, it is possible to obtain already-generated mutant strains of C. elegans either from other researchers or from depositories of mutant strains. It is important to note that not every gene is represented by a mutation. The Caenorhabditis Genetics Center at the University of Minnesota, a depository of mutant worms funded by the National Institutes of Health, has thousands of strains available. Second, it is possible to silence genes in wild-type worms using double-stranded RNA (dsRNA) through RNA interference (RNAi). The experimental procedure for exposing worms to dsRNA is very simple; either soaking worms in a solution of the dsRNA or feeding worms E. coli that expresses the dsRNA will produce worms with silenced genes. ${ }^{[236]}$ Table 2 lists online resources for mutant strains of C. elegans and dsRNA against worm genes.

\subsubsection{Genetics and Chemical Genetics}

The approach of chemical genetics may be of interest to researchers with a chemical background studying the worm. It is possible to draw parallels between the approach of chemical genetic screening and the more traditional approach of genetic screening. In a forward genetic screen, random mutagenesis creates a population of mutants, which can be screened for a 
change in the phenotype of interest. Identification of the mutated gene (or genes) that produced the phenotypic change creates a link, either direct or indirect, between the function of the gene and the phenotype of interest. In a forward chemical genetic screen, treatment of the organisms with a library of small molecules replaces random mutagenesis. The success of a chemical genetic screen relies upon the assumption that the members of the chemical library are capable of altering the activity of proteins in a specific manner. In principle, a compound from the library that produced a change in the phenotype of interest has disrupted a protein whose function is related, directly or indirectly, to the phenotype of interest. ${ }^{[237]}$ In a reverse genetic screen, the creation of a mutation in a gene of interest enables observation of the resulting change in phenotype of the organism. In a reverse chemical genetic screen, in vitro methods identify members from a chemical library that bind to a protein of interest. Treatment of organism with small molecules that bind to the protein of interest enables observation of the resulting change in phenotype of the organism. ${ }^{[237]}$

Many of the experimental challenges in the approach of chemical genetics are chemical in nature. Typically, the most difficult tasks in a chemical genetic screen are the identification of the protein targeted by a small molecule, and the validation that this interaction is specific. ${ }^{[237]}$ These problems are well-suited to a biochemical approach. An additional challenge in the development of appropriate chemical libraries is that an understanding of the relationship between chemical structure of small molecules and their ability to bind tightly to proteins remains elusive. The investigation of how to predict and design ligand-protein specificity is an important and active area of chemical research. ${ }^{[238]}$ 


\section{Summary and Outlook}

\subsection{Model Organisms for Chemists: Alternatives to the Worm?}

For some research questions, worms and other multicellular organisms are probably too complex. Unicellular organisms like yeast and E. coli are likely to retain their positions as powerful biochemical models. To study basic intercellular interactions, biofilm-forming bacteria (such as Pseudomonas aeruginosa), or slime molds that aggregate into multicellular slugs (Dictyostelium discoideum) may be preferable to higher, more complex organisms. Mycoplasma genitalium, a bacterium with the smallest genome $-580 \mathrm{~kb}$, coding for fewer than 500 proteins - of any known free-living organism, has proven useful in the identification of a minimal set of genes that are essential for life. ${ }^{[5]}$ In 2010, Venter and coworkers transplanted chemically synthesized copies of the $M$. genitalium genome into recipient cells of the yeast Saccharomyces cerevisiae. ${ }^{[239]}$ This work represents a step towards the chemical specification of a living organism.

In order to make the leap from understanding how an individual cell operates to understanding how a human being operates, multicellular model organisms are essential. The real power of C. elegans is that it is the simplest model organism for studying multicellular life. C. elegans is simple both in a biological sense - worms are small; they have less than 1000 cells; they have a simple body plan — and in a practical sense — maintaining worms is significantly easier and cheaper than maintaining either multicellular organisms of higher complexity, or mammalian cell cultures. C. elegans also has many advantages with respect to accessibility and resources. 
Some other multicellular organisms do have specific features that make them particularly useful for specific areas of research. For example, the puffer fish (Fugu rubripes), has one of the smallest genomes among vertebrates, and therefore assists in the identification of the necessary genes for vertebrates. ${ }^{[240]}$ Frogs (Xenopus spp.) and chickens (Gallus gallus) have large embryos that develop outside of the mother, and are convenient organisms for the study of development. ${ }^{[241,242]}$ Planaria (Schmidtea mediterranea, and other species) are of special interest for the study of tissue regeneration. ${ }^{[243,244]}$ For understanding fundamental questions about the nature of multicellular life, however, and particularly for understanding the molecular basis for organism-level phenomena, C. elegans appears to be the best of the currently available choices.

\subsection{Relevance of the Worm to Human Health}

Are worms directly relevant to human health? Research with C. elegans cannot capture all aspects of human biology. There are, however, numerous examples of discoveries made in the worm that were informative for human biology. For example, it was in C. elegans that genes regulating aging ${ }^{[245]}$ and genes regulating apoptosis ${ }^{[246]}$ were initially discovered. Later work demonstrated that similar genetic pathways exist in humans. ${ }^{[245,246]}$ From a scientific standpoint, even in cases where mechanisms of genetic control differ, it will be fascinating to see whether the underlying chemistries of organism-level phenomena are preserved across species as diverse as worms and humans. C. elegans has the potential to be a valuable system for understanding the underlying molecular mechanisms of human disease, and for testing the activity, and also the toxicity, of candidate drugs and treatments. In order for C. elegans to be useful for screening candidate drugs, however, it will be necessary to demonstrate that experimental results in the worm are predictive of human outcomes. ${ }^{[247]}$ A research direction with important implications 
for global human health is the use of C. elegans to gain a better understanding of parasitic worms and parasitic worm infections. Initial work has already shown the usefulness of C. elegans in the discovery of new anthelmintic drugs that are effective in mammals. ${ }^{[161]}$

\subsection{How Can Chemistry Be Exploited for Worm Research?}

Often the discovery of new biology is driven by new tools. What additional tools and capabilities are needed? Below, we suggest potential directions for chemists.

A clear area where chemistry can be exploited for C. elegans research is in the development of new tissue- and molecule-specific dyes. The most commonly-used molecular label in C. elegans research is green fluorescent protein (GFP), but there are limits to what GFP can do - many cellular compounds are not gene products. Small organic dyes, which are used to label sub-cellular components in in vitro research, are not always usable for research with C. elegans because the uptake of the dye can be hindered by the cuticle or the intestinal lining (or the eggshell, in the case of embryos). ${ }^{[201]}$ This need for useful dyes is an opportunity for chemists to explore new strategies for labeling the worm. The work of Bertozzi and coworkers using a combination of modified sugars and "click chemistry" to label glycans is an excellent example of how chemistry can be utilized for worm biology. ${ }^{[120]}$ To guide the design of new, "worm-penetrating" dyes, it may also be useful to characterize the permeability and chemical selectivity of both the cuticle and the intestinal lining of the worm.

Chemistry could provide a new approach in the discovery of new genes. Over half of the genes in the genome of C. elegans have an unknown function. ${ }^{[248]}$ These are genes that are not orthologous to genes of known function and have not been identified in phenotype-based 
forward genetic screens. The best phenotypes for genetic screens are those that can be easily and rapidly identified — defects in locomotion or development, for example. A chemical approach could be useful in identifying new mutant phenotypes for genetic screens based on chemical reactivity (for example, altered reactivity of the cuticle could indicate a change in the chemical composition of the cuticle). With this strategy, chemistry might enable the identification of new classes of mutations.

A chemical approach could be useful in the continuing development of a bacteria-free, chemically-defined medium for C. elegans. ${ }^{[27]}$ Worms grown in current formulations of bacteria-free medium exhibit slower development than worms that are fed bacteria, suggesting that the chemically-defined medium does not have the same nutritive value as the bacterial diet. The development of a chemically-defined medium that enables worms to develop as they do with a bacterial diet would be useful, and would also be informative with regards to the nutritional needs of C. elegans. It is possible that the nutritive value of the bacterial diet may be due to the fact that worms are filter feeders, and therefore the physical state of the food may be important. The encapsulation of chemically-defined medium in vesicles or in digestible, bacteria-sized beads could potentially increase the ability of $C$. elegans to ingest the medium.

Another potential direction for chemists is to examine the effects of simple organic reactions in vivo to explore how known chemical reactions interact with living systems. For example, Branda and coworkers treated worms with a photoswitchable molecule-a derivative of bis(pyridinium) dithienylethene - that undergoes a reversible, photoinducible switch from a colorless, open-ring isomer to a colored, closed-ring isomer. Switching to the closed-ring isomer induced a reversible paralysis in a significant fraction of worms containing the photoswitchable 
molecule. ${ }^{[249]}$ Although the mechanism of the paralysis remains unknown (the authors proposed that it could be related to the fact that the closed-ring isomer is more easily reduced than the open-ring isomer), this work suggests that exploring how organic chemistry interacts with multicellular organisms could be a fruitful direction for chemical research.

\subsection{For What Should Chemists Use the Worm?}

What types of research questions that can be attempted using the worm are likely to be interesting to chemists?

For pharmaceutical research, the worm may be useful for testing the activity and toxicity of drug leads in vivo. While the predictive value of drug testing in worms for activity in humans is uncertain, C. elegans is amenable to high-throughput and hypothesis-based screening, and would enable candidate drugs to be tested in complex, multicellular organism containing

multiple cell- and tissue-types. ${ }^{[250]}$ It should certainly be possible to study the interaction of worms with chemically simple xenobiotics and toxins, such as heavy metals. Worms may also open a window into phenomena - effects of starvation, radiation, increased or reduced temperature, vitamin deficiency, anoxia, and reperfusion injury-in which the mechanism of injury, and the biological response to it, are likely to be general rather than specific to a particular organism. It is least likely that worms will be useful in studying the effects of xenobiotics on specific enzymes, receptors, pathways and systems that are specific to an organism or class of organisms.

Despite the complexity of the worm, it should still be possible to maintain a reductionist approach. The worm should enable chemists to examine the effects that i) very simple molecules 
(such as $\mathrm{O}_{2}, \mathrm{H}_{2} \mathrm{~S}, \mathrm{NO}, \mathrm{CO}, \mathrm{CO}_{2}$ ), ii) universal chemical phenomena (ionizing radiation, radical formation, formation and management of reactive oxygen species, reduction/oxidation), iii) fundamental chemical considerations (kinetics, thermodynamics, stereochemistry, reactivity, $\mathrm{pH}$ ), and iv) basic physical parameters (temperature, pressure) have on life.

Research with $C$. elegans has only begun to unravel the mysteries of aging, death, behavior, learning, and memory. We believe that investigating the underlying chemical states and reactions that correspond to these processes will be an attractive goal for chemists.

\section{Acknowledgements}

This research was supported by a grant from the Department of Energy under award no. DE-FG02-OOER4585, and by a grant from Vertex Pharmaceuticals to Harvard University. 


\section{References}

[1] C. H. Bennett in Emerging Syntheses in Science, (Ed.: D. Pines), Perseus Books Publishing, New York, 1988, pp. 215-231.

[2] S. Lloyd, in IEEE Control Systems Magazine, Vol. 21, 2001, pp. 7-8.

[3] G. Bell, A. O. Mooers, Biol. J. Linn. Soc. 1997, 60, 345.

[4] D. W. McShea, Evolution 1996, 50, 477.

[5] J. I. Glass, N. Assad-Garcia, N. Alperovich, S. Yooseph, M. R. Lewis, M. Maruf, C. A. Hutchison, 3rd, H. O. Smith, J. C. Venter, Proc. Natl. Acad. Sci. U. S. A. 2006, 103, 425.

[6] D. Sinclair, K. Mills, L. Guarente, Annu. Rev. Microbiol. 1998, 52, 533.

[7] E. J. Stewart, R. Madden, G. Paul, F. Taddei, PLoS Biol. 2005, 3, e45.

[8] T. Stiernagle, Maintenance of C. elegans (February 11, 2006), WormBook, ed. The C. elegans Research Community, WormBook, doi/10.1895/wormbook.1.101.1, http://www.wormbook.org.

[9] A. Capes-Davis, G. Theodosopoulos, I. Atkin, H. G. Drexler, A. Kohara, R. A. MacLeod, J. R. Masters, Y. Nakamura, Y. A. Reid, R. R. Reddel, et al., Int. J. Cancer 2010, 127, 1.

[10] S. Brenner, ChemBioChem 2003, 4, 683.

[11] S. Brenner in The Nematode Caenorhabditis elegans, (Ed.: W. B. Wood), Cold Spring Harbor Laboratory Press, Cold Spring Harbor, 1988, pp. ix-xiii.

[12] S. Brenner, L. Wolpert, My Life in Science, BioMed Central Limited, London, 2001.

[13] J. E. Sulston, H. R. Horvitz, Dev. Biol. 1977, 56, 110.

[14] J. E. Sulston, E. Schierenberg, J. G. White, J. N. Thomson, Dev. Biol. 1983, 100,64 .

[15] J. G. White, E. Southgate, J. N. Thomson, S. Brenner, Philos. Trans. R. Soc. Lond. B. Biol. Sci. 1986, 314, 1.

[16] A. Fire, S. Xu, M. K. Montgomery, S. A. Kostas, S. E. Driver, C. C. Mello, Nature 1998, 391, 806.

[17] The C. elegans Sequencing Consortium, Science 1998, 282, 2012. 
[18] L. W. Hillier, A. Coulson, J. I. Murray, Z. Bao, J. E. Sulston, R. H. Waterston, Genome Res. 2005, 15, 1651.

[19] I. Antoshechkin, P. W. Sternberg, Nat. Rev. Genet. 2007, 8, 518.

[20] Wormatlas. Z. F. Altun, L. A. Herndon, C. Crocker, R. Lints, D. H. Hall (ed.s). 2002-2010. http://www.wormatlas.org.

[21] R. C. Cassada, R. L. Russell, Dev. Biol. 1975, 46, 326.

[22] D. Gems, J. J. McElwee, Mech. Ageing Dev. 2005, 126, 381.

[23] S. Brenner, Genetics 1974, 77, 71.

[24] D. Garigan, A. L. Hsu, A. G. Fraser, R. S. Kamath, J. Ahringer, C. Kenyon, Genetics 2002, 161, 1101.

[25] D. A. Garsin, J. M. Villanueva, J. Begun, D. H. Kim, C. D. Sifri, S. B. Calderwood, G. Ruvkun, F. M. Ausubel, Science 2003, 300, 1921.

[26] A. Barriere, M. A. Felix, Curr. Biol. 2005, 15, 1176.

[27] N. J. Szewczyk, E. Kozak, C. A. Conley, BMC Biotechnol. 2003, 3, 1.

[28] T. Kaletta, M. O. Hengartner, Nat. Rev. Drug Discovery 2006, 5, 387.

[29] G. M. Rubin, M. D. Yandell, J. R. Wortman, G. L. Gabor Miklos, C. R. Nelson, I. K. Hariharan, M. E. Fortini, P. W. Li, R. Apweiler, W.

Fleischmann, et al., Science 2000, 287, 2204.

[30] E. Kim, A. Magen, G. Ast, Nucleic Acids Res. 2007, 35, 125.

[31] A. C. Carrano, Z. Liu, A. Dillin, T. Hunter, Nature 2009, 460, 396.

[32] C. Morck, L. Olsen, C. Kurth, A. Persson, N. J. Storm, E. Svensson, J. O. Jansson, M. Hellqvist, A. Enejder, N. J. Faergeman, et al., Proc. Natl. Acad. Sci. U. S. A. 2009, 106, 18285.

[33] M. E. Forsythe, D. C. Love, B. D. Lazarus, E. J. Kim, W. A. Prinz, G. Ashwell, M. W. Krause, J. A. Hanover, Proc. Natl. Acad. Sci. U. S. A. 2006, 103, 11952.

[34] J. G. Lawrence, Cell 2002, 110, 407.

[35] T. Blumenthal, D. Evans, C. D. Link, A. Guffanti, D. Lawson, J. ThierryMieg, D. Thierry-Mieg, W. L. Chiu, K. Duke, M. Kiraly, et al., Nature 2002, 417,851 . 
[36] J. Spieth, D. Lawson, Overview of Gene Structure (January 18, 2006), WormBook, ed. The C. elegans Research Community, WormBook, doi/10.1895/wormbook.1.65.1, http://www.wormbook.org.

[37] H. H. Kazazian, Jr., Science 2004, 303, 1626.

[38] Scientific Frontiers in Developmental Toxicology and Risk Assessment, (Eds.: Committee on Developmental Toxicology, Board on Environmental Studies and Toxicology, Commission on Life Sciences, National Research Council), National Academies Press, Washington, D.C., 2000, pp. 296-308.

[39] G. Ruvkun, O. Hobert, Science 1998, 282, 2033.

[40] Y. Wang, D. E. Levy, Curr. Biol. 2006, 16, 89.

[41] S. H. Panowski, A. Dillin, Trends Endocrinol. Metab. 2009, 20, 259.

[42] S. Wolff, A. Dillin, Exp. Gerontol. 2006, 41, 894.

[43] L. Partridge, D. Gems, Nat. Rev. Genet. 2002, 3, 165.

[44] R. B. Beckstead, C. S. Thummel, Cell 2006, 124, 1137.

[45] C. R. Gissendanner, K. Crossgrove, K. A. Kraus, C. V. Maina, A. E. Sluder, Dev. Biol. 2004, 266, 399.

[46] J. M. Maglich, A. Sluder, X. Guan, Y. Shi, D. D. McKee, K. Carrick, K. Kamdar, T. M. Willson, J. T. Moore, Genome Biol. 2001, 2, 1.

[47] D. B. Magner, A. Antebi, Trends Endocrinol. Metab. 2008, 19, 153.

[48] D. L. Motola, C. L. Cummins, V. Rottiers, K. K. Sharma, T. Li, Y. Li, K. Suino-Powell, H. E. Xu, R. J. Auchus, A. Antebi, et al., Cell 2006, 124, 1209.

[49] A. Mimoto, M. Fujii, M. Usami, M. Shimamura, N. Hirabayashi, T. Kaneko, N. Sasagawa, S. Ishiura, Biochem. Biophys. Res. Commun. 2007, 364, 883.

[50] T. Bacaj, M. Tevlin, Y. Lu, S. Shaham, Science 2008, 322, 744.

[51] B. H. Cheung, M. Cohen, C. Rogers, O. Albayram, M. de Bono, Curr. Biol. 2005, 15, 905 .

[52] H. Schulenburg, C. L. Kurz, J. J. Ewbank, Immunol. Rev. 2004, 198, 36.

[53] J. E. Mellem, P. J. Brockie, D. M. Madsen, A. V. Maricq, Nat. Neurosci. 2008, 11, 865 .

[54] S. R. Lockery, M. B. Goodman, Nat. Neurosci. 2009, 12, 377. 
[55] S. J. Husson, I. Mertens, T. Janssen, M. Lindemans, L. Schoofs, Prog. Neurobiol. 2007, 82, 33.

[56] M. Nguyen, A. Alfonso, C. D. Johnson, J. B. Rand, Genetics 1995, 140, 527.

[57] R. Ranganathan, E. R. Sawin, C. Trent, H. R. Horvitz, J. Neurosci. 2001, 21, 5871 .

[58] V. J. Simpson, T. E. Johnson, Int. Rev. Neurobiol. 1996, 39, 223.

[59] M. de Bono, A. Villu Maricq, Annu. Rev. Neurosci. 2005, 28, 451.

[60] C. H. Rankin, Curr. Biol. 2004, 14, R617.

[61] E. M. Hedgecock, R. L. Russell, Proc. Natl. Acad. Sci. U. S. A. 1975, 72, 4061.

[62] B. P. Braeckman, K. Houthoofd, J. R. Vanfleteren, Intermediary Metabolism (February 16, 2009), WormBook, ed. The C. elegans Research Community, WormBook, doi/10.1895/wormbook.1.146.1, http://www.wormbook.org.

[63] S. J. Holt, D. L. Riddle, Mech. Ageing Dev. 2003, 124, 779.

[64] J. J. McElwee, E. Schuster, E. Blanc, J. Thornton, D. Gems, Mech. Ageing Dev. 2006, 127, 458.

[65] A. G. Tielens, C. Rotte, J. J. van Hellemond, W. Martin, Trends Biochem. Sci. 2002, 27, 564.

[66] A. F. Cooper, S. D. Van Gundy, J. Nematol. 1970, 2, 305.

[67] J. L. Watts, Trends Endocrinol. Metab. 2009, 20, 58.

[68] J. Kuhnl, T. Bobik, J. B. Procter, C. Burmeister, J. Hoppner, I. Wilde, K. Luersen, A. E. Torda, R. D. Walter, E. Liebau, FEBS J. 2005, 272, 1465.

[69] K. D. Kimura, H. A. Tissenbaum, Y. Liu, G. Ruvkun, Science 1997, 277, 942.

[70] T. V. Kurzchalia, S. Ward, Nat. Cell Biol. 2003, 5, 684.

[71] A. U. Rao, L. K. Carta, E. Lesuisse, I. Hamza, Proc. Natl. Acad. Sci. U. S. A. 2005, 102, 4270 .

[72] W. A. Van Voorhies, S. Ward, J. Exp. Biol. 2000, 203, 2467.

[73] G. L. Anderson, D. B. Dusenbery, J. Nematol. 1977, 9, 253.

[74] T. G. Nystul, M. B. Roth, Proc. Natl. Acad. Sci. U. S. A. 2004, 101, 9133.

[75] A. R. Mendenhall, B. LaRue, P. A. Padilla, Genetics 2006, 174, 1173. 
[76] P. A. Padilla, T. G. Nystul, R. A. Zager, A. C. Johnson, M. B. Roth, Mol. Biol. Cell 2002, 13, 1473.

[77] V. A. Hajeri, J. Trejo, P. A. Padilla, BMC Cell Biol. 2005, 6, 47.

[78] R. L. Foll, A. Pleyers, G. J. Lewandovski, C. Wermter, V. Hegemann, R. J. Paul, Comp. Biochem. Physiol. Biochem. Mol. Biol. 1999, 124, 269.

[79] H. Jiang, R. Guo, J. A. Powell-Coffman, Proc. Natl. Acad. Sci. U. S. A. 2001, 98, 7916.

[80] A. K. Corsi, Anal. Biochem. 2006, 359, 1.

[81] S. Q. Cai, F. Sesti, Nat. Neurosci. 2009, 12, 611.

[82] F. Sesti, S. Liu, S. Q. Cai, Trends Cell Biol. 2010, $20,45$.

[83] T. Finkel, Curr. Opin. Cell Biol. 2003, 15, 247.

[84] Y. Shibata, R. Branicky, I. O. Landaverde, S. Hekimi, Science 2003, 302, 1779 .

[85] Z. A. Medvedev, Biol. Rev. Camb. Philos. Soc. 1990, 65, 375.

[86] S. Rea, T. E. Johnson, Dev. Cell 2003, 5, 197.

[87] K. Ashrafi, F. Y. Chang, J. L. Watts, A. G. Fraser, R. S. Kamath, J. Ahringer, G. Ruvkun, Nature 2003, 421, 268.

[88] K. Houthoofd, B. P. Braeckman, I. Lenaerts, K. Brys, A. De Vreese, S. Van Eygen, J. R. Vanfleteren, Exp. Gerontol. 2002, 37, 1359.

[89] M. R. Klass, Mech. Ageing Dev. 1977, 6, 413.

[90] L. S. Tain, E. Lozano, A. G. Saez, A. M. Leroi, BMC Dev. Biol. 2008, 8, 28.

[91] B. Lakowski, S. Hekimi, Proc. Natl. Acad. Sci. U. S. A. 1998, 95, 13091.

[92] M. Hansen, A. Chandra, L. L. Mitic, B. Onken, M. Driscoll, C. Kenyon, PLoS Genet. 2008, 4, e24.

[93] K. Jia, B. Levine, Autophagy 2007, 3, 597.

[94] K. Houthoofd, B. P. Braeckman, T. E. Johnson, J. R. Vanfleteren, Exp. Gerontol. 2003, 38, 947.

[95] S. J. Lee, C. T. Murphy, C. Kenyon, Cell Metab. 2009, 10, 379.

[96] A. Schlotterer, G. Kukudov, F. Bozorgmehr, H. Hutter, X. Du, D. Oikonomou, Y. Ibrahim, F. Pfisterer, N. Rabbani, P. Thornalley, et al., Diabetes 2009, 58, 2450. 
[97] T. J. Schulz, K. Zarse, A. Voigt, N. Urban, M. Birringer, M. Ristow, Cell Metab. 2007, 6, 280.

[98] J. R. Cypser, P. Tedesco, T. E. Johnson, Exp. Gerontol. 2006, 41, 935.

[99] M. H. Chuang, S. H. Chiou, C. H. Huang, W. B. Yang, C. H. Wong, Bioorg. Med. Chem. 2009, 17, 7831.

[100] Y. Honda, S. Honda, Ann. N. Y. Acad. Sci. 2002, 959, 466.

[101] M. G. Benedetti, A. L. Foster, M. C. Vantipalli, M. P. White, J. N. Sampayo, M. S. Gill, A. Olsen, G. J. Lithgow, Exp. Gerontol. 2008, 43, 882.

[102] N. Ishii, N. Senoo-Matsuda, K. Miyake, K. Yasuda, T. Ishii, P. S. Hartman, S. Furukawa, Mech. Ageing Dev. 2004, 125, 41.

[103] N. Saul, K. Pietsch, R. Menzel, S. R. Sturzenbaum, C. E. Steinberg, J. Gerontol. A Biol. Sci. Med. Sci. 2010, 65, 626.

[104] M. A. Wilson, B. Shukitt-Hale, W. Kalt, D. K. Ingram, J. A. Joseph, C. A. Wolkow, Aging Cell 2006, 5, 59.

[105] A. Dillin, A. L. Hsu, N. Arantes-Oliveira, J. Lehrer-Graiwer, H. Hsin, A. G. Fraser, R. S. Kamath, J. Ahringer, C. Kenyon, Science 2002, 298, 2398.

[106] S. S. Lee, R. Y. Lee, A. G. Fraser, R. S. Kamath, J. Ahringer, G. Ruvkun, Nat. Genet. 2003, 33, 40.

[107] J. Feng, F. Bussiere, S. Hekimi, Dev. Cell 2001, 1, 633.

[108] L. A. Herndon, P. J. Schmeissner, J. M. Dudaronek, P. A. Brown, K. M. Listner, Y. Sakano, M. C. Paupard, D. H. Hall, M. Driscoll, Nature 2002, $419,808$.

[109] S. E. Hulme, S. S. Shevkoplyas, A. P. McGuigan, J. Apfeld, W. Fontana, G. M. Whitesides, Lab Chip 2010, 10, 589.

[110] M. J. Gravato-Nobre, H. R. Nicholas, R. Nijland, D. O'Rourke, D. E. Whittington, K. J. Yook, J. Hodgkin, Genetics 2005, 171, 1033.

[111] M. Christensen, A. Estevez, X. Yin, R. Fox, R. Morrison, M. McDonnell, C. Gleason, D. M. Miller, 3rd, K. Strange, Neuron 2002, 33, 503.

[112] J. S. Duerr, Immunohistochemistry (June 19, 2006), WormBook, ed. WormBook, The C. elegans Research Community, doi/10.1895/wormbook.1.105.1, http://www.wormbook.org.

[113] A. Mádi, S. Mikkat, C. Koy, B. Ringel, H.-J. Thiesen, M. O. Glocker, Biochim. Biophys. Acta, Proteins Proteomics 2008, 1784, 1763. 
[114] B. B. J. Tops, S. Gauci, A. J. R. Heck, J. Krijgsveld, J. Proteome Res. 2009, 9, 341.

[115] M.-Q. Dong, J. D. Venable, N. Au, T. Xu, S. K. Park, D. Cociorva, J. R. Johnson, A. Dillin, J. R. Yates, III, Science 2007, 317, 660.

[116] J. Krijgsveld, R. F. Ketting, T. Mahmoudi, J. Johansen, M. Artal-Sanz, C. P. Verrijzer, R. H. Plasterk, A. J. Heck, Nat. Biotechnol. 2003, 21, 927.

[117] L. Jing, C. Tanxi, W. Peng, C. Ziyou, C. Xiulan, H. Junjie, X. Zhensheng, X. Peng, S. Linan, L. Pingsheng, et al., Proteomics 2009, 9, 4539.

[118] K. Nishiwaki, Y. Kubota, Y. Chigira, S. K. Roy, M. Suzuki, M. Schvarzstein, Y. Jigami, N. Hisamoto, K. Matsumoto, Nat. Cell Biol. 2004, 6,31 .

[119] J. A. Hanover, M. E. Forsythe, P. T. Hennessey, T. M. Brodigan, D. C. Love, G. Ashwell, M. Krause, Proc. Natl. Acad. Sci. U. S. A. 2005, 102, 11266.

[120] S. T. Laughlin, C. R. Bertozzi, ACS Chem. Biol. 2009, 4, 1068.

[121] C. M. Dempsey, S. M. Mackenzie, A. Gargus, G. Blanco, J. Y. Sze, Genetics 2005, 169, 1425.

[122] F. U. Hartl, M. Hayer-Hartl, Nat. Struct. Mol. Biol. 2009, 16, 574.

[123] J. Drake, C. D. Link, D. A. Butterfield, Neurobiol. Aging 2003, $24,415$.

[124] C. Y. Ewald, C. Li, Brain Struct. Funct. 2009, 214, 263.

[125] S. M. Yatin, S. Varadarajan, C. D. Link, D. A. Butterfield, Neurobiol. Aging 1999, 20, 325.

[126] T. Gidalevitz, A. Ben-Zvi, K. H. Ho, H. R. Brignull, R. I. Morimoto, Science 2006, 311, 1471.

[127] J. F. Morley, H. R. Brignull, J. J. Weyers, R. I. Morimoto, Proc. Natl. Acad. Sci. U. S. A. 2002, 99, 10417.

[128] J.-C. Rochet, P. T. Lansbury, Curr. Opin. Struct. Biol. 2000, 10, 60.

[129] C. D. Link, Proc. Natl. Acad. Sci. U. S. A. 1995, 92, 9368.

[130] D. Kokel, D. Xue, ChemBioChem 2006, 7, 2010.

[131] J. M. Pinkston, D. Garigan, M. Hansen, C. Kenyon, Science 2006, 313, 971.

[132] J. Pinkston-Gosse, C. Kenyon, Nat. Genet. 2007, 39, 1403.

[133] J. Downward, Nat. Rev. Cancer 2003, 3, 11. 
[134] G. J. Beitel, S. G. Clark, H. R. Horvitz, Nature 1990, 348, 503.

[135] S. G. Clark, M. J. Stern, H. R. Horvitz, Nature 1992, 356, 340.

[136] M. Han, A. Golden, Y. Han, P. W. Sternberg, Nature 1993, 363, 133.

[137] G. Ludewig, L. Lehmann, H. Esch, L. W. Robertson, Environ. Toxicol. Pharmacol. 2008, 25, 241.

[138] G. I. Evan, K. H. Vousden, Nature 2001, 411, 342.

[139] M. M. Metzstein, G. M. Stanfield, H. R. Horvitz, Trends Genet. 1998, 14, 410.

[140] D. Kokel, Y. Li, J. Qin, D. Xue, Nat. Chem. Biol. 2006, 2, 338.

[141] A. Buckpitt, B. Boland, M. Isbell, D. Morin, M. Shultz, R. Baldwin, K. Chan, A. Karlsson, C. Lin, A. Taff, et al., Drug Metab. Rev. 2002, 34, 791.

[142] R. Snyder, C. C. Hedli, Environ. Health Perspect. 1996, 104 Suppl 6, 1165.

[143] A. R. Burns, I. M. Wallace, J. Wildenhain, M. Tyers, G. Giaever, G. D. Bader, C. Nislow, S. R. Cutler, P. J. Roy, Nat. Chem. Biol. 2010, 6, 549.

[144] P. J. Hotez, P. J. Brindley, J. M. Bethony, C. H. King, E. J. Pearce, J. Jacobson, J. Clin. Invest. 2008, 118, 1311.

[145] P. J. Brindley, M. Mitreva, E. Ghedin, S. Lustigman, PLoS Negl. Trop. Dis. 2009, 3, e538.

[146] T. G. Geary, D. P. Thompson, Vet. Parasitol. 2001, 101, 371.

[147] J. S. Gilleard, D. J. Woods, J. A. Dow, Trends Parasitol. 2005, 21, 302.

[148] C. Dieterich, R. J. Sommer, Trends Genet. 2009, 25, 203.

[149] M. Mitreva, M. L. Blaxter, D. M. Bird, J. P. McCarter, Trends Genet. 2005, $21,573$.

[150] D. T. Jamison, A. Creese, T. Prentice, The World Health Report 1999: Making a Difference, The World Health Organization, Geneva, Switzerland, 1999.

[151] J. Bethony, S. Brooker, M. Albonico, S. M. Geiger, A. Loukas, D. Diemert, P. J. Hotez, Lancet 2006, 367, 1521.

[152] S. Geerts, B. Gryseels, Clin. Microbiol. Rev. 2000, 13, 207.

[153] M. Albonico, Q. Bickle, M. Ramsan, A. Montresor, L. Savioli, M. Taylor, Bull. World Health Organ. 2003, 81, 343. 
[154] M. Moran, J. Guzman, K. Henderson, A.-L. Ropars, A. McDonald, L. McSherry, L. Wu, B. Omune, A. Illmer, T. Strum, et al., Neglected Disease Research \& Develoment: New Times, New Trends, The George Institute for International Health, Sydney, 2009.

[155] D. P. Knox, P. Geldhof, A. Visser, C. Britton, Trends Parasitol. 2007, 23, 105.

[156] M. S. Kwa, J. G. Veenstra, M. Van Dijk, M. H. Roos, J. Mol. Biol. 1995, 246,500 .

[157] A. L. Scott, E. Ghedin, Parasitol. Int. 2009, 58, 6.

[158] C. Britton, L. Murray, Mol. Biochem. Parasitol. 2002, 122, 21.

[159] S. Ranganathan, R. Menon, R. B. Gasser, Biotechnol. Adv. 2009, 27, 439.

[160] M. Driscoll, E. Dean, E. Reilly, E. Bergholz, M. Chalfie, J. Cell Biol. 1989, 109, 2993.

[161] R. Kaminsky, P. Ducray, M. Jung, R. Clover, L. Rufener, J. Bouvier, S. S. Weber, A. Wenger, S. Wieland-Berghausen, T. Goebel, et al., Nature 2008, $452,176$.

[162] S. Hashmi, W. Tawe, S. Lustigman, Trends Parasitol. 2001, 17, 387.

[163] P. McVeigh, T. G. Geary, N. J. Marks, A. G. Maule, Trends Parasitol. 2006, 22,385 .

[164] S. Hartmann, R. Lucius, Int. J. Parasitol. 2003, 33, 1291.

[165] J. Croese, J. O'Neil, J. Masson, S. Cooke, W. Melrose, D. Pritchard, R. Speare, Gut 2006, 55, 136.

[166] S. Tawill, L. Le Goff, F. Ali, M. Blaxter, J. E. Allen, Infect. Immun. 2004, $72,398$.

[167] S. M. Politz, M. Philipp, Parasitol. Today 1992, 8, 6.

[168] L. Murray, P. Geldhof, D. Clark, D. P. Knox, C. Britton, Int. J. Parasitol. 2007, 37, 1117.

[169] P. B. Allen, A. E. Sgro, D. L. Chao, B. E. Doepker, J. Scott Edgar, K. Shen, D. T. Chiu, J. Neurosci. Methods 2008, 173, 20.

[170] A. J. Chang, C. I. Bargmann, Proc. Natl. Acad. Sci. U. S. A. 2008, 105, 7321.

[171] A. J. Chang, N. Chronis, D. S. Karow, M. A. Marletta, C. I. Bargmann, PLoS Biol. 2006, 4, e274. 
[172] T. V. Chokshi, A. Ben-Yakar, N. Chronis, Lab Chip 2009, 9, 151.

[173] N. Chronis, M. Zimmer, C. I. Bargmann, Nat. Methods 2007, 4, 727.

[174] K. Chung, M. M. Crane, H. Lu, Nat. Methods 2008, 5, 637.

[175] K. Chung, H. Lu, Lab Chip 2009, 9, 2764.

[176] S. Chung, D. Clark, C. Gabel, E. Mazur, A. Samuel, BMC Neurosci. 2006, 7,30 .

[177] J. Clausell-Tormos, D. Lieber, J. C. Baret, A. El-Harrak, O. J. Miller, L. Frenz, J. Blouwolff, K. J. Humphry, S. Koster, H. Duan, et al., Chem. Biol. 2008, $15,427$.

[178] M. M. Crane, K. Chung, H. Lu, Lab Chip 2009, 9, 38.

[179] X. Cui, L. M. Lee, X. Heng, W. Zhong, P. W. Sternberg, D. Psaltis, C. Yang, Proc. Natl. Acad. Sci. U. S. A. 2008, 105, 10670.

[180] B. Pinan-Lucarre*, C. V. Gabel*, S. E. Hulme, S. S. Shevkoplyas, R. D. Slone, J. Xue, Y. Qiao, S. Weisberg, G. M. Whitesides, A. D. T. Samuel, et al., Submitted.

[181] J. M. Gray, D. S. Karow, H. Lu, A. J. Chang, J. S. Chang, R. E. Ellis, M. A. Marletta, C. I. Bargmann, Nature 2004, 430, 317.

[182] S. X. Guo, F. Bourgeois, T. Chokshi, N. J. Durr, M. A. Hilliard, N. Chronis, A. Ben-Yakar, Nat. Methods 2008, 5, 531.

[183] X. Heng, D. Erickson, L. R. Baugh, Z. Yaqoob, P. W. Sternberg, D. Psaltis, C. Yang, Lab Chip 2006, 6, 1274.

[184] S. E. Hulme, S. S. Shevkoplyas, J. Apfeld, W. Fontana, G. M. Whitesides, Lab Chip 2007, 7, 1515.

[185] N. Kim, C. M. Dempsey, J. V. Zoval, J.-Y. Sze, M. J. Madou, Sens. Actuators, B 2007, 122, 511 .

[186] D. Lange, C. W. Storment, C. A. Conley, G. T. A. Kovacs, Sens. Actuators, $B$ 2005, 107, 904.

[187] S. R. Lockery, K. J. Lawton, J. C. Doll, S. Faumont, S. M. Coulthard, T. R. Thiele, N. Chronis, K. E. McCormick, M. B. Goodman, B. L. Pruitt, J. Neurophysiol. 2008, 99, 3136.

[188] H. Ma, L. Jiang, W. Shi, J. Qin, B. Lin, Biomicrofluidics 2009, 3, 44114.

[189] S. Park, H. Hwang, S. W. Nam, F. Martinez, R. H. Austin, W. S. Ryu, PLoS One 2008, 3, e2550. 
[190] J. Qin, A. R. Wheeler, Lab Chip 2007, 7, 186.

[191] P. Rezai, A. Siddiqui, P. R. Selvaganapathy, B. P. Gupta, Lab Chip 2010, 10, 220.

[192] C. B. Rohde, F. Zeng, R. Gonzalez-Rubio, M. Angel, M. F. Yanik, Proc. Natl. Acad. Sci. U. S. A. 2007, 104, 13891.

[193] F. Zeng, C. B. Rohde, M. F. Yanik, Lab Chip 2008, 8, 653.

[194] Y. Zhang, H. Lu, C. I. Bargmann, Nature 2005, 438, 179.

[195] M. Zimmer, J. M. Gray, N. Pokala, A. J. Chang, D. S. Karow, M. A. Marletta, M. L. Hudson, D. B. Morton, N. Chronis, C. I. Bargmann, Neuron 2009, 61, 865 .

[196] W. Shi, J. Qin, N. Ye, B. Lin, Lab Chip 2008, 8, 1432.

[197] J. Krajniak, H. Lu, Lab Chip 2010, 10, 1862.

[198] J. N. Stirman, M. Brauner, A. Gottschalk, H. Lu, J. Neurosci. Methods 2010, 191, 90 .

[199] D. B. Weibel, W. R. DiLuzio, G. M. Whitesides, Nat. Rev. Microbiol. 2007, $5,209$.

[200] Y. Xia, G. M. Whitesides, Angew. Chem. 1998, 37, 550.

[201] H. Hutter in C. elegans Methods and Applications, Vol. 351, (Ed.: K. Strange), Humana Press, Inc., Totowa, NJ, 2006, pp. 155-174.

[202] R. Kerr, V. Lev-Ram, G. Baird, P. Vincent, R. Y. Tsien, W. R. Schafer, Neuron 2000, 26, 583.

[203] C. I. Bargmann, L. Avery, Methods Cell Biol. 1995, 48, 225.

[204] M. F. Yanik, H. Cinar, H. N. Cinar, A. D. Chisholm, Y. Jin, A. Ben-Yakar, Nature 2004, 432, 822.

[205] A. C. Hart, ed., Behavior (July 3, 2006), WormBook, ed. The C. elegans Research Community, WormBook, doi/10.1895/wormbook.1.87.1, http://www.wormbook.org.

[206] M. A. Hilliard, A. J. Apicella, R. Kerr, H. Suzuki, P. Bazzicalupo, W. R. Schafer, EMBO J. 2005, 24, 63.

[207] J. D. Corbett, M. R. Cho, D. E. Golan, Biophys. J. 1994, 66, 25.

[208] M. A. Unger, H. P. Chou, T. Thorsen, A. Scherer, S. R. Quake, Science $2000,288,113$. 
[209] R. Pulak in C. elegans Methods and Applications, Vol. 351, (Ed.: K. Strange), Humana Press, Inc., Totowa, NJ, 2006, pp. 275-286.

[210] L. Luo, C. V. Gabel, H. I. Ha, Y. Zhang, A. D. Samuel, J. Neurophysiol. 2008, 99, 2617.

[211] W. S. Ryu, A. D. T. Samuel, J. Neurosci. 2002, 22, 5727.

[212] D. A. Clark, C. V. Gabel, T. M. Lee, A. D. Samuel, J. Neurophysiol. 2007, 97, 1903.

[213] D. Ramot, B. E. Johnson, T. L. Berry, Jr., L. Carnell, M. B. Goodman, PLoS One 2008, 3, e2208.

[214] C. V. Gabel, H. Gabel, D. Pavlichin, A. Kao, D. A. Clark, A. D. T. Samuel, J. Neurosci. 2007, 27, 7586.

[215] I. Mori, H. Sasakura, A. Kuhara, Curr. Opin. Neurobiol. 2007, 17, 712.

[216] G. A. Nelson, T. A. Jones, A. Chesnut, A. L. Smith, J. Radiat. Res. (Tokyo) 2002, 43 Suppl, S199.

[217] A. Ward, J. Liu, Z. Feng, X. Z. S. Xu, Nat. Neurosci. 2008, 11, 916.

[218] H. Ye, B. Ye, D. Wang, Neurobiol. Learn. Mem. 2008, 90, 10.

[219] S. H. Simonetta, D. A. Golombek, J. Neurosci. Methods 2007, 161, 273.

[220] C. Fang-Yen, L. Avery, A. D. Samuel, Proc. Natl. Acad. Sci. U. S. A. 2009, 106, 20093.

[221] J. M. Zengel, H. F. Epstein, Cell Motil. 1980, 1, 73.

[222] T. Hellerer, C. Axang, C. Brackmann, P. Hillertz, M. Pilon, A. Enejder, Proc. Natl. Acad. Sci. U. S. A. 2007, 104, 14658.

[223] S. Ward, N. Thomson, J. G. White, S. Brenner, J. Comp. Neurol. 1975, 160, 313.

[224] R. A. Butcher, J. R. Ragains, E. Kim, J. Clardy, Proc. Natl. Acad. Sci. U. S. A. 2008, 105,14288 .

[225] P. Y. Jeong, M. Jung, Y. H. Yim, H. Kim, M. Park, E. Hong, W. Lee, Y. H. Kim, K. Kim, Y. K. Paik, Nature 2005, 433, 541.

[226] B. J. Blaise, J. Giacomotto, B. Elena, M. E. Dumas, P. Toulhoat, L. Segalat, L. Emsley, Proc. Natl. Acad. Sci. U. S. A. 2007, 104, 19808.

[227] B. J. Blaise, J. Giacomotto, M. N. Triba, P. Toulhoat, M. Piotto, L. Emsley, L. Segalat, M. E. Dumas, B. Elena, J. Proteome Res. 2009, 8, 2542. 
[228] S. J. Park, M. B. Goodman, B. L. Pruitt, Proc. Natl. Acad. Sci. U. S. A. 2007, 104, 17376.

[229] J. C. Doll, N. Harjee, N. Klejwa, R. Kwon, S. M. Coulthard, B. Petzold, M. B. Goodman, B. L. Pruitt, Lab Chip 2009, 9, 1449.

[230] W. A. Van Voorhies, S. Ward, Proc. Natl. Acad. Sci. U. S. A. 1999, 96, 11399.

[231] H. Suda, T. Shouyama, K. Yasuda, N. Ishii, Biochem. Biophys. Res. Commun. 2005, 330, 839.

[232] K. Houthoofd, B. P. Braeckman, I. Lenaerts, K. Brys, F. Matthijssens, A. De Vreese, S. Van Eygen, J. R. Vanfleteren, Neurobiol. Aging 2005, 26, 689.

[233] C. Lagido, J. Pettitt, A. J. Porter, G. I. Paton, L. A. Glover, FEBS Lett. 2001, 493, 36.

[234] J. E. Richmond, Electrophysiological Recordings from the Neuromuscular Junction of C. elegans (October 6, 2006), WormBook, ed. The C. elegans Research Community, WormBook, http://www.wormbook.org.

[235] D. M. Raizen, L. Avery, Neuron 1994, 12, 483.

[236] J. Ahringer, Reverse Genetics (August 20, 2005), WormBook, ed. The C. elegans Research Community, WormBook, doi/10.1895/wormbook.1.47.1, http://www.wormbook.org.

[237] B. R. Stockwell, Nat. Rev. Genet. 2000, 1, 116.

[238] G. M. Whitesides, V. M. Krishnamurthy, Q. Rev. Biophys. 2005, 38, 385.

[239] D. G. Gibson, G. A. Benders, C. Andrews-Pfannkoch, E. A. Denisova, H. Baden-Tillson, J. Zaveri, T. B. Stockwell, A. Brownley, D. W. Thomas, M. A. Algire, et al., Science 2008, 319, 1215.

[240] S. Aparicio, J. Chapman, E. Stupka, N. Putnam, J. M. Chia, P. Dehal, A. Christoffels, S. Rash, S. Hoon, A. Smit, et al., Science 2002, 297, 1301.

[241] M. Asashima, Y. Ito, T. Chan, T. Michiue, M. Nakanishi, K. Suzuki, K. Hitachi, K. Okabayashi, A. Kondow, T. Ariizumi, Dev. Dyn. 2009, 238, 1309.

[242] B. De Groef, S. V. Grommen, V. M. Darras, Mol. Cell. Endocrinol. 2008, 293, 17.

[243] S. N. Austad, J. Gerontol. A Biol. Sci. Med. Sci. 2009, 64, 192.

[244] A. Sánchez Alvarado, C. R. Biol. 2007, 330, 498. 
[245] C. Kenyon, Philos. Trans. R. Soc. Lond. B. Biol. Sci. 2011, 366, 9.

[246] M. O. Hengartner, H. R. Horvitz, Philos. Trans. R. Soc. Lond. B. Biol. Sci. 1994, 345, 243.

[247] J. Giacomotto, L. Segalat, Br. J. Pharmacol. 2010, 160, 204.

[248] R. S. Kamath, A. G. Fraser, Y. Dong, G. Poulin, R. Durbin, M. Gotta, A. Kanapin, N. Le Bot, S. Moreno, M. Sohrmann, et al., Nature 2003, 421, 231.

[249] U. Al-Atar, R. Fernandes, B. Johnsen, D. Baillie, N. R. Branda, J. Am. Chem. Soc. 2009, 131, 15966.

[250] L. Ségalat, ACS Chem. Biol. 2007, 2, 231.

[251] F. R. Blattner, G. Plunkett, 3rd, C. A. Bloch, N. T. Perna, V. Burland, M. Riley, J. Collado-Vides, J. D. Glasner, C. K. Rode, G. F. Mayhew, et al., Science 1997, 277, 1453.

[252] P. Stragier, R. Losick, Annu. Rev. Genet. 1996, 30, 297.

[253] N. Hoiby, T. Bjarnsholt, M. Givskov, S. Molin, O. Ciofu, Int. J. Antimicrob. Agents 2010, 35, 322.

[254] D. R. Smith, L. A. Doucette-Stamm, C. Deloughery, H. Lee, J. Dubois, T. Aldredge, R. Bashirzadeh, D. Blakely, R. Cook, K. Gilbert, et al., J. Bacteriol. 1997, 179, 7135.

[255] P. Renesto, H. Ogata, S. Audic, J. M. Claverie, D. Raoult, FEMS Microbiol. Rev. 2005, 29, 99.

[256] P. D. Curtis, Y. V. Brun, Microbiol. Mol. Biol. Rev. 2010, 74, 13.

[257] R. D. Adam, Clin. Microbiol. Rev. 2001, 14, 447.

[258] D. F. Mandoli, Annu. Rev. Plant Physiol. Plant Mol. Biol. 1998, 49, 173.

[259] D. Elrad, A. R. Grossman, Curr. Genet. 2004, 45, 61.

[260] M. Schmidt, G. Gessner, M. Luff, I. Heiland, V. Wagner, M. Kaminski, S. Geimer, N. Eitzinger, T. Reissenweber, O. Voytsekh, et al., Plant Cell 2006, 18, 1908.

[261] S. J. Annesley, P. R. Fisher, Mol. Cell. Biochem. 2009, 329, 73.

[262] L. K. Fritz-Laylin, S. E. Prochnik, M. L. Ginger, J. B. Dacks, M. L. Carpenter, M. C. Field, A. Kuo, A. Paredez, J. Chapman, J. Pham, et al., Cell 2010, 140, 631.

[263] I. Hershkowitz, Microbiol. Rev. 1988, 52, 536. 
[264] S. Leonelli, Endeavour 2007, 31, 34.

[265] R. L. Wallace, Integr. Comp. Biol. 2002, 42, 660.

[266] The Nematode Caenorhabditis elegans, (Ed.: W. B. Wood), Cold Spring Harbor Laboratory Press, Cold Spring Harbor, 1988.

[267] M. T. Yamamoto, Exp. Anim. (Tokyo) 2010, 59, 125.

[268] R. L. Morris, M. P. Hoffman, R. A. Obar, S. S. McCafferty, I. R. Gibbons, A. D. Leone, J. Cool, E. L. Allgood, A. M. Musante, K. M. Judkins, et al., Dev. Biol. 2006, 300, 219.

[269] A. R. Kriegstein, V. Castellucci, E. R. Kandel, Proc. Natl. Acad. Sci. U. S. A. 1974, 71, 3654.

[270] R. Dahm, R. Geisler, C. Nüsslein-Volhard in Encyclopedia of Molecular Cell Biology and Molecular Medicine, Vol. 15, 2nd ed., (Ed.: R. A. Meyers), Wiley-VCH, Weinheim, 2005, pp. 593-626.

[271] Biology of the Laboratory Mouse, (Ed.: E. L. Green), Dover Publications, New York, 1968.

[272] The Chimpanzee Sequencing and Analysis Consortium, Nature 2005, 437, 69.

[273] B. R. Ellerbrock, E. M. Coscarelli, M. E. Gurney, T. G. Geary, J. Biomol. Screen. 2004, 9, 147.

[274] C. D. Link, C. J. Johnson, V. Fonte, M. Paupard, D. H. Hall, S. Styren, C. A. Mathis, W. E. Klunk, Neurobiol. Aging 2001, 22, 217.

[275] P. W. Faber, C. Voisine, D. C. King, E. A. Bates, A. C. Hart, Proc. Natl. Acad. Sci. U. S. A. 2002, 99, 17131.

[276] C. Voisine, H. Varma, N. Walker, E. A. Bates, B. R. Stockwell, A. C. Hart, PLoS One 2007, 2, e504.

[277] P. Cao, Y. Yuan, E. A. Pehek, A. R. Moise, Y. Huang, K. Palczewski, Z. Feng, PLoS One 2010, 5, e9312.

[278] M. Lakso, S. Vartiainen, A. M. Moilanen, J. Sirvio, J. H. Thomas, R. Nass, R. D. Blakely, G. Wong, J. Neurochem. 2003, 86, 165.

[279] C. Bessou, J. B. Giugia, C. J. Franks, L. Holden-Dye, L. Segalat, Neurogenetics 1998, 2, 61.

[280] A. Gaud, J. M. Simon, T. Witzel, M. Carre-Pierrat, C. G. Wermuth, L. Segalat, Neuromuscul. Disord. 2004, 14, 365. 
[281] S. S. Siddiqui, S. Loganathan, S. Krishnaswamy, L. Faoro, R. Jagadeeswaran, R. Salgia, Cancer Biol. Ther. 2008, 7, 856.

[282] R. Francis, M. K. Barton, J. Kimble, T. Schedl, Genetics 1995, 139, 579.

[283] R. A. Alegado, M. C. Campbell, W. C. Chen, S. S. Slutz, M. W. Tan, Cell. Microbiol. 2003, 5, 435.

[284] N. Ventura, S. L. Rea, R. Testi, Exp. Gerontol. 2006, 41, 974. 


\section{Legends for Figures}

Figure 1. The nematode C. elegans. (a) In the laboratory, the typical habitat of C. elegans is in a Petri dish on the surface of agar that has been seeded with E. coli. The inset shows a population of worms of mixed age. (b) An adult hermaphrodite crawling on an agar surface.

Figure 2. A microfluidic device for performing lifelong observation of C. elegans. (a) A schematic diagram of a device with four chambers. Each chamber houses a single worm for its entire adult lifespan. Upstream of each chamber is a worm clamp - a tapered microfluidic channel that enables temporary immobilization of worms for high-resolution imaging. On-chip valves allow each chamber to be isolated fluidically. The design is scalable-it is possible to incorporate more than four chambers into the design. (b) Photomicrographs of a single worm within a microfluidic chamber for its entire adult lifespan. Continuous flow of suspended bacteria from the inlet to the outlet provides food and removes waste. (c) Photomicrographs of the worm from (b) immobilized within the worm clamp on days 3,5, and 7. Reversing the direction of flow through the device loads worms into the clamps. This figure was adapted from Hulme et al. ${ }^{[109]}$

Figure 3. Summary of global investment in research and development for neglected diseases in fiscal year 2008. ${ }^{[154]}$ 
Figure 4. Microfluidic methods for immobilizing C. elegans. (a) Schematic diagram of an array of 128 worm clamps. This device enables rapid ( $<15 \mathrm{~min})$, temporary, non-invasive immobilization of over 100 worms for high-resolution microscopy and laser-mediated microsurgery (adapted from Hulme et al. ${ }^{[184]}$ ). (b) By fabricating a PDMS device with two layers of channels separated by a thin membrane of PDMS, it is possible to immobilize worms by pressurizing the upper layer of channels with air. The pressurization deflects the PDMS membrane and immobilizes the worm. This illustration is adapted from Chokshi et al. ${ }^{[172]}$ (c) The application of suction to an array of parallel microchannels pulls the worm against the channels, and thus immobilizes the worm. The left pannel (i) shows the array of microchannels for immobilizing worms in the center of the field of view. Leading to, and away from, this region are several valve-controlled microchannels. These channels enable the introduction of worms into the immobilization region, and allow the sorting of worms into channels for either waste or collection following immobilization (scale bar: $100 \mu \mathrm{m}$ ). The right pannel (ii) shows a close view of a worm immobilized by suction against the array of microchannels (scale bar: $10 \mu \mathrm{m})$. These images are reproduced, with permission, from Figure 2 of Rohde et al. ${ }^{[192]}$ (C) 2007 National Academy of Sciences, U.S.A.). 
Figure 5. Microfluidic chambers and droplets for observing C. elegans. (a) An array of posts provides an environment of "artificial soil" in which worms can crawl. The device is made of a liquid-filled PDMS chamber sealed covalently to glass. Although the images show only one worm, the device enables the observation of the locomotory behavior of several worms simultaneously. The circular posts in (i) and (ii) are $100 \mu \mathrm{m}$ in diameter; the posts in (iii) and (iv) are $200 \mu \mathrm{m}$ in diameter. These images are reproduced from Figure 3 of Lockery et al. ${ }^{[187]}$ (used with permission). (b) A mirofabricated maze for determining bacterial preferences in C. elegans. The device consists of channels embossed in PDMS in conformal contact with an agar surface. The channels are filled with air; worms crawl on the surface of the agar, and are confined by the channels. Zhang and coworkers ${ }^{[194]}$ placed samples of different bacteria at the end of the radial microchannels, placed worm in the center of the device, and observed which bacteria the worms preferred. The image is reprinted by permission from Macmillan Publishers Ltd: Nature 438: 179-184, (C) 2005. (c) An array of free-standing microdroplets for observing locomotion in C. elegans. By flowing odorant-containing air over the array of droplets, Luo and coworkers were able to monitor the temporal dynamics of the locomotory response of worms to odorants. The droplets confined the swimming of the worms to a specific area. The image is reproduced from Figure 1 of Luo et al. ${ }^{[210]}$ (used with permission). 


\section{Legends for Schemes}

Scheme 1. Small molecules that do, and do not, inhibit apoptosis in C. elegans. The lower panel shows the formation of reactive, potentially toxic, metabolites in the breakdown of naphthalene. ${ }^{[141]}$ The metabolic processes involve cytochrome P450 (CYP), epoxide hydrolase (EPH), and dihydrodiol dehydrogenase (DDH).

Scheme 2. Structural motifs associated with molecules that do, and do not, accumulate in C. elegans. ${ }^{[143]}$

Scheme 3. Anthelminthics for parasitic worm infections in humans.

Scheme 4. Three active components of the C. elegans dauer-inducing pheromone. ${ }^{[224]}$ 


\section{Tables}

\section{Table 1. Comparing model organisms}

\begin{tabular}{|c|c|c|}
\hline Organism & \multicolumn{2}{|c|}{$(+)$ Advantages and (-) Disadvantages } \\
\hline \multicolumn{3}{|l|}{ Unicellular Prokaryotes } \\
\hline $\begin{array}{l}\text { Escherichia coli }{ }^{[251]} \\
\text { Gram-negative bacterium; lives in gut of } \\
\text { animals (enteric) }\end{array}$ & $\begin{array}{l}(+) \\
(+) \\
(+) \\
(+) \\
(+) \\
(-) \\
(-)\end{array}$ & $\begin{array}{l}\text { Inexpensive/easy to grow } \\
\text { Genome is available } \\
\text { Straightforward genetic tools exist } \\
\text { Best studied organism } \\
\text { Model for molecular genetics } \\
\text { Limited differentiation } \\
\text { Limited intercellular interaction }\end{array}$ \\
\hline $\begin{array}{l}\text { Bacillus subtilis }^{[252]} \\
\quad \text { Gram-positive bacterium; soil dwelling }\end{array}$ & $\begin{array}{l}(+) \\
(+) \\
(+) \\
(-) \\
(-)\end{array}$ & $\begin{array}{l}\text { Inexpensive/easy to grow } \\
\text { Genome is available } \\
\text { Simple model of differentiation and morphogenesis (sporulation) } \\
\text { Some differentiation, but much less than / different from multicellular } \\
\text { organisms } \\
\text { Limited intercellular interaction }\end{array}$ \\
\hline $\begin{array}{l}\text { Mycoplasma genitalium }{ }^{[5]} \\
\text { smallest known free-living bacterium; } \\
\text { human pathogen }\end{array}$ & $\begin{array}{l}(+) \\
(+) \\
(+) \\
(-) \\
(-)\end{array}$ & $\begin{array}{l}\text { Inexpensive/easy to grow } \\
\text { Genome is available } \\
\text { Useful for understanding the minimal set of genes needed by a free-living } \\
\text { organism } \\
\text { Limited differentiation } \\
\text { Limited intercellular interaction }\end{array}$ \\
\hline $\begin{array}{l}\text { Pseudomonas aeruginosa }{ }^{[253]} \\
\text { Gram-negative bacterium; pathogen of } \\
\text { animals and plants; human pathogen } \\
\text { (e.g., in cystic fibrosis) }\end{array}$ & $\begin{array}{l}(+) \\
(+) \\
(+) \\
(-) \\
(-)\end{array}$ & $\begin{array}{l}\text { Inexpensive/easy to grow } \\
\text { Genome is available } \\
\text { Model of bacterial virulence, biofilms, quorum sensing } \\
\text { Limited differentiation } \\
\text { Limited intercellular interaction }\end{array}$ \\
\hline $\begin{array}{l}\text { Methanobacterium thermoautotrophicum } \\
\text { archaebacterium; requires only } \mathrm{H}_{2}, \mathrm{CO}_{2} \text {, } \\
\mathrm{N}_{2} \text { or } \mathrm{NH}_{4}^{+} \text {, and inorganic salts; produces } \\
\mathrm{CH}_{4}\end{array}$ & $\begin{array}{l}(+) \\
(+) \\
(+) \\
(+) \\
(-) \\
(-) \\
(-)\end{array}$ & $\begin{array}{l}\text { Inexpensive/easy to grow } \\
\text { Genome is available } \\
\text { Alternative source of fuel(?) } \\
\text { Unique metabolic processes } \\
\text { Limited differentiation } \\
\text { Limited intercellular interaction } \\
\text { Very different metabolism from higher organisms }\end{array}$ \\
\hline $\begin{array}{l}\text { Rickettsia prowazekii }{ }^{[255]} \\
\text { Gram-negative bacterium; genome } \\
\text { resembles mitochondrial genome; } \\
\text { obligate intracellular pathogen }\end{array}$ & $\begin{array}{l}(+) \\
(+) \\
(-) \\
(-) \\
(-) \\
(-)\end{array}$ & $\begin{array}{l}\text { Genome is available } \\
\text { Model of bacterial virulence } \\
\text { Difficult to grow (obligate pathogen) } \\
\text { Difficult genetic manipulation } \\
\text { Limited differentiation } \\
\text { Limited intercellular interaction }\end{array}$ \\
\hline $\begin{array}{l}\text { Caulobacter crescentus }{ }^{[256]} \\
\text { Gram-negative bacterium; asymmetric } \\
\text { division produces flagellated cell and } \\
\text { stalked cell }\end{array}$ & $\begin{array}{l}(+) \\
(+) \\
(+) \\
(-)\end{array}$ & $\begin{array}{l}\text { Inexpensive/easy to grow } \\
\text { Genome is available } \\
\text { Simple model of cellular differentiation and development } \\
\text { Limited intercellular interaction }\end{array}$ \\
\hline \multicolumn{3}{|l|}{ Unicellular eukaryotes } \\
\hline $\begin{array}{l}\text { Giardia lamblia }{ }^{[257]} \\
\text { unicellular flagellated eukaryote; free- } \\
\text { living cyst or parasite (mammals) }\end{array}$ & $\begin{array}{l}(+) \\
(+) \\
(+) \\
(-)\end{array}$ & $\begin{array}{l}\text { Genome is available } \\
\text { Model of parasite } \\
\text { Simple model of cellular differentiation } \\
\text { limited intercellular interaction }\end{array}$ \\
\hline
\end{tabular}


Acetabularia acetabulum ${ }^{[258]}$

giant unicellular green algae $(0.5-10 \mathrm{~cm}$ in length); well-defined morphology (rhizoid, stalk, and cap)

Chlamydomonas reinhardtii ${ }^{[259,260]}$ green algae; can grow in the dark; has simple visual system (eyespot)

Dictyostelium discoideum ${ }^{[261]}$ "social amoeba" or "slime mold"; matures from unicellular amoeba to motile, multicellular slug, to multicellular, sporeforming fruiting body

Naegleria gruberi ${ }^{[262]}$ unicellular eukaryote; switches between amoeboid and flagellate forms

Saccharomyces cerevisiae ${ }^{[263]}$ budding yeast
(+) Largest unicellular organism

$(+)$ Simple model of morphogenesis / development

$(+)$ Possible to make grafts of different cells

$(-)$ Very different cell size / body plan from higher organisms

(-) Not amenable to high-throughput screens

$(+)$ Inexpensive/easy to grow

$(+)$ Genome is available

(+) Model for photosynthesis

(+) Model for vision / evolution of vision

$(+)$ Inexpensive/easy to grow

$(+)$ Genome is available

$(+)$ Model of host in bacterial infection

$(+)$ Model for differentiation and development

$(+)$ Model for chemotactic locomotion

(+) Short life cycle

(-) Very different cellular organization, life-cycle from higher organisms

$(+)$ Inexpensive/easy to grow

$(+)$ Genome is available

$(+)$ Simple model of cellular differentiation

$(-)$ Limited intercellular interaction

(+) Simple model of eukaryotic cell

$(+)$ Genome is available

$(+)$ Straightforward genetic tools exist

$(+)$ Simple development (sporulation)

$(+)$ Some intercellular interaction (mating)

\begin{tabular}{l} 
Invertebrate Multicellular Eukaryotes \\
\hline Arabidopsis thaliana ${ }^{[264]}$ \\
fruitless flowering plant \\
Rotifers $^{[265]}$ \\
phylum of planktonic metazoans \\
Schmidtea mediterranea ${ }^{[243,244]}$ \\
planarian (free-living flatworm); \\
regenerates lost body parts; $3-12$ mm \\
long \\
Caenorhabditis elegans ${ }^{[266]}$ \\
parasitic)
\end{tabular}

(+) Inexpensive/easy to grow

$(+)$ Genome is available

(+) Lifespan: 6-8 weeks

(+) Best studied plant

(-) Plant physiology differs from animal physiology

$(+)$ Inexpensive/easy to grow

$(+)$ Have differentiated organs

$(+)$ Small; $\sim 1000$ cells

(+) Invariant development

(+) Transparent

(-) Complex and slow life cycles

(-) Not amenable to high-throughput screens

(-) No transgenic technology exists

$(+)$ Inexpensive/easy to grow

$(+)$ Genome is available

(+) Has organs/differentiated tissues

$(+)$ Simple model of regeneration

(+) Simple model of tissue plasticity

(-) Not amenable to high-throughput screens

(-) No transgenic technology exists

(-) Not amenable to (non-RNAi) genetic manipulation

(+) Inexpensive/easy to grow

$(+)$ Genome is available

$(+)$ Straightforward genetic tools exist

$(+)$ Short generation time: $2-3$ days

$(+)$ Short lifespan: 2-3 weeks

(+) Small; exactly 959 somatic cells

$(+)$ Invariant development

$(+)$ Transparent

$(+)$ Has organs/differentiated tissues

$(+)$ Mutants can be frozen

$(+) /(-) 50-80 \%$ of worm genes homologous to human genes 


\begin{tabular}{|c|c|c|}
\hline $\begin{array}{l}\text { Drosophila melanogaster } \\
\text { fruit fly }\end{array}$ & $\begin{array}{c}(+) \\
(+) \\
(+) \\
(+) \\
(+) /(-) \\
(-)\end{array}$ & $\begin{array}{l}\text { Inexpensive/easy to grow } \\
\text { Genome is available } \\
\text { Straightforward genetic tools exist } \\
\text { Short generation time: } \sim 10 \text { days } \\
50-80 \% \text { of fly genes homologous to human genes } \\
\text { Mutants cannot be frozen }\end{array}$ \\
\hline $\begin{array}{l}\text { Strongylocentrotus purpuratus } \\
\text { sea urchin }\end{array}$ & $\begin{array}{l}(+) \\
(+) \\
(+) \\
(-)\end{array}$ & $\begin{array}{l}\text { Genome is available } \\
\text { Can be fertilized in vitro easily } \\
\text { Transparent embryo; simple larval development } \\
\text { Not amenable to high-throughput screens }\end{array}$ \\
\hline $\begin{array}{l}\text { Aplysia californica }{ }^{[269]} \\
\text { sea slug }\end{array}$ & $\begin{array}{l}(+) \\
(+) \\
(-) \\
(-)\end{array}$ & $\begin{array}{l}\text { Genome is available } \\
\text { Useful for studying nerve growth, function } \\
\text { Not amenable to high-throughput screens } \\
\text { No transgenic technology exists }\end{array}$ \\
\hline \multicolumn{3}{|c|}{ Vertebrate Multicellular Eukaryotes } \\
\hline $\begin{array}{l}\text { Fugu rubripes } \\
\text { Pufferfish }\end{array}$ & $\begin{array}{l}(+) \\
(+) \\
(-) \\
(-) \\
(-)\end{array}$ & $\begin{array}{l}\text { Very small genome for a vertebrate } \\
\text { Genome is available } \\
\text { Produces lethal toxin } \\
\text { Not amenable to high-throughput screens } \\
\text { No transgenic technology exists }\end{array}$ \\
\hline $\begin{array}{l}\text { Danio rerio }^{[270]} \\
\text { Zebrafish }\end{array}$ & $\begin{array}{l}(+) \\
(+) \\
(+) \\
(-) \\
(-)\end{array}$ & $\begin{array}{l}\text { Draft genome is available } \\
\text { Small } \\
\text { Embryos are transparent } \\
\text { Long generation time: } 2-4 \text { months } \\
\text { Isogenic strains are not available }\end{array}$ \\
\hline $\begin{array}{l}\text { Xenopus laevis } \\
\text { Frog }\end{array}$ & $\begin{array}{l}(+) \\
(+) \\
(-) \\
(-) \\
(-)\end{array}$ & $\begin{array}{l}\text { Embryos are large and develop outside of mother } \\
\text { Model for development, teratogenesis } \\
\text { Difficult to manipulate and cultivate } \\
\text { Long generation time: } \sim 4 \text { months } \\
\text { Not amenable to high-throughput screens }\end{array}$ \\
\hline $\begin{array}{l}\text { Gallus gallus }^{[242]} \\
\quad \text { chicken }\end{array}$ & $\begin{array}{l}(+) \\
(+) \\
(-) \\
(-) \\
(-)\end{array}$ & $\begin{array}{l}\text { Embryos are large and develop outside of mother } \\
\text { Model for development } \\
\text { Difficult to manipulate and cultivate } \\
\text { Long generation time: }>6 \text { months } \\
\text { Not amenable to high-throughput screens }\end{array}$ \\
\hline $\begin{array}{l}\text { Mus musculus }{ }^{[271]} \\
\quad \text { Mouse }\end{array}$ & $\begin{array}{l}(+) \\
(+) \\
(-) \\
(-) \\
(-) \\
(-) \\
(-)\end{array}$ & $\begin{array}{l}\text { Genome is available } \\
\text { Strong genetic, physiological overlap with humans } \\
\text { Ethical concerns } \\
\text { Expensive } \\
\text { Long generation time ( } 2-3 \text { months) } \\
\text { Long lifespan } \\
\text { Not amenable to high-throughput screens }\end{array}$ \\
\hline $\begin{array}{l}\text { Pan troglodytes } \\
\text { Chimpanzee }\end{array}$ & $\begin{array}{l}(+) \\
(+) \\
(-) \\
(-) \\
(-) \\
(-) \\
(-)\end{array}$ & $\begin{array}{l}\text { Genome is available } \\
\text { Most closely related to humans } \\
\text { Ethical concerns } \\
\text { Expensive/labor intensive to maintain } \\
\text { Long generation time / lifespan } \\
\text { Not amenable to high-throughput screens } \\
\text { Development of transgenic technology carries ethical concerns }\end{array}$ \\
\hline
\end{tabular}


Table 2. Resources available to researchers of C. elegans

\begin{tabular}{|c|c|}
\hline Resource & Description \\
\hline $\begin{array}{l}\text { The WormBook } \\
\text { http://www.wormbook.org }\end{array}$ & $\begin{array}{l}\text { An up-to-date online } \\
\text { reference book for the } \\
\text { biology of } C \text {. elegans. } \\
\text { Includes an extensive section } \\
\text { of experimental methods. }\end{array}$ \\
\hline $\begin{array}{l}\text { WormAtlas } \\
\text { http://www.wormatlas.org }\end{array}$ & $\begin{array}{l}\text { An online database of the } \\
\text { anatomy of } C \text {. elegans, } \\
\text { including electron } \\
\text { micrographs of serial } \\
\text { transverse slices of the body } \\
\text { of the worm. }\end{array}$ \\
\hline $\begin{array}{l}\text { WormBase } \\
\text { http://www.wormbase.org }\end{array}$ & $\begin{array}{l}\text { A searchable database of the } \\
\text { genome and proteome of the } \\
\text { worm. }\end{array}$ \\
\hline $\begin{array}{l}\text { The Kyoto Encyclopedia } \\
\text { of Genes and Genomes } \\
\text { http://www.genome.ad.jp/ } \\
\text { kegg/kegg2.html }\end{array}$ & $\begin{array}{l}\text { A searchable database of } \\
\text { genes for multiple model } \\
\text { organisms, including worm. }\end{array}$ \\
\hline $\begin{array}{l}\text { Reactome } \\
\text { http://www.reactome.org }\end{array}$ & $\begin{array}{l}\text { An online database of } \\
\text { biological pathways for } \\
\text { multiple model organisms, } \\
\text { including worm. }\end{array}$ \\
\hline $\begin{array}{l}\text { Caenorhabditis } \\
\text { Research Center } \\
\text { University of Minnesota } \\
\text { http://www.cbs.umn.edu/ } \\
\text { CGC/ }\end{array}$ & $\begin{array}{l}\text { An NIH-supported depository } \\
\text { of mutant worms. }\end{array}$ \\
\hline $\begin{array}{l}\text { RNAi Database } \\
\text { http://rnai.org }\end{array}$ & $\begin{array}{l}\text { An online database of } \\
\text { changes in phenotype in } \\
\text { C. elegans in responses to } \\
\text { treatment with RNAi. }\end{array}$ \\
\hline $\begin{array}{l}\text { Geneservice } \\
\text { http://www.geneservice. } \\
\text { co.uk/ }\end{array}$ & $\begin{array}{l}\text { A vendor of RNAi for } \\
C . \text { elegans genes, sold in } \\
\text { library form or as individual } \\
\text { clones expressed in } E \text {. coli }\end{array}$ \\
\hline $\begin{array}{l}\text { Addgene } \\
\text { http://www.addgene.org/ } \\
\text { Andrew_Fire }\end{array}$ & $\begin{array}{l}\text { Distributes vector kits } \\
\text { containing cDNAs for } \\
\text { fluorescent proteins }\end{array}$ \\
\hline $\begin{array}{l}\text { Nematode.net } \\
\text { http://nematode.net }\end{array}$ & $\begin{array}{l}\text { An online resource for } \\
\text { genomic data for parasitic } \\
\text { nematodes. Maintained by } \\
\text { the Genome Sequencing } \\
\text { Center at Washington } \\
\text { University in St. Louis. }\end{array}$ \\
\hline $\begin{array}{l}\text { Genetic Nomenclature } \\
\text { for C. elegans } \\
\text { http://wiki.wormbase.org/ } \\
\text { index.php/UserGuide: } \\
\text { Nomenclature }\end{array}$ & $\begin{array}{l}\text { A guide to the proper genetic } \\
\text { nomenclature for } C \text {. elegans. } \\
\text { Supervised by wormbase.org } \\
\text { and the Caenorhabditis } \\
\text { Genetics Center at the } \\
\text { University of Minnesota. }\end{array}$ \\
\hline
\end{tabular}


Table 3. Essential amino acids ${ }^{[27]}$ and neurotransmitters ${ }^{[59]}$ in C. elegans and humans.

\begin{tabular}{|c|c|c|}
\hline Amino acids & C. elegans & Humans \\
\hline Arginine & $E^{[a]}$ & $\mathrm{E}$ in development \\
\hline Histidine & $\mathrm{E}$ & E \\
\hline Lysine & $E$ & $\mathrm{E}$ \\
\hline Aspartic acid & $\mathrm{NE}$ & $\mathrm{NE}$ \\
\hline Glutamic acid & NE & NE \\
\hline Serine & NE & NE \\
\hline Threonine & $\mathrm{E}$ & $\mathrm{E}$ \\
\hline Asparagine & $\mathrm{NE}$ & NE \\
\hline Glutamine & NE & NE \\
\hline Alanine & NE & NE \\
\hline Isoleucine & $E$ & $E$ \\
\hline Leucine & $\mathrm{E}$ & E \\
\hline Methionine & $\bar{E}$ & $\mathrm{E}$ \\
\hline Phenylalanine & $\mathrm{E}$ & $\mathrm{E}$ \\
\hline Tryptophan & $\mathrm{E}$ & $\mathrm{E}$ \\
\hline Tyrosine & $\mathrm{NE}$ & $\mathrm{E}$ in development \\
\hline Valine & $\mathrm{E}$ & E \\
\hline Cysteine & $\mathrm{NE}$ & $\mathrm{E}$ in development \\
\hline Glycine & NE & NE \\
\hline Proline & NE & NE \\
\hline Neurotransmitters & Used in C. elegans? & Used in Humans? \\
\hline Acetylcholine & $\mathrm{Y}$ & $\mathrm{Y}$ \\
\hline GABA & $Y$ & $Y$ \\
\hline Nitric oxide & Y & Y \\
\hline Serotonin & Y & Y \\
\hline Dopamine & Y & Y \\
\hline Glutamic acid & Y & $Y$ \\
\hline Octapamine & Y & $\mathrm{N}$ \\
\hline Tyramine & $\mathrm{Y}$ & $\mathrm{N}$ \\
\hline Epinephrine & $\mathrm{N}$ & Y \\
\hline Norepinephrine & $\mathrm{N}$ & $\mathrm{Y}$ \\
\hline Histamine & $\mathrm{N}$ & Y \\
\hline Neuropeptides ${ }^{[b]}$ & $\mathrm{Y}$ & $Y$ \\
\hline
\end{tabular}

[a] E: essential NE: non-essential

[b] Although humans and worms use neuropeptides, they do not use the same neuropeptides. 
Table 4. Human diseases studied in C. elegans

\begin{tabular}{|c|c|c|c|}
\hline Disease & Approach & Phenotype of disease in worm & References \\
\hline \multirow[t]{2}{*}{ Alzheimer's Disease } & $\begin{array}{l}\text { HTS for inhibitors of presenilin } \\
\text { homolog in worm }\end{array}$ & Decreased egg-laying & [273] \\
\hline & $\begin{array}{l}\text { Transgenic expression of } \\
\text { amyloid- } \beta \text { in worm }\end{array}$ & $\begin{array}{l}\text { Protein oxidation; paralysis; formation of } \\
\text { amyloid fibrils }\end{array}$ & $\begin{array}{c}{[123,125,129} \\
274]\end{array}$ \\
\hline \multirow[t]{2}{*}{ Huntington's Disease } & $\begin{array}{l}\text { Transgenic expression of } \\
\text { polyQ expansions in worm }\end{array}$ & $\begin{array}{l}\text { Decreased locomotion; increased rate of } \\
\text { age-related decline in locomotion; formation } \\
\text { of insoluble polyQ aggregates }\end{array}$ & {$[126,127]$} \\
\hline & $\begin{array}{l}\text { Transgenic expression of } \\
\text { Huntingtin and mutation of } \\
\text { C. elegans polyQ enhancer } \\
\text { gene (pqe-1) }\end{array}$ & $\begin{array}{l}\text { Neuronal death and degeneration; } \\
\text { decreased food consumption }\end{array}$ & {$[275,276]$} \\
\hline Parkinson's Disease & $\begin{array}{l}\text { Transgenic expression of } \\
\text { human } \alpha \text {-synuclein in worm }\end{array}$ & $\begin{array}{l}\text { Altered dopamine (DA) concentration; } \\
\text { degeneration of DAergic neurons; reduced } \\
\text { motility; altered distribution of DA vesicles at } \\
\text { synapse }\end{array}$ & {$[277,278]$} \\
\hline Depression & $\begin{array}{l}\text { Mutation of genes in } \\
\text { conserved serotonergic } \\
\text { signaling pathway to } \\
\text { determine mechanism of } \\
\text { antidepressants }\end{array}$ & $\begin{array}{l}\text { Enhanced serotonergic signaling increased } \\
\text { egg-laying; reduced serotonergic signaling } \\
\text { decreased egg-laying }\end{array}$ & [121] \\
\hline $\begin{array}{l}\text { Duchenne muscular } \\
\text { dystrophy }\end{array}$ & $\begin{array}{l}\text { Worm has dystrophin-like } \\
\text { gene (dys-1). Examined } \\
\text { effects of } d y s-1 \text { mutations. }\end{array}$ & $\begin{array}{l}\text { Decreased locomotion; muscle cell } \\
\text { degeneration; altered response of muscle } \\
\text { cells to acetylcholine and } \\
\text { acetylchoinesterase inhibitors }\end{array}$ & {$[279,280]$} \\
\hline Lung cancer & $\begin{array}{l}\text { Transgenic expression of wild- } \\
\text { type and mutant c-Met in } \\
\text { worm }\end{array}$ & $\begin{array}{l}\text { Decreased locomotion; paralysis; growth } \\
\text { arrest; changes in body morpology }\end{array}$ & [281] \\
\hline Carcinogenesis & $\begin{array}{l}\text { Exposed worms to known } \\
\text { carcinogens }\end{array}$ & Inhibition of apoptosis in development & [140] \\
\hline Tumor formation & $\begin{array}{l}\text { Mutation of } g l d-1 \text {, a tumor } \\
\text { suppression gene in worm }\end{array}$ & Tumor-like proliferation of germ cells & {$[131,282]$} \\
\hline Bacterial infection & Fed worms infectious bacteria & Colonization of gut by bacteria; death & [283] \\
\hline $\begin{array}{l}\text { Diabetes / insulin } \\
\text { resistance }\end{array}$ & $\begin{array}{l}\text { Mutation of conserved } \\
\text { hexosamine signaling } \\
\text { pathway }\end{array}$ & $\begin{array}{l}\text { Elevated storage of glycogen and trehalose; } \\
\text { decreased storage of lipids }\end{array}$ & {$[33,119]$} \\
\hline $\begin{array}{l}\text { Human mitochondrial- } \\
\text { associated diseases }\end{array}$ & $\begin{array}{l}\text { Mutation of conserved } \\
\text { mitochondrial proteins }\end{array}$ & $\begin{array}{l}\text { Severe loss-of-function and null mutations } \\
\text { lead to growth arrest, death; mild loss-of- } \\
\text { function mutations can increase lifespan }\end{array}$ & [284] \\
\hline
\end{tabular}


Table 5. Global prevalence of the helminthic infections in humans

\begin{tabular}{|c|c|}
\hline Helminth & $\begin{array}{l}\text { No. People } \\
\text { Infected }^{144]} \\
\text { (million) }\end{array}$ \\
\hline $\begin{array}{l}\text { Ascaris lumbricoides } \\
\text { soil-transmitted nematode }\end{array}$ & 807 \\
\hline $\begin{array}{l}\text { Trichuris trichiura } \\
\text { "whipworm"; soil-transmitted } \\
\text { nematode }\end{array}$ & 604 \\
\hline $\begin{array}{l}\text { Necator americanus } \\
\text { Anclyostoma duodenale } \\
\text { "hookworm"; soil-transmitted } \\
\text { nematodes }\end{array}$ & 576 \\
\hline $\begin{array}{l}\text { Schistosoma haematobium } \\
\text { Schistosoma mansoni } \\
\text { Schistosoma japonicum } \\
\text { flukes }\end{array}$ & 207 \\
\hline $\begin{array}{l}\text { Wuchereria bancrofti } \\
\text { Brugia malayi } \\
\text { lymphatic filariae; infection } \\
\text { can cause painful swelling } \\
\text { of legs and genitals } \\
\text { (elephantiasis) }\end{array}$ & 120 \\
\hline $\begin{array}{l}\text { Strongyloides stercoralis } \\
\text { "threadworm"; soil- } \\
\text { transmitted nematode }\end{array}$ & $30-100$ \\
\hline $\begin{array}{l}\text { Clonorchis sinensis } \\
\text { Opisthorchis viverinni } \\
\text { Paragonimus spp. } \\
\text { Fasciolopsis buski } \\
\text { Fasciola hepatica } \\
\quad \text { food-borne flukes }\end{array}$ & $>40$ \\
\hline $\begin{array}{l}\text { Onchocerca volvulus } \\
\text { filarial nematode; carries } \\
\text { endosymbiotic bacterium } \\
\text { that causes "River } \\
\text { Blindness" }\end{array}$ & 37 \\
\hline $\begin{array}{l}\text { Loa loa } \\
\quad \text { filarial nematode }\end{array}$ & 13 \\
\hline $\begin{array}{l}\text { Taenia solium } \\
\text { pork tapeworm }\end{array}$ & 0.4 \\
\hline $\begin{array}{l}\text { Dracunculus medinensis } \\
\text { "Guinea worm"; filarial } \\
\text { nematode }\end{array}$ & 0.01 \\
\hline
\end{tabular}




\section{Biographical Sketches}

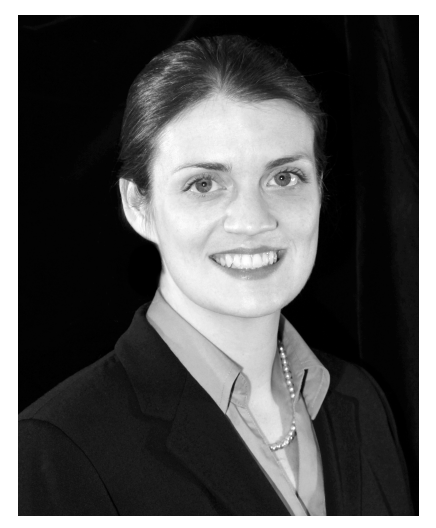

S. Elizabeth Hulme received a B.S. in chemistry from McGill University in 2004. She completed her Ph.D. in chemistry with G. M. Whitesides at Harvard University in 2010. Currently, she is studying molecular mechanisms of aging as a postdoctoral researcher with Kurt W. Runge at the Cleveland Clinic.

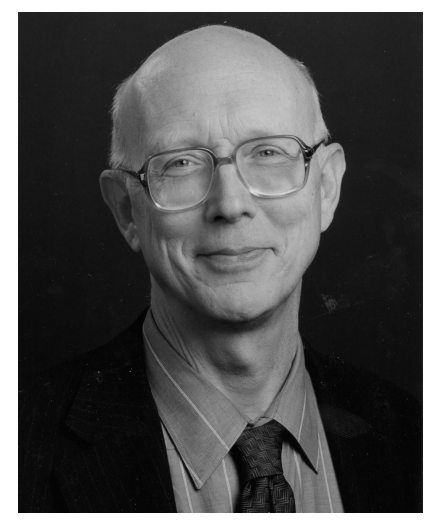

George M. Whitesides is now the Woodford L. and Ann A. Flowers University Professor at Harvard University. He received his Ph.D. in 1964 with Professor J. D. Roberts at CalTech, and was a member of the Chemistry Faculty at MIT from 1963 to 1982. His current research interests are in chemistry, materials science, and biochemistry. 


\section{Suggestion for the Table of Contents}

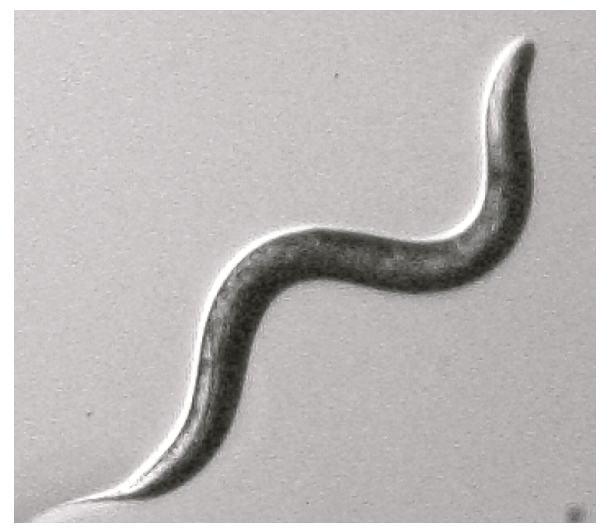

The worm-Caenorhabditis elegans - is a popular model organism for genetic research.

Although the worm is a simple organism, it still exhibits many of the complex phenomena found in higher organisms, including aging, behavior, cognition, and susceptibility to disease. This review provides an introduction to worm biology and argues that $C$. elegans is a useful system for the examination of complex biological phenomena from a chemical perspective. 


\section{Keywords}

1. Biochemistry

2. Caenorhabditis elegans

3. Chemical biology

4. Model organism

5. Worm 


\section{Graphical Material: Figures}

Figure 1
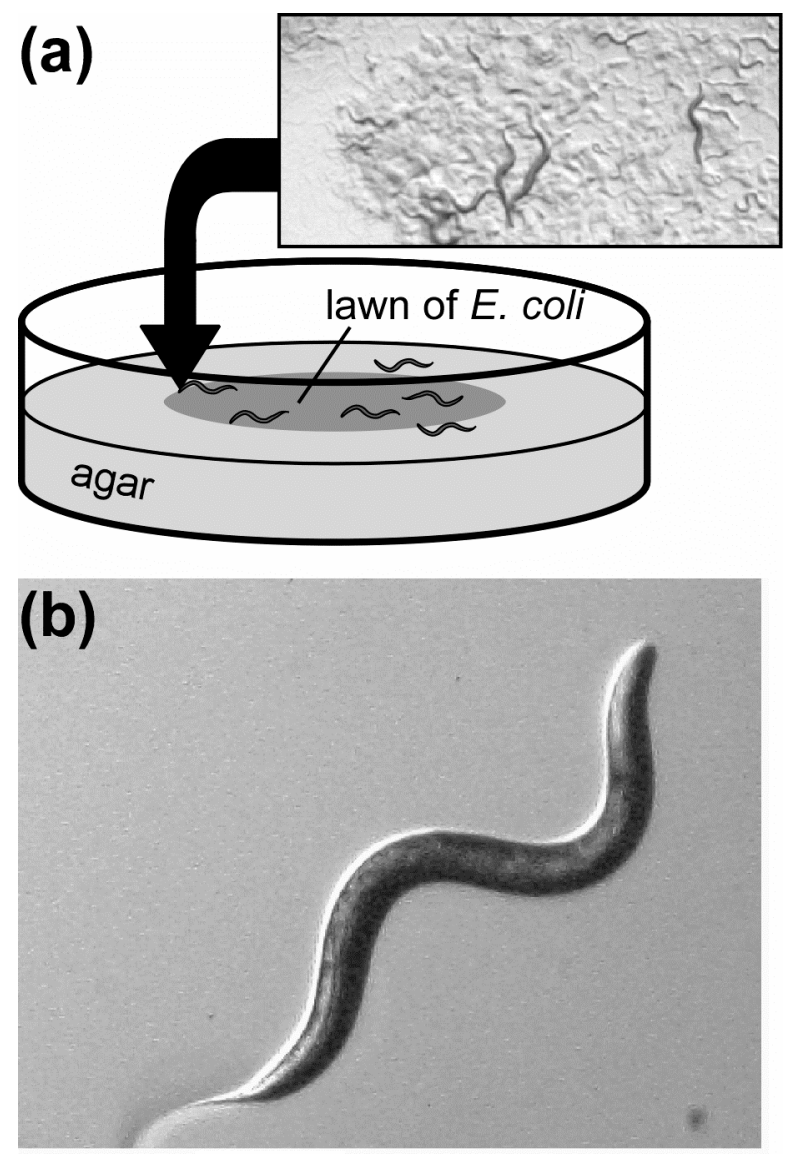

$250 \mu \mathrm{m}$ 
Figure 2

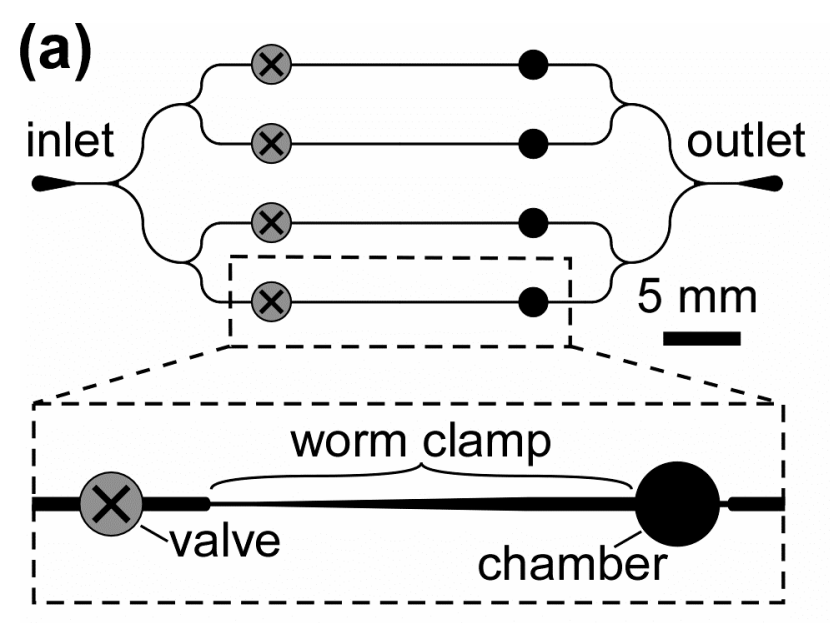

(b)
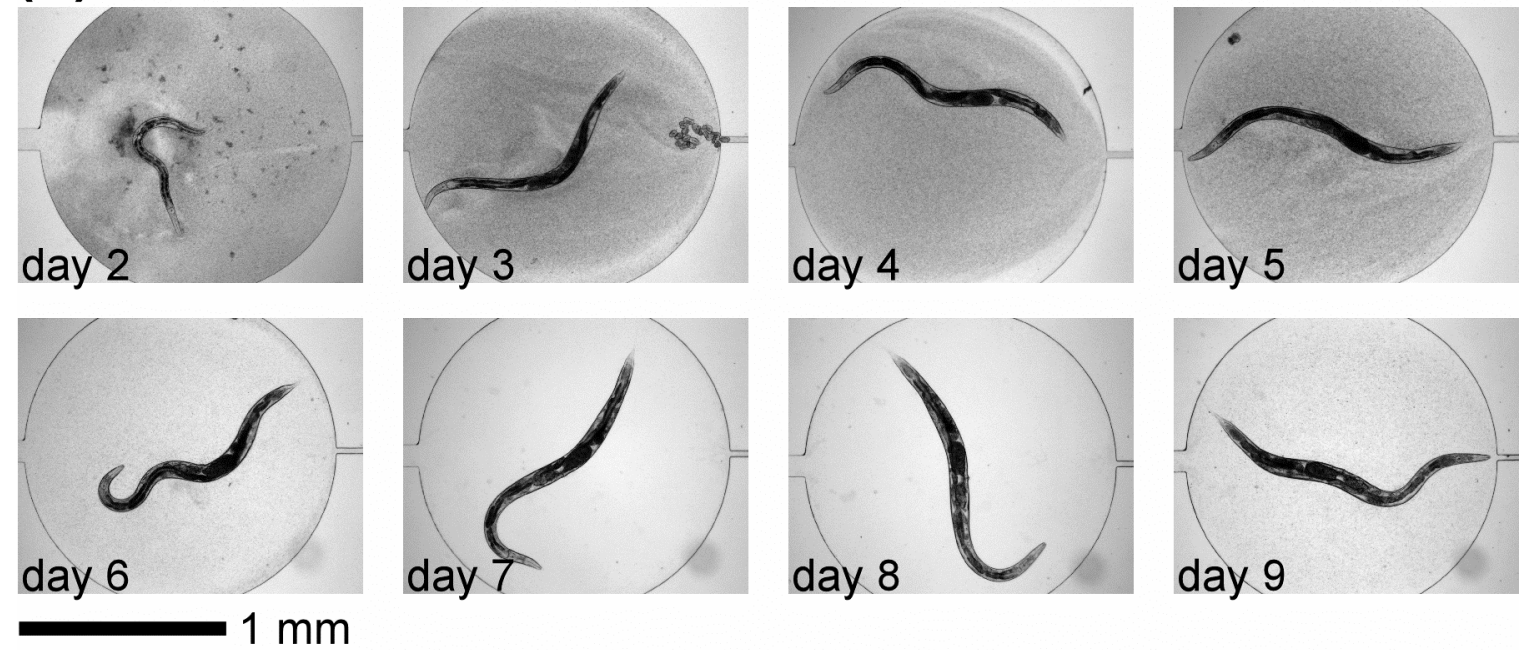

(c)

day 3

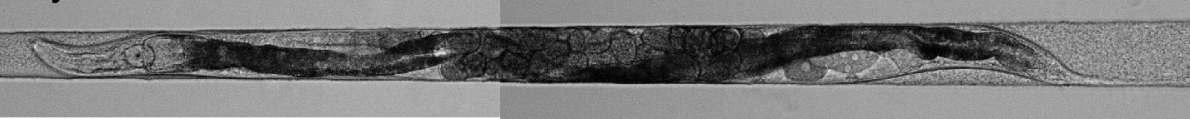

day 5

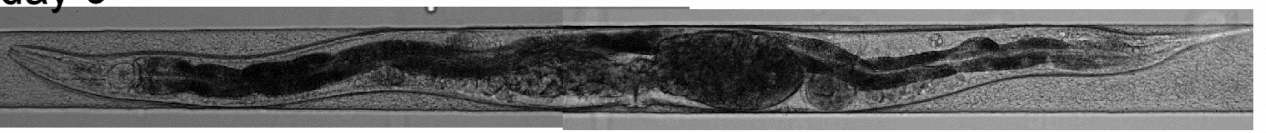

day 7

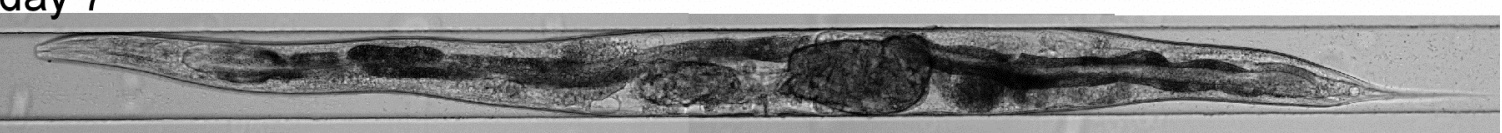

$200 \mu \mathrm{m}$ 


\section{Figure 3}

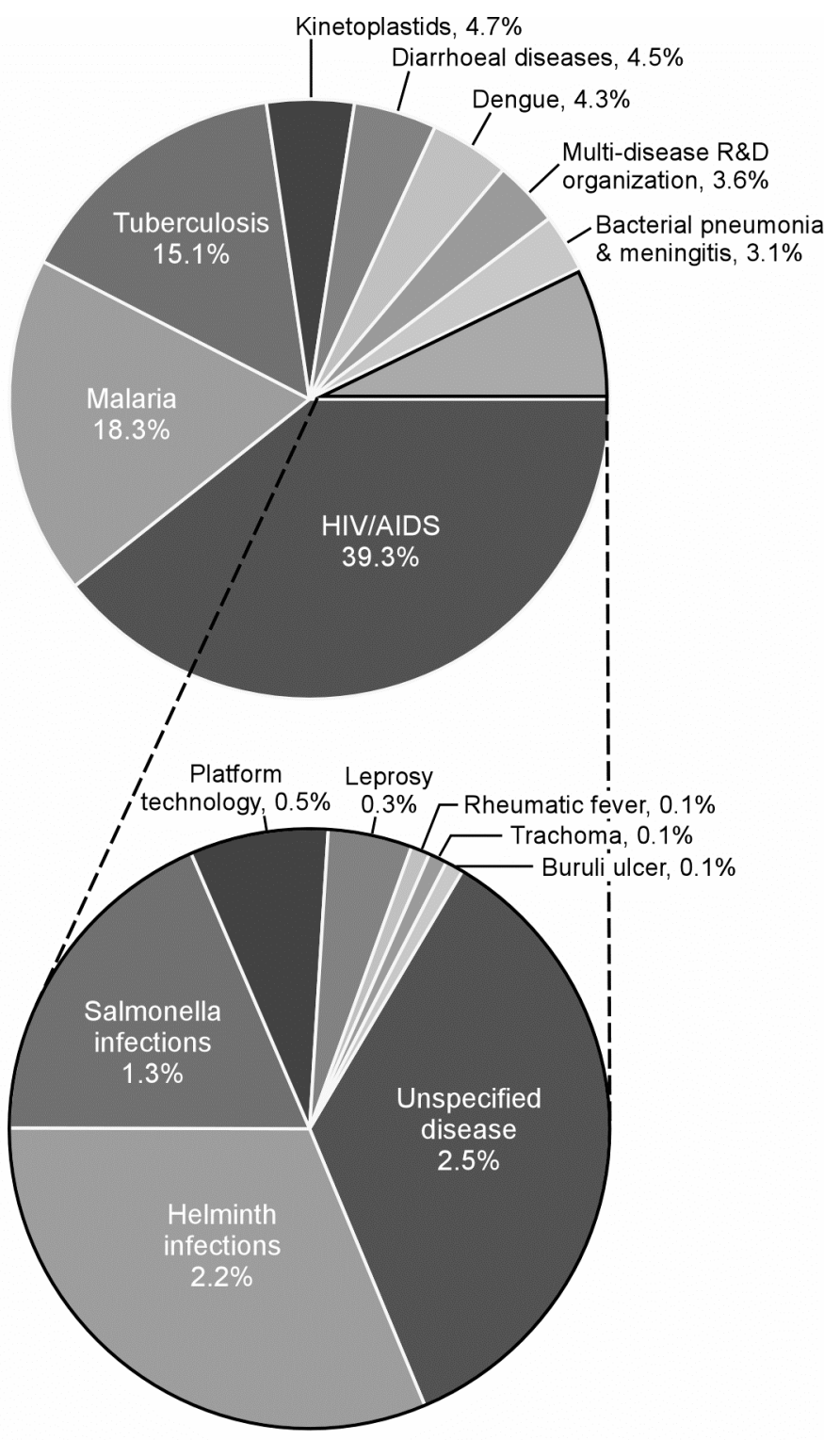

Global Funding for

Neglected Disease R\&D, FY2008 (Total investment: 3.09 billion USD) 
Figure 4

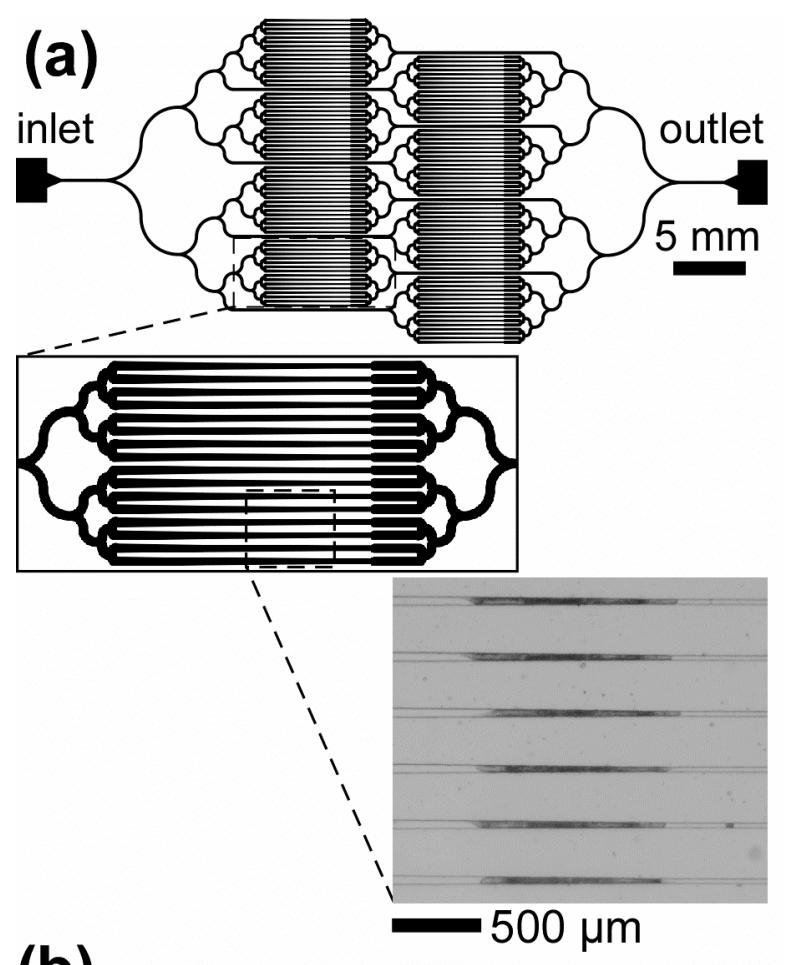

(b)

immobilization via compression

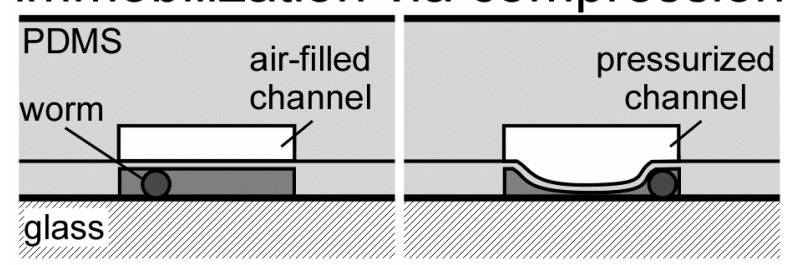

(c)

immobilization via suction

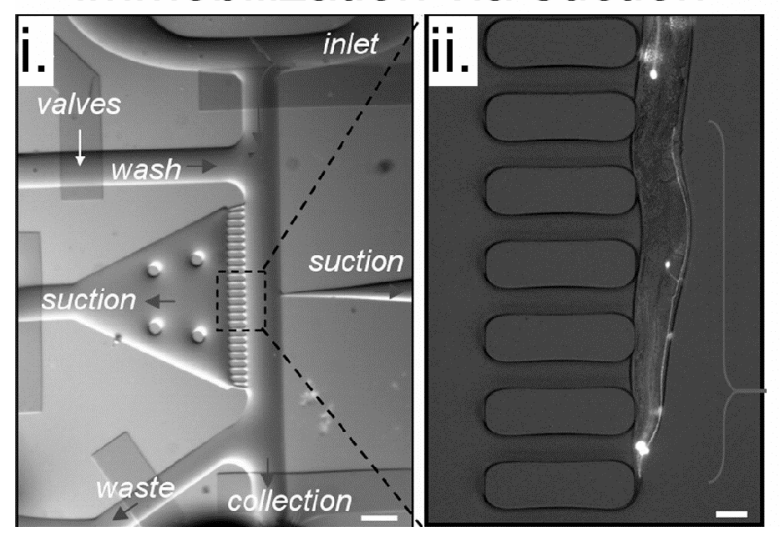




\section{Figure 5}

(a) liquid-filled PDMS on glass

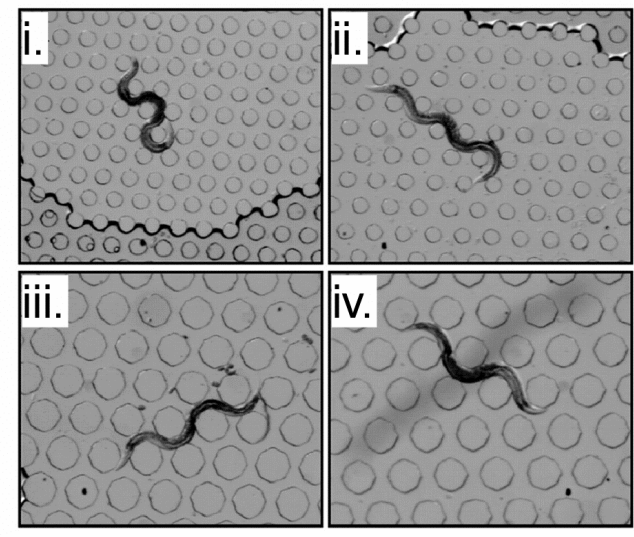

(b) air-filled PDMS on agar

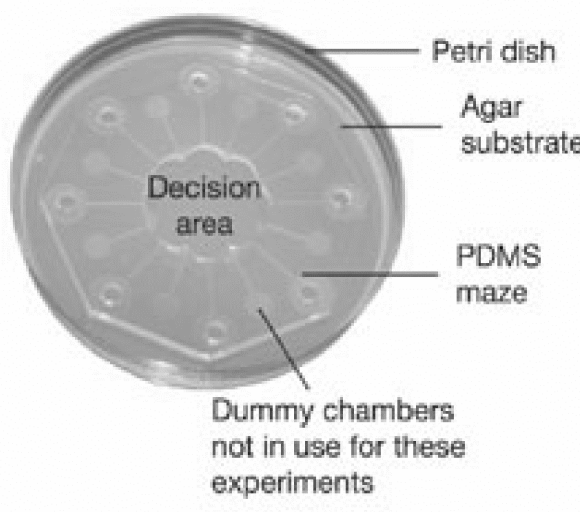

(c) free-standing liquid droplets

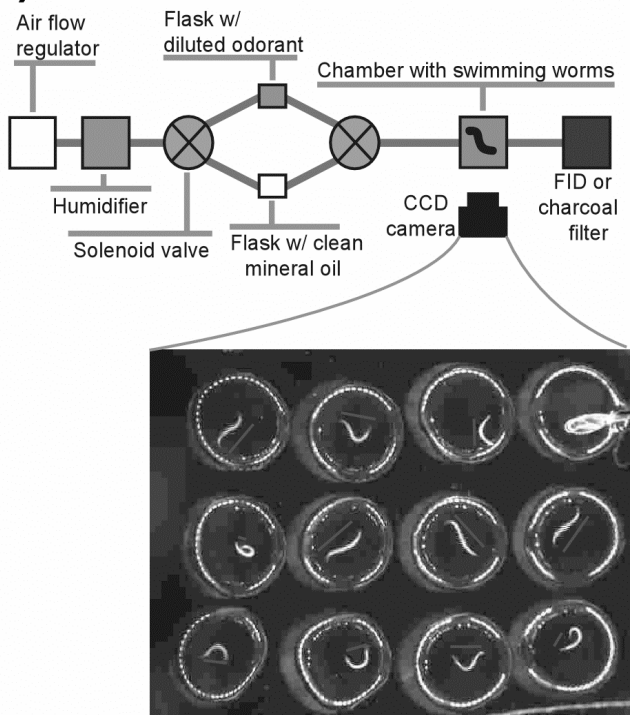




\section{Graphical Material: Schemes}

\section{Scheme 1}

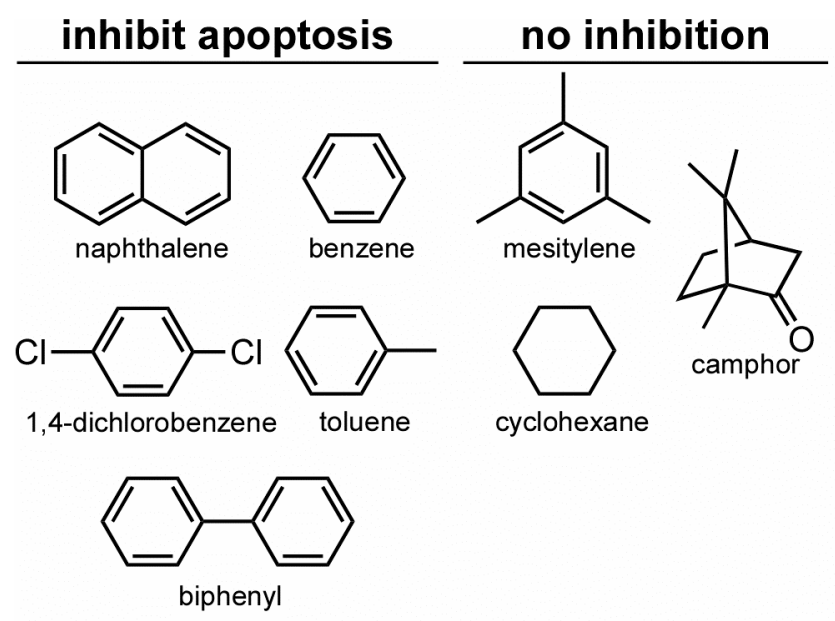

\section{Metabolism of naphthalene}

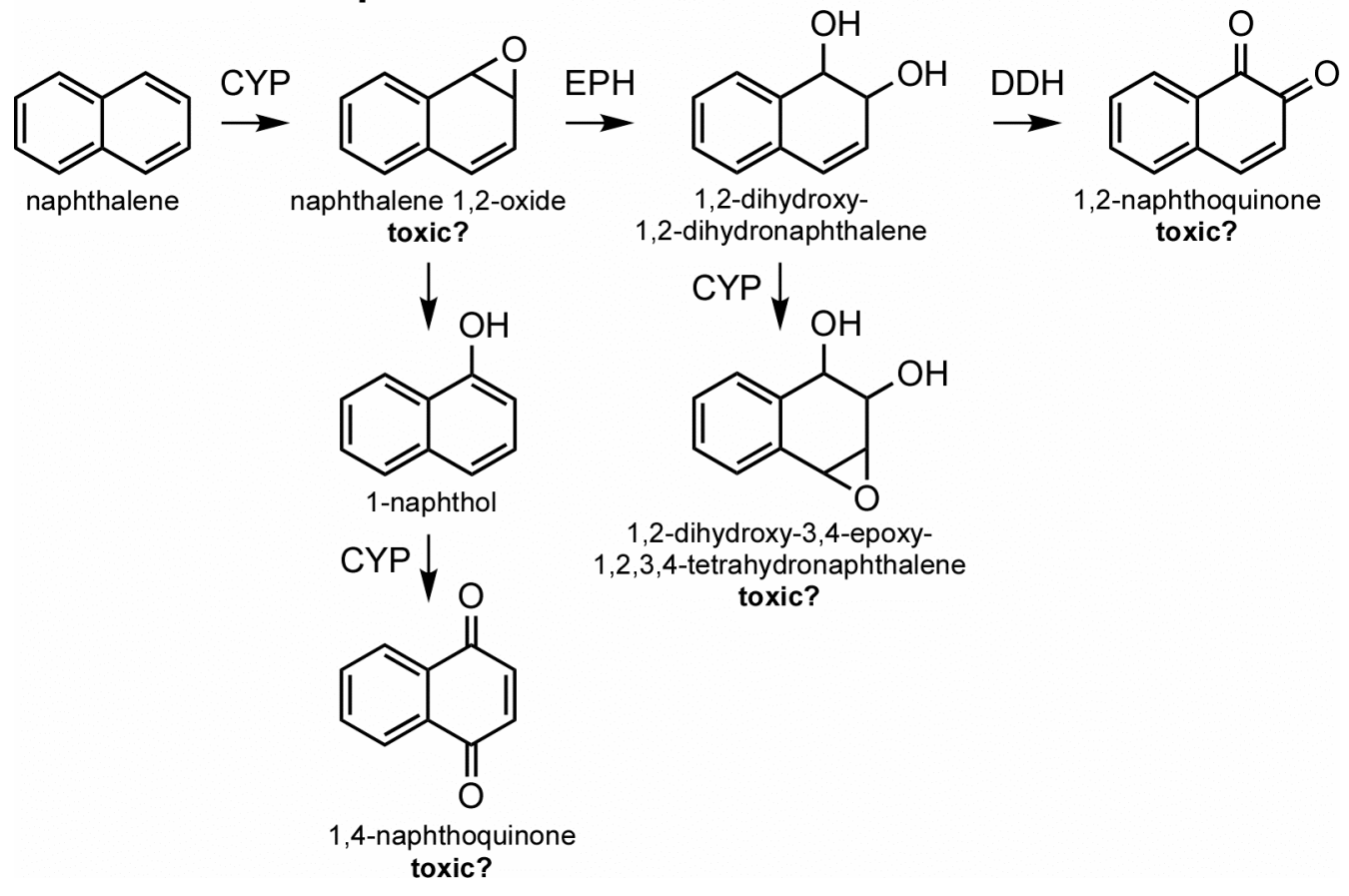




\section{Scheme 2}
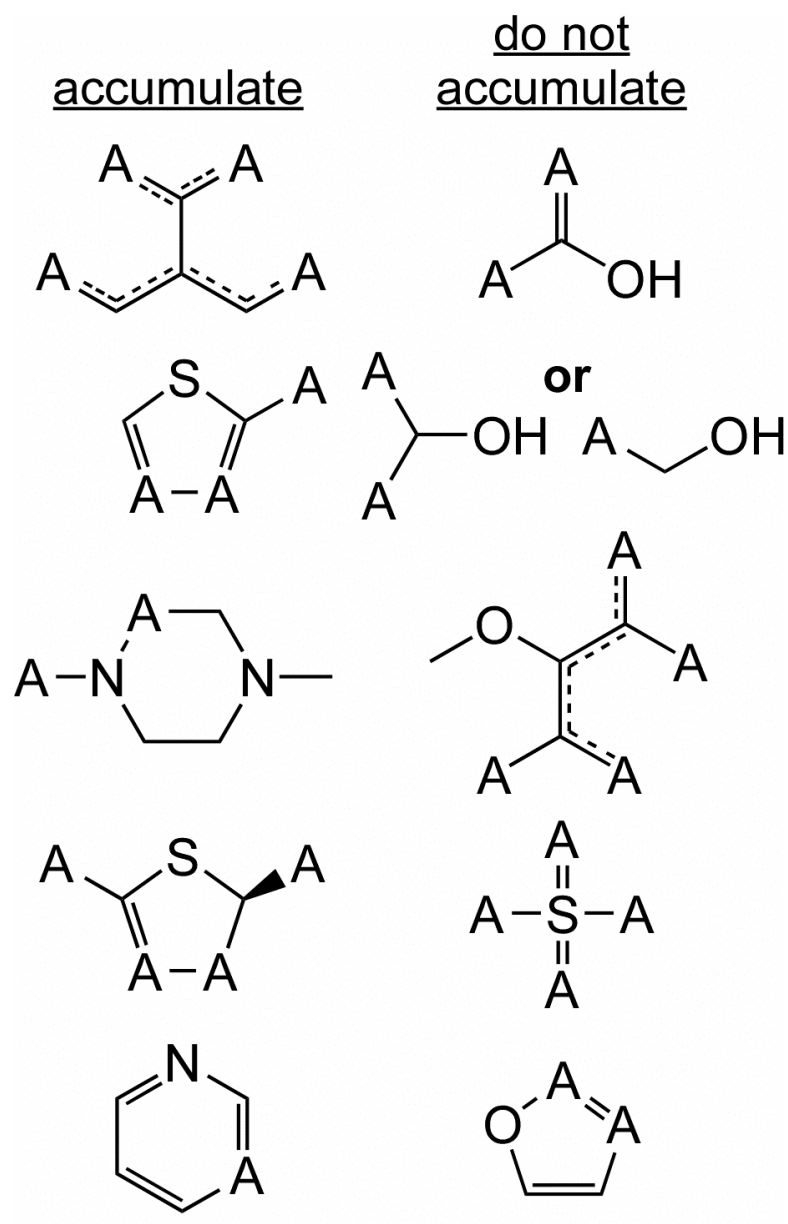

A: $C, N, O$, or $S$

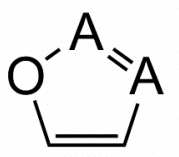




\section{Scheme 3}<smiles>CCCSc1ccc2[nH]c(NC(=O)OC)nc2c1</smiles><smiles>CN1CCCN=C1/C=C/c1cccs1</smiles>

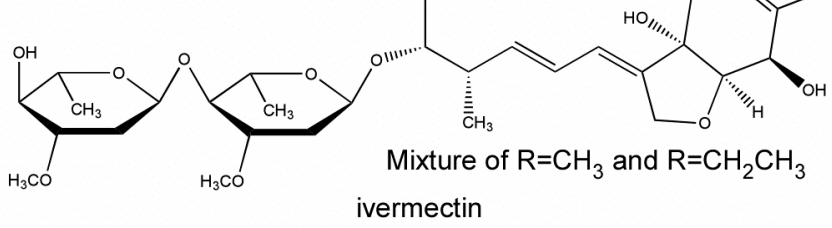<smiles>CCN(CC)C(=O)N1CCN(C)CC1</smiles><smiles>O=C(C1CCCCC1)N1CC(=O)N2CCc3ccccc3C2C1</smiles><smiles>CC(C)NCC1CCc2cc(CO)c([N+](=O)[O-])cc2N1</smiles> 


\section{Scheme 4}<smiles>CC(=O)CC[C@@H](C)O[C@H]1O[C@@H]2C[C@@H](O)[C@H](O)[C@H]1O2</smiles><smiles>C[C@H](CCCCC(=O)O)O[C@H]1OC2C[C@@H](O)[C@H](O)[C@H]1O2</smiles><smiles>C[C@H](CCCC/C=C/C(=O)O)O[C@H]1O[C@@H]2C[C@@H](O)[C@H](O)[C@H]1O2</smiles> 


\section{Graphical Material: Suggestion for Frontispiece}

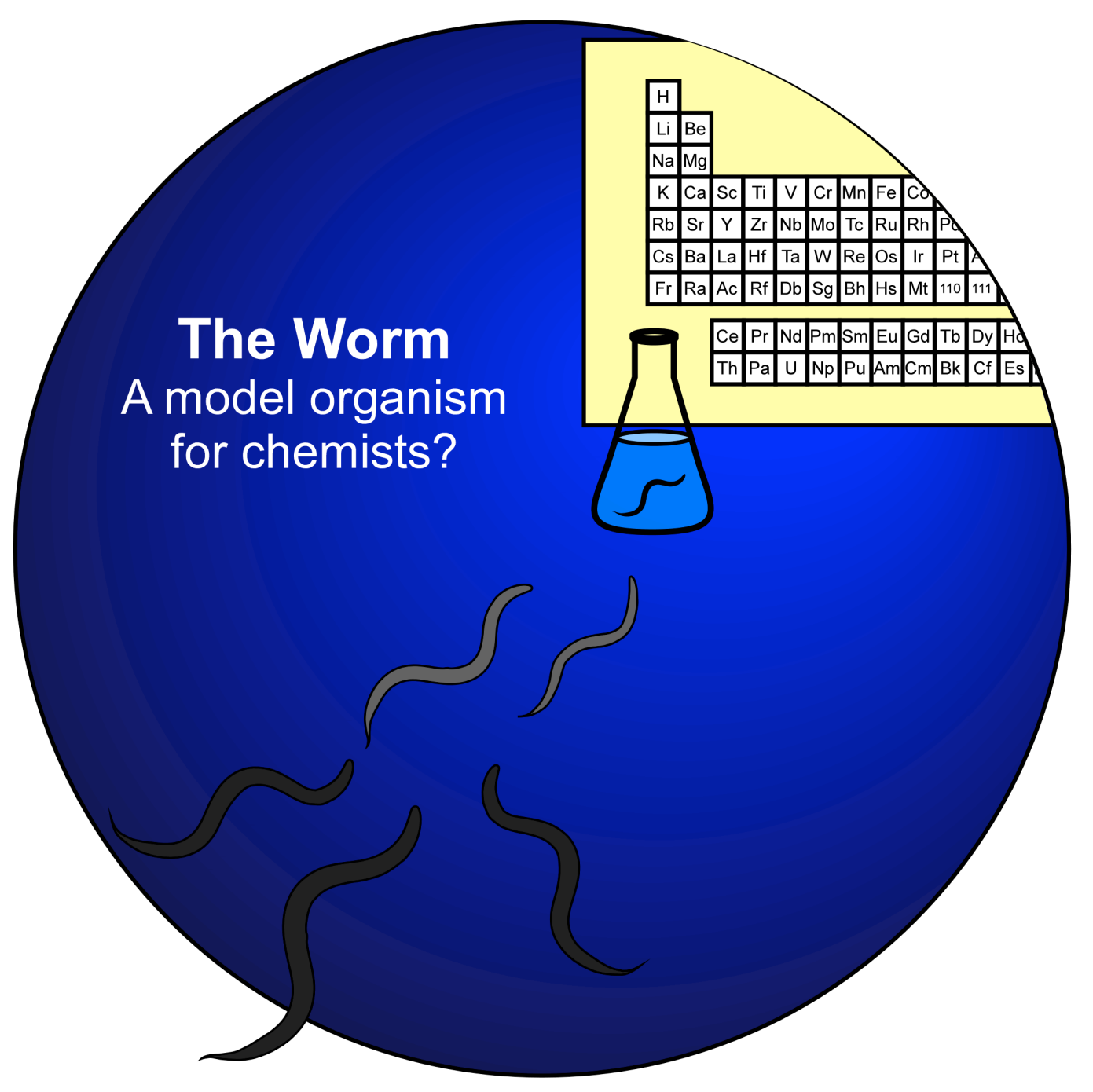

